


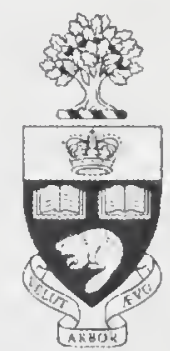

Presented to the

LIBRARIES of the

UNIVERSITY OF TORONTO

b)

\section{Garrett Herman}

$233+2880$ 

Digitized by the Internet Archive in 2020 with funding from University of Toronto 


\section{FÜR DARWIN.}

VON

\section{FRIT\% MÜLLER.}

"Caeterum, nullius in verba jurans, aliorum inventa consarcinare haud institui; quae inse quaesivi, reperi, repetitis vicibus diversoque tempore observavi, ... . propono. 6

O. F. Müller, Histor. rermium.

MIT 67 FIGUREN IN HOLZSCHNIT'T.

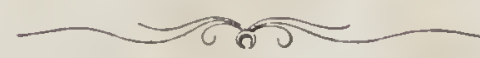

LEIPZIG,

VERLAG VON WILHELM ENGELMANN.

1864. 



\section{VORW ORT.}

Die folgenden Blätter wollen nicht die für und wider Darwin's Lehre von der Entstehung der Arten vorgebrachten Gründe aufs Neue erörtein und gegeneinander abwägen. Sie wollen einfach auf einige dieser Lehre günstige Thatsachen hinweisen, gesammelt auf demselben Boden Südamerika's, auf welchem in DARwin, wie er uns erzählt, zuerst der Gedanke aufkeimte, sich mit sder Entstehung der Arten, diesem Geheimniss der Geheimnisse " zu beschäftigen.

Nur durch Herbeischaffen neuen verwerthbaren Stoffes wird sich allmählich die Streitfrage für eine endgültige Entscheidung spruchreif machen lassen, und dieses erscheint einstweilen wichtiger als eine wiederholte Zergliederung des bereits vorliegenden. Zudem bleibt es billig fürs Frste D $D_{A R} w$ in selbst überlassen, die Angriffe der Gegner abzuwehren von dem stolzen Baue, den er mit solcher Meisterhand aufgeführt.

Desterro, 7. September 1863 .

F. M. 

I.

Als ich Charles Darwin’s Buch »über die Entstehung der Arten “ gelesen hatte, schien es mir, dass einer der Wege und der sicherste vielleicht, die darin entwickelten Ansichten auf ihre Richtigkeit zu prüfen, der sei, dass man eine möglichst ins Einzelne gehende Anwendung auf eine bestimmte Thiergruppe versuche. Ein solcher Versuch, sei es für dịe Familien einer Klasse, sei es für die Gattungen einer grösseren Familie, oder für die Arten einer reichen Gattung einen Stammbaum aufzustellen, und von den gemeinsamen Urahnen der verschiedenen engeren und weiteren Kreise möglichst ausgeführte und anschauliche Bilder zu entwerfen, konnte ein dreifach verschiedenes Ergebniss liefern.

Es konnten 1. Darwix's Voraussetzungen bei ihrer Anwendung zu unvereinbaren, sich widersprechenden Folgerungen führen, aus denen dann auf die Irrigkeit der Voraussetzungen zurückgeschlossen werden durfte.

Waren DARwin's Ansichten falsch, so war zu erwarten, dass Widersprüche ihre Anwendung im Einzelnen auf jedem Schritte begleiten, und dass sie, sich häufend, die Voraussetzungen, aus denen sie hervorgegangen, mit vereinter Wucht auf's Gründlichste zermalmen würden, so wenig auch die auf jeden besonderen Fall gebauten Schlüsse die Unbedingtheit mathematischer Beweise haben mochten.

Es konnte 2. der Versuch in ausgedehnterer oder beschränkterer Weise gelingen. War es möglich, auf Grund und mit Hilfe der Darwix'schen Lehre zu zeigen, in welcher Folge die verschiedenen engeren und weiteren Kreise aus der gemeinsamen Grundform und von einander sich losgelöst, in welcher Folge sie die jetzt sie bezeichnenden Eigenthümlichkeiten erworben, welche Umwandlungen sie im Laufe der 
Zeiten erlitten hatten, - war eine solche ron inneren Widersprüchen freie Aufstellung eines Stammbaumes, einer Urgeschichte der betrachteten Thiergruppe möglich, so musste diese Aufstellung, je vollständiger sie die bekannten Arten in sich aufnahm, und je tiefer sie in das Einzelnste des Baues hinabzusteigen vermochte, um so mehr in sich selbst die Bürgschaft der Wahrheit tragen, und um so überzeugender den Beweis liefern, dass der Grund, auf dem sie gebaut, kein lockerer Sand, dass er mehr, als blos » ein geistreicher Traum « sei.

Freilich war es 3. auch möglich, und dies musste ron vorn herein als der wahrscheinlichere Fall erscheinen, dass der Versuch an den ihm entgegentretenden Schwierigkeiten scheiterte, ohne die Frage, für oder wider, in Anerkennung erzwingender Weise zu entscheiden. Glückte es indess nur, für sich selbst auf diesem Wege zu einem einigermassen gesicherten selbstständigen Urtheile über diese so tief in die höchsten Fragen eingreifende Angelegenheit zu gelangen, so musste auch das schon als reicher Gewinn gelten.

Entschlossen, den Versuch zu wagen, hatte ich zunächst für eine bestimmte Klasse mich zu entscheiden. Die Wahl musste sich auf diejenigen beschränken, deren Hauptformen leicht in einiger Mannichfaltigkeit lebend zu erhalten waren. Eine so lange und bunte, und doch so innig rerknüpfte Reihe nun, wie sie aus der Klasse der Kruster die Krabben und Krebse, die Maulfüsser, die Diastyliden, die Amphipoden und Asseln, die Ostracoden und Daphniden, die Copepoden und Schmarotzerkrebse, die Rankenfüsser und Wurzellirebse unserer Küste boten, (nur die Phyllopoden und Xiphosuren fehlten), stand mir aus keiner anderen Klasse zur Terfügung. Auch ohne diesen Umstand hätte indessen die Wahl der Kruster kaum zweifelhaft sein können. Nirgends, wie das schon, von rerschiedenen Seiten ausgesprochen wurde, ist ja die Versuchung dringender, den Ausdrücken: "Terwandtschaft, Hervorgehen aus gemeinsamer Grundform «, und ähnlichen eine mehr als blos bildliche Bedeutung beizulegen, als bei den niederen Krustern. Namentlich bei den Schmarotzerkrebsen pflegte ja längst alle Welt, als wäre die Umwandlung der Arten cine selbstrerständliche Sache, in kaum bildlich zu deutender Weise ron ihrer Verkümmerung durch's Schma- 
rotzerleben zu reden. Es mochte wohl Niemandem als eines Gottes würdiger Zeitvertreib erscheinen, sich mit dem Ausdenken dieser wumderlichen Verkrüppelungen zu belustigen und so liess man sie durch eigene Schuld, wie Adam beim Sündenfall, von der früheren Tollkommenheit herabsinken.

Dass bereits ein grosser Theil der weiteren und engeren Kreise, in die sich diese Klasse gliedert, als endgültig festgestellt gelten durfte, während bei zwei anderen Klassen, in denen ich heimisch war, den Ringelwürmern und Quallen, alle versuchten Anordnungen nur als rorläufige Uebersichten erscheinen mussten, war ein weiterer nicht zu unterschätzender Vorzug. Diese unverrückbaren Gruppen, wie die scharfgezeichneten Formen des starren reichgegliederten Hautgerüstes, waren nicht nur als sichere Ausgangs- und Stützpuncte, sie waren auch als wohlthätige unerbittliche Schranken rom höchsten Werthe bei einer Aufgabe, bei der nun einmal, ihrer Natur nach, die Phantasie frei ihre Schwingen entfalten musste.

Indem ich also begann, mir ron diesem neuen Standpuncte der DARwin'schen Lehre aus unsere Kruster näher anzusehen, indem ich rersuchte, die Anordnung derselben in die Form eines Stammbaumes zu bringen und über den wahrscheinlichen Bau der Stammeltern mir Rechenschaft zu geben, sah ich freilich bald, - und ich war darauf gefasst gewesen, - dass es langjähriger Vorarbeiten bedürfen würde, ehe die eigentliche Aufgabe in ernstlichen Angriff genommen werden könne. Die bisherigen systematischen Arbeiten legten meist mehr Gewicht auf die die Gattungen, Familien, Ordnungen scheidenden, als auf die die Glieder jedes Kreises unter sich rerknüpfenden Merkmale und lieferten deshalb oft verhältnissmässig wenig rerwendbaren Stoff. Tor Allem aber war eine eingehende Kenntniss der Entwickelung unentbehrlich, und Jedermann weiss, wie lückenhaft in dieser Beziehung das bisher Erkannte ist. Diese Lücken waren um so schwieriger auszufüllen, da man, wie vax Bexedex für die Decapoden bemerkt, wegen der oft unglaublich verschiedenen Entwickelung nächstrerwandter Formen, meist Familie für Familie, oft Gattung für Gattung, ja man kann in Hinblick auf Penēus hinzusetzen, bisweilen selbst Art für Art besonders 
studiren musste, und da diese Untersuchungen, an sich mühsam und zeitraubend, in ihrem Erfolge oft ron einem glücklichen Ungefähr abhingen.

Musste so aber auch der "Stammbaum der Krebse «als ein Unternehmen erscheinen, für dessen befriedigende Ausführung die Kraft und die Lebensfrist eines Einzelnen kaum ausreichen mochte, selbst unter günstigeren Verhältnissen, als eine entlegene Insel, f'ern vom grossen Markte des wissenschaftlichen Lebens, fern von Bibliotheken und Museen, sie bieten konnte, - so wurde mir doch täglich seine Ausführbarkeit weniger zweifelhaft, und täglich machten mich neue Erfahrungen der DiRwix'schen Lehre günstiger gestimmt.

Wenn ich mich nun entschliesse, über die Gründe mich auszusprechen, die sich mir aus der Betrachtung unserer Kruster zu Gunsten der Darwix'schen Ansichten ergaben, und die - neben allgemeineren Erwägungen und beiläufigen Erfahrungen auf anderen Gebieten wesentlich dazu beitrugen, die Richtigkeit jener Ansichten mir immer wahrscheinlicher zu machen, so bestimmt mich dazu hauptsächlich eine Aeusserung Darwin’s. "Wer immer ", sagter, (Uebers.v.Brown, S. 456), »sich zur Ansicht neigt, dass Arten veränderlich sind, wird durch ge) wissenhaftes Geständniss seiner Ueberzeugung der Wissenschaft einen "guten Dienst leisten. " Dem in diesen Worten enthaltenen Wunsche entspreche ich meinerseits un so lieber, da dies nur Gelegenheit bietet, öffentlich dem Danke Worte zu leihen, zu dem ich mich Darwin auf's Tiefste verpflichtet fühle für die Belehrung und Anregung, die ich seinem Buche in so reichem Maasse schulde. So werfe ich denn getrost dieses Sandkorn in die Wagschale gegen den „Berg von Vorurtheilen, unter welchem dieser Gegenstand vergraben ist, umbekümmert, ob auch mich die Priester einer alleinseligmachenden Wissenschaft zu den Träumern rechnen werden und zu den Kindern an Erkenntniss der Naturgesetze. «

II.

Eine falsche Voraussetzung wird früher oder später, wenn man weiter und weiter den aus ihr fliessenden Folgerungen nachgeht, zu 
Ungereimtheiten und greifbaren Widersprüchen führen. Solche Widersprüche zwischen den aus Darwix's Lehre für die Klasse der Kruster sich ergebenden Schlüssen aufzufinden, habe ich mich viel bemüht während der nicht kurzen Zeit peinlichen $Z_{w}$ weifels, in der das Zünglein der Wage mir völlig ungewiss schwankte zwischen dem Für und dem Wider, und in der jede zu rascherer Entscheidung führende Thatsache mir hoch willkommen sein musste. Ich habe keinen gefunden, weder damals, noch später. Die ich gefunden zu haben meinte, lösten sich bei näherer Betrachtung, oder rerwandelten sich selbst in Stützen der DARwix' schen Lehre.

Auch ron anderen Seiten sind, soriel mir bekannt geworden, keine nothwendigen Folgerungen der Darwix'schen Voraussetzungen als in offenem, unvereinbarem Widerspruche stehend nachgewiesen worden. Und doch, da zu den Gegnern Dakwin's die gründlichsten Kenner der Thierwelt gehören, sollte man meinen, dass es ihnen ein Leichtes hätte sein müssen, ihn längst unter der Menge ungereimter widerspruchsroller Folgerungen zu erdrücken, wenn solche überhaupt aus seiner Lehre zu ziehen wären. Auf diesen Mangel nachgewiesener Widersprüche glaube ich ganz dasselbe Gewicht legen zu dürfen zu Gunsten Darwix's, das wider ihn seine Gegner dem Mangel nachgewiesener Zwischenformen zwischen den Arten rerschiedener Erdschichten beimessen. Letzterem Umstande wird übrigens, abgesehen von den Gründen, die DaRwix für ein nur sehr ausnahmsweises Erhaltensein solcher Zwischenformen gibt, keine übergrosse Bedcutung beizulegen geneigt sein, wer je die Entwicklung eines Thieres an aus dem Meere gefischten Larren rerfolgt, und dabei Monate, Jahre lang rergeblich nach Z wischenformen gesucht hat, ron denen er doch weiss, dass sie zu Tausenden ihn umschwärmen.

In welcher Weise nun überhaupt Widersprüche sich als nothwendige Ausflüsse der Darw rx’schen Voraussetzungen herausstellen könnțen, mögen einige Beispiele reranschaulichen.

Es scheint für alle Krabben, die längere Zeit ausser Wasser sich aufhalten, Bedürfniss zu sein, (weshalb, berührt uns hier nicht), dass ron hintenher Luft in ihre Kiemenhöhle eintrete. Diese Krabben 
nun, die sich mehr oder minder dem Wasser entfremdet haben, gehören den verschiedensten Familien an : den Raniniden Ranina), Eriphinen (Eriphia gonagra), Grapsoiden (Aratus, Sesarma u. A.), Ocypodiden (Gelasimus, Ocypoda) u. s. w. Die Scheidung dieser Familien würde ohne Zweifel in weit frühere Zeit zu setzen sein, als die Gewohnheit einzelner ihrer Mitglieder, das Wasser zu verlassen. Die auf Luftathmung bezüglichen Einrichtungen könnten also nicht ron einem gemeinsamen Stammvater ererbt, also kaum in übereinstimmender Weise gebaut sein. Fände sich eine solche, nicht auf zufällige Aehnlichkeit zurückführbare Uebereinstimmung, so würde sie als Beweis gegen die Richtigkeit der DARwn'schen Ansichten in die Wage zu legen sein. Ich werde weiter unten zeigen, wie in diesem Falle der Befund, weit entfernt solche Widersprüche zu bieten, viehmehr im vollsten Einklange steht, mit dem was sich aus DARwn's Lehre roraussagen liess.

Ein zweites Beispiel. Man kennt vier Arten ron Melita (valida, setipes, anisochir, Fresnelii), und ich kann eine fünfte hinzufügen (Fig. 1),

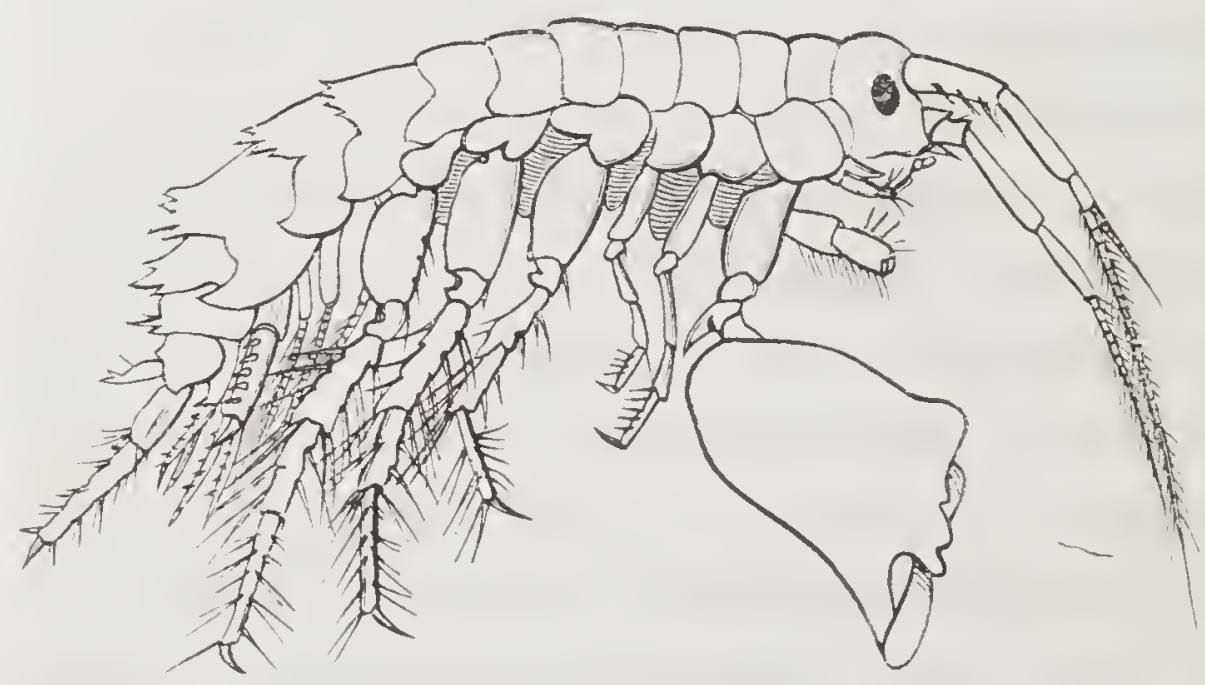

Fig. 1. deren zweites Fusspaar auf der einen Seite eine kleine Hand von gewöhnlicher Bildung, auf der anderen aber eine ungeheuere Kneifzange trägt. Diese Asymmetrie ist etwas so Ungewöhnliches unter den Amphipoden, die Bildung der Kneifzange weicht soweit ab ron dem was man sonst in dieser Ordnung sieht und ist so übereinstimmend bei den fünf Arten, dass man diese unbedenklich als denselben, nur ihnen unter den bekannten Arten gemeinsamen Stammeltern entsprossen ansehen müsste. Einer dieser Arten nun, der ron SArigry in Aegypten gesammelten

Fig. 1. Melita exilii n. sp. Männchen, 5 mal vergr. Zwischen den Füssen sieht man die grossen Kiemenblätter vorragen. 
M. Fresnelii, soll die den anderen zukommende Nebengeissel der vorderen Fühler fehlen. Bei der Zuverlässigkeit aller Arbeiten SAvigry's ist die Richtigkeit dieser Angabe kaum zu bezweifeln. Besässe nun die An- oder Abwesenheit der Nebengeissel die Redeutung eines Gattungen scheidenden Mlerkmals, die man ihr beizulegen pflegt, oder fänden sich sonstige erhebliche Unterschiede zwischen Melita Fresnelii und den anderen genannten Arten, die es natürlich erscheinen liessen, jene als eigene Gattung abzuscheiden, diese mit den übrigen Melitaarten vereinigt zu lassen, d.h., im Sinne der Darwin'schen Lehre, anzunehmen, dass alle anderen Melita gemeinsame Stammeltern besassen, die nicht zugleich Stammeltern der Melita Fresnelii gewesen, - so würde das im Widerspruch stehen mit dem aus der Bildung der Kneifzange gezogenen Schlusse, dass Melita Fresnelii und die vier andern genannten Arten gemeinsame Stammeltern besassen, die nicht zugleich Stammeltern der übrigen Melitaarten gewesen. - Es würde folgen

aus der Bildung der Kneifzange:

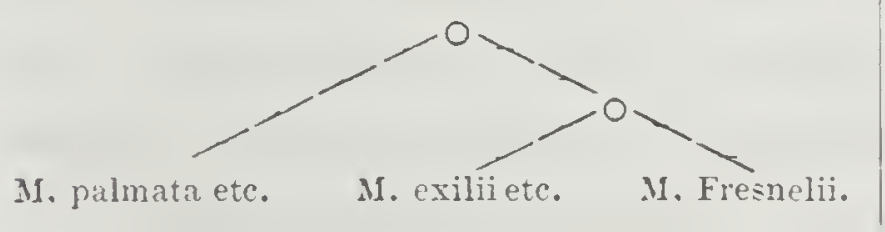

aus der An- und Abwesenheit der Yebengeissel:

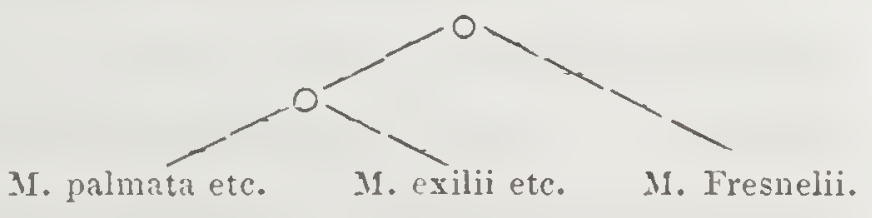

Wie im ersten Falle, bei den Krabben, eine typische Uebereinstimmung unabhängig ron einander entstandener Einrichtungen, so würde im zweiten jede tiefer greifende Verschiedenheit als nächst verwandt anzusprechender Arten ein für DARwiv's Lehre sehr bedenklicher Umstand sein. Nun scheint mir aber, dass die Nebengeissel in keiner Weise einen Grund abgeben kann, die enge verwandtschaftliche Beziehung von Melita Fresnelii zu M. exilii u. s. w. zu bezweifeln, welche anzunehmen die eigenthümliche Bildung der unparen Kneifzange gebietet. Man muss für's Erste an die Möglichkeit denken, dass die nicht immer leicht aufzufindende Nebengeissel von SAvigiry doch nur übersehen wurde, wie auch Spexce Bate vermuthet. Fehlt sie wirklich, so ist daran zu erinnern, dass ich sie bei Arten der Gattungen Leucothoë, Cyrtophium, Amphilochus finde, bei welchen Gattungen sie von $\mathrm{S}_{A^{-}}$ vigny, Daxa, Spexce Bate vermisst wurde, dass eine durch den Bau der Hüftblätter (épimères $E_{D w}$, coxae Sr. B.), der Schwanzfüsse 
(uropoda Weetwoonj u. s. w. als echte Amphithoë ${ }^{1}$ sich ausweisende hiesige Art sie besitzt, dass sie bei manchem Cerapus zu einem kaum nachweisbaren Reste verkümmert, ja dass sie bisweilen in der Jugend vorhanden ist, im reifen Alter (wenn auch vielleicht nie spurlos) schwindet, wie Spence Bate bei Acanthonotus Owenii und Atylus carinatus fand und wie ich für einen durch gefiederte Kiemen merkwürdigen Atylus unseres Meeres bestätigen kann, und dass nach alledem noch heute, wo die wachsende Menge der bekannt gewordenen Amphipoden und die dadurch herbeigeführte Zersplitterung in zahlreiche Gattungen ein Herabsteigen zu sehr kleinlichen Unterscheidungsmerkmalen erfordert, dennoch die Benutzung der Nebengeissel als Gattungsmerkmal beanstandet werden muss und dass also der Fall der Melita Fresnelii kein Bedenken gegen Darwin's Lehre erregen kann.

\section{III.}

Wenn die Widerspruchslosigkeit der Folgerungen, die für ein engeres und somit leichter zu übersehendes Gebiet aus ihr flossen, ein günstiges Vorurtheil für Dakwin's Ansichten erwecken musste, so durfte es als ein wirklicher Triumph derselben begrüsst werden, wenn weit greifende Schlüsse, die auf sie gebaut wurden, nachträglich durch Thatsachen bestätigt wurden, deren Bestehen die bisherige Wissenschaft in keiner Weise ahnen liess. Aus manchen Erfolgen dieser Art, ron denen ich berichten könnte, 'wähle ich als Beispiele zwei aus, die mir von besonderer Wichtigkeit waren und Entdeckungen betreffen, deren grosse Bedeutung für die Morphologie und Systematik der Kruster auch die Gegner DARwin's nicht in Abrede stellen werden.

Betrachtungen über die Entwickelungsgeschichte der Kruster hatten mich zu dem Schlusse geführt, dass wenn überhaupt höhere und niedere Kruster ron gemeinsamen Urahnen ableitbar wären, auch erstere einst Nauplius-ähnliche Zustände durchlaufen haben müssten. Wenig später entdeckte ich Nauplius-ähnliche Larven ron Garneelen, (TroscheL's

1) Ich nehme diese, wie alle genannten Amphipodengattungen in der ihnen ron Spexce Bate (Catal, of Amphipodous Crustacea) gegebenen Begrenzung. 
Arch. für Naturgesch. 1563. I. S. 8) und gestehe, dass dieser Fund für mich den ersten entscheidenden Ausschlag zu Darwin's Gunsten gab.

Die den Krabben und Krebsen, den Amphipoden und Asseln zukommende gleiche Zahl ron Leibesringen ${ }^{1}$, ron denen die sieben letzten

1) Wie Crats betrachte ich die Augen der Kruster nicht als Gliedmassen und rechne daher keinen besonderen Augenring an, zähle dagegren das Mittelstück des Schwanzes mit, dem man rielfach die Bedeutung eines Leibesringes abspricht. Gegen die Deutung als Leibesring ist wohl nur der Nangel der Gliedmassen anzuführen, dafür namentlich das Verhalten des Darmes, der in diesem Stücke auszumünden pflegt, bisweilen selbst es seiner ganzen Länge nach durchsetzt, wie bei Microdeutopus und einigen anderen Amphipoden. Bei Microdeutopus fühlt man sich sogar versucht, wie schon SPExcE BATE hervorhebt, kleine Fortsätze dieses röhrenförmigen Schwanzstückes als rerkümmerte Gliedmassen zu deuten. Auch BELL (British Stalk-eyed Crust. pag. XX) will bei Palaemon serratus Gliedmassen des letzten Ringes in Form kleiner beweglicher Spitzen beobachtet haben.

Man hat mehrfach rersucht, den Leib der höheren Kruster in kleinere aus gleicher Ringzahl gebildete Abschnitte zu zerlegen und diese Abschnitte bald aus 3, bald aus 5, bald aus 7 Kingen zusammengesetzt, ohne dass einer dieser Versuche sich allgemeiner Zustimmung hätte erfreuen können. Meine eigenen Untersuchungen leiten mich zu einer Auffassung, die sich nahe an die ras BExEDEx's anschliesst. Ich nelrme vier Abschnitte ron je 5 Pingen an: Urleib, Vorderleib, Hinterleib, Mittelleib. Der Urleib begreift die Ringe, die die Naupliusförmige Larre aus dem Eie mitbringt; später wird er durch die in seiner Mitte sich entwickelnden jüngeren Abschnitte in Kopf und Schwanz getrennt. Jiesem Urleibe gehören die beiden Füh lerpaare, die Kinnbacken (mandibulae) und die Schwanzfüsse (posterior pair of pleopoda SP. B.) an. Noch beim erwachsenen Thiere verräth sich die Zusammengehörigkeit dieser Endabschnitte bisweilen durch die Aehnlichkeit ihrer Anhänge, besonders die des äussern Astes der Schwanzfüsse mit dem äusseren Aste der sog. Schuppe) des zweiten Fühlerpaars. Selbst zu Trägern höherer Sinneswerkzeuge können, wie die Fühler, so die Schwanzfüsse werten, wie das Ohr der Mysis zeigt.

Jie zeitliche Folge der leibesabschnitte scheint ursprünglich die gewesen zu sein, dass erst der Vorderleib, dann der Hinterleib, zuletzt der Mittelleib sich bildete. Der Vorderleib erscheint beim erwachsenen Thiere ganz oder zum Theile mit dem Kopfe rerschmolzen, seine Anhänge (diagonopoda WEsTw.) alle oder theilweise der Nahrungsaufnahme dienstbar und meist scharf ron denen der folgenden Gruppe geschieden. Die Ringe des Mittelleibes scheinen stets sofort nach ihrem Auftreten Gliedmassen zu treiben, während die Ringe des Hinterleibes oft während längerer Abschnitte des Larrenlebens, oder selbst für immer (bei manchen weiblichen Diastylideen) sich fusslos erhalten; ein Grund, neben manchen anderen, den Mittelleib der Krebse nicht, wie es üblich ist, dem stets fusslosen Hinterleibe der Insecten gleichzustellen. Die Anhänge des Mittelleibes (pereiopoda) scheinen niemals, selbst nicht in ihrer jugencilichsten Form, zwei gleichwerthige Aeste zu besitzen, - eine Figenthümlichkeit, die clie Anhänge des Hinterleibes auszuzeichnen pflegt. Es ist dieses ein Umstand, der als wichtiges Bedenken gegen die Gleich- 
stets abweichend ron den vorhergehenden ausgestattet sind, musste unabweislich als Erbtheil derselben Urahnen angesprochen werden. Wenn nun heute noch die Mehrzahl der Krabben und Krebse und überhaupt der stieläugigen Kruster Zoëa-ähnliche Entwicklungszustände durchläuft, und dieselbe Weise der Verwandlung ihren Stammeltern zuzuschreiben war, so musste ein Gleiches, wenn auch nicht für die Stammeltern der Asseln und Amphipoden, so doch für die gemeinsamen Urahnen dieser und der stieläugigen Kruster gelten. Eine solche Annahme aber war jedenfalls sehr gewagt, so lange ihr nicht eine einzige Thatsache aus dem eigenen Gebiete der Edriophthalmen zur Stütze gegeben werden konnte, da der Bau dieser so in sich abgeschlossenen Gruppe fast unvereinbar schien mit manchen Eigenthünlichkeiten der Zoëa. So bildete für mich dieser Punct lange eine der Hauptschwierigkeiten bei Anwendung der Darwin'schen Ansichten auf die Kruster, und kaum durfte ich hoffen, noch jetzt bei Amphipoden oder Asseln Spuren jenes Durchgangs durch die Zoëaform erhalten zu finden und damit einen thatsächlichen Beweis für die Richtigkeit jenes Schlusses zu erlangen. Da machte mich var Benedex's Angabe, dass eine Scheerenassel (Tanais Dulongii), nach Mrtake Enwards in die gleiche Familie mit der gemeinen Wasserassel gehörig, einen Panzer besitze, wie die Decapoden, auf diese Thiere aufmerksam, und eine nähere Untersuchung ergab, dass diese Asseln trener, als irgend ein anderer der erwachsenen Kruster manche der wesentlichsten Zoëreigenthümlichkeiten, namentlich deren Athmungsweise bewahrt haben. Während bei allen anderen

stellung des Mittelleibes der Ma lacostraca mit dem bei den Copepoden die Schwimmfüsse, bei den Cirripedien die Rankenfüsse tragenden Leibesabschnitte geltend zu machen ist.

Die Füsse des Hinterleibes und des Schwanzes in eine Gruppe 'als fausses pattes abdominales, oder als pleopoda) zusammenzufassen, scheint nicht gerechtfertigt. Wo eine Verwandlung stattfindet, entstehen sie wohl immer zu verschiedenen Zeiten, und durchaus verschieden sind sie fast immer in Bau und Verrichtung. Selbst bei den Amphipoden, wo die Schwanzfüsse den beiden letzten Paaren der Hinterleibsfüsse ähnlich zu sehen pflegen, sind sie in der Kegel durch irgendwelche Eigenthümlichkeit ausgezeichnet, und während die Hinterleibsfüsse in ermüdender Einförmigkeit sich durch die ganze Ordnung wiederholen, grehören bekanntlich die Schwanzfüsse zu den veränderlichsten Theilen des Amphipodenleibes. 
Asseln die Hinterleibsfüsse der Athmung dienen, sind diese bei unserer Scheerenassel (Fig. 2) reine Bewegungswerkzenge, in die nie ein Blutkörperchen eintritt, und der Hauptsitz der Athmung ist, wie bei den Zoëa in den von reichlichen Blutströmen durchrieselten Seitentheilen des

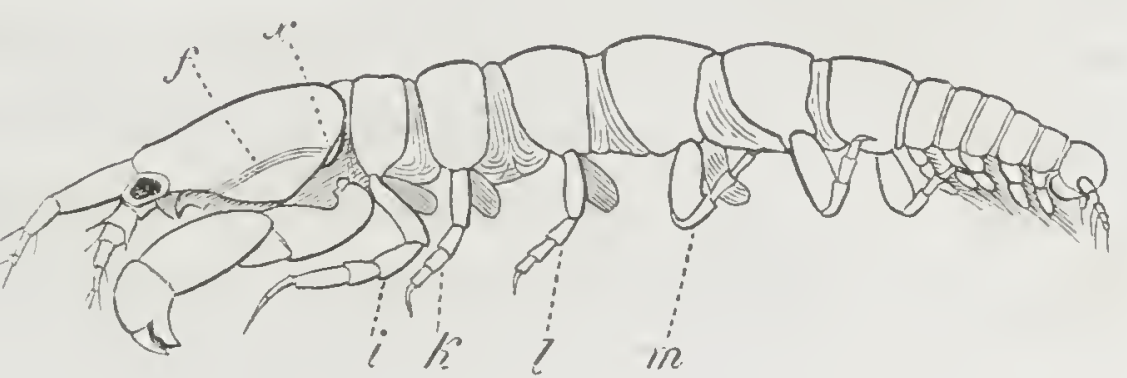

Fig. 2.

Panzers, unter welchem ein beständiger Wasserstrom hinzieht, unterhalten, wie bei Zoëa und den erwachsenen Decapoden, durch einen Anhang des zweiten Kieferpaares, der allen anderen Edriophthalmen abgeht.

Beide Entdeckungen, das sei nebenbei bemerkt, dankt die Wissenschaft weniger einem glücklichen Zufall, als unmittelbar DARwis und seiner Lehre.

Penēusarten leben in den Meeren Europa's, wie hier; ihre Naupliusbrut ist sicher manchem der zahlreichen Forscher, die jene Meere ausbeuten, und mir selbst wiederholt unbeachtet durch die Hände gegangen; denn sie hat Nichts, was ihr unter den so mannichfaltigen und oft so wunderlichen Naupliusformen eine besondere Aufmerksamkeit zulenken könnte. Als ich, wegen der Aehnlichkeit der Bewegung in ihr eine junge Peneus-Zoëa vermuthend, zum ersten Male eine solche Larve eingefangen hatte, und nun unter dem Mikroskope einen von jenen Zoëa himmelweit verschiedenen Nauplius fand, hätte ich diesen ohne Zweifel, als der Entwicklungsreihe, die ich verfolgte, völlig fremd, bei Seite geworfen, wenn nicht gerade der Gedanke an frühere Nauplius-ähnliche Zustände der höheren Krebse, die ich freilich kaum noch in der Gegenwart erhalten glaubte, mich lebhaft beschäftigt hätte.

Und hätte ich nicht schon lange unter den Edriophthalmen nach Resten der vorausgesetzten Zoëazustände gesucht und Alles mit Eifer

Fig. 2. Tanais dubius 1 : Kr. S. 25 mal vergr. Man sieht die Eingangsöffnung $\langle x\rangle$, in die rom Panzer überwölbte Höhlung, in welcher einAnhang des zweiten Kieferpaares ' $f$ ) spielt. An 4 Füssen $(i, k, l, m)$ finden sich Anlagen der Blätter, die später die Bruthöhle bilden. 
erfasst, was diese widerspenstige Ordnung mir fügsam zu machen versprach, so hätte schwerlich rax Bexeden's kurze Andeutung mich so elektrisch berührt und zu erneuter Beschäftigung mit den Scheerenasseln angeregt, und dies um so weniger, da ich schon einmal, an der Ostsee mich mit ihnen geplagt hatte, ohne weiter als meine Vorgänger kommen zu können, und da zweimal auf denselben Gegenstand zurückzukommen, nicht eben nach meinem Geschmack ist.

\section{IV.}

Unsere Scheerenassel, die überhaupt in fast allen Verhältnissen ihres Baues ein höchst merkwürdiges Thier ist, lieferte mir noch eine zweite, für die Lehre von der Entstehung der Arten durch natürliche Züchtung, beachtenswerthe Thatsache.

Wo bei den Krustern hand-, oder scheerenförmige Bildungen rorkommen, pflegen dieselben bei den Männchen stärker, als bei den WVeibchen entwickelt zu sein, und schwellen bei ihnen oft zu ganz unverhältnissmässiger Grösse an, wie wir es oben bei Melita sahen. Ein bekannteres Beispiel solcher Riesenscheeren liefern die Männchen der sogenannten Winkerkrabben (Gelasimus), von denen man sagt, dass sie diese Scheere beim Laufen "hocherhaben tragen, als ob sie damit winkten «; - eine Angabe, die wenigstens nicht für alle Arten richtig ist; eine kleine besonders grossscheerige Art, die ich z. B. in den Mandioccafeldern an der Mündung des Cambriú zu Tausenden herumlaufen sah, hält sie stets dicht an den Leib gepresst. - Eine zweite Eigenthümlichkeit der Krustermännchen besteht nicht selten in einer reichlicheren Entwickhung zarter Fäden an der Geissel der vorderen Fühler, die Spence Bate Hörfäden (auditory cilia) nennt, und die ich, wie ror mir, ohne dass ich es wusste, Lexpig als Riechwerkzeuge deutete. So bilden sie, wie auch van BENEDEN für Bodotria angibt, lange dichte Büschel bei den Männchen mancher Diastylideen, deren Weibchen sie nur in spärlicher Anzahl besitzen. Für die Copepoden machte Claus auf die Verschiedenheit der Geschlechter in dieser Beziehung aufmerksam. Es spricht, beiläufig bemerkt, diese stärkere Entwicklung 
bei den Männchen, wie mir scheint, sehr zu Gunsten der von LeyDiG und mir vertretenen Ansicht, da auch sonst ja die männlichen 'Thiere nicht selten durch den Geruch beim Aufspüren der brünstigen Weibchen geleitet werden.

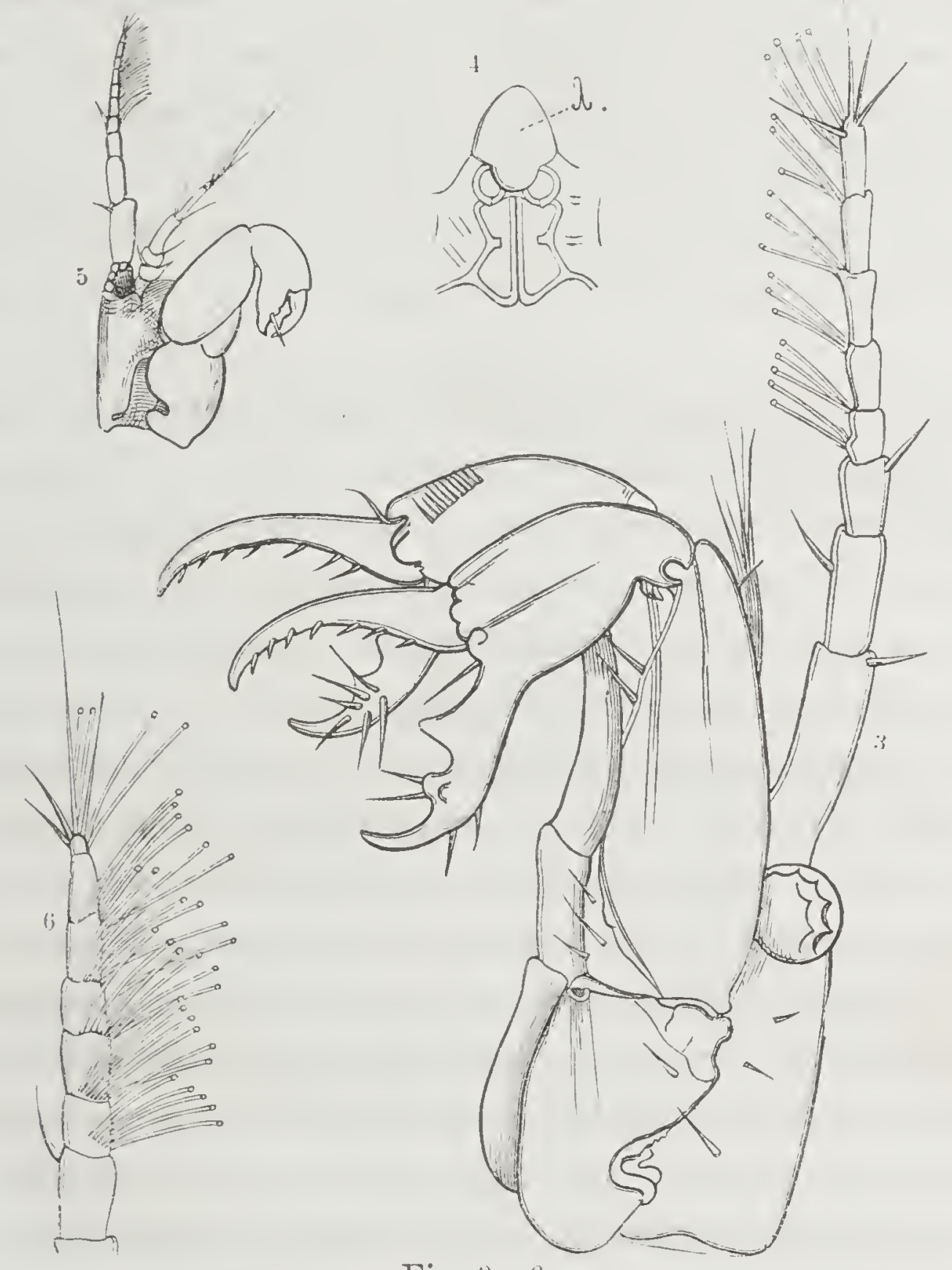

Fig. 3-6.

Bei unserer Scheerenassel nun gleichen die jungen Männchen bis zur letzten der Geschlechtsreife vorausgehenden Häutung den Weibchen; dann aber erleiden sie eine bedeutende Verwandlung. Sie ver-

Fig.3. Kopf der gewöhnlichen Form der Männchen von Tanais dubius (?) KR. 90 mal vergr. Zwischen den Scheerenfüssen ragen die Endborsten des zweiten Fühlerpaars vor. - Fig. 4. Mundgegend desselben, v. unten. 2. Oberlippe. - Fig. 5. Kopf der seltneren Form der Männchen, 25 mal vergr. - Fig. 6. Fühlergeissel desselben mit den Riechfäden, 90 mal vergrr. 
lieren unter Anderem die beweglichen Anhänge des Mundes bis auf diejenigen, die der Unterhaltung des Athemstromes dienen; man findet ihren Darm stets leer und sie scheinen nur noch der Liebe zu leben. Was aber das Merkwürdigste ist, sie erscheinen nun unter zwei verschiedenen Gestalten. Die einen (Fig. 3) bekommen gewaltige, langfingrige, recht bewegliche Scheeren und statt des einzigen Riechfadens der Weibchen deren etwa 12 bis 17 , die zu zwei bis drei an den Gliedern der Fühlergeissel stehen. Die andern (Fig. 5 ; behalten die plumpe Scheerenform der Weibchen; dafür aber sind ihre Fühler (Fig. 6, mit weit zahlreicheren Riechfäden ausgerüstet, die zu 5 bis 7 beisammen stehen.

Zunächst, ehe ich auf deren Bedeutung eingehe, noch ein Wort über die Thatsache selbst. Es war natürlich, daran zu denken, ob nicht etwa zwei verschiedene Arten mit sehr ähnlichen Weibchen und mehr verschiedenen Männchen zusammenlebten, oder ob nicht die Männchen, statt in zwei scharf geschiedenen Formen aufzutreten, nur innerhalb sehr weiter Grenzen veränderlich wären. Ich kann weder das Eine, noch das Andere ammehmen. Unsere Scheerenassel lebt zwischen dicht rerfilzten Wasserfäden, die einen etwa zolldicken Ueberzug auf Steinen in der Nähe des Ufers bilden. Bringt man eine Handroll dieses grünen Filzes in ein grösseres Glas mit reinem Seewasser, so sieht man bald seine Wände sich mit Hunderten, ja Tausenden dieser kleinen plumpen weisslichen Asseln bedecken. So habe ich mit der einfachen Linse manches Tausend, und ich habe mit dem Mikroskope sorgfältig viele Hunderte durchgemustert, aber ich habe keine Verschiedenheiten unter den Weibchen und keine Zwischenformen zwischen den zweierlei Männchen auffinden können.

Das Torkommen num dieser zweierlei Männchen wird der Schule als blosses Curiosum, es wird denen, welche den "Schöpfungsplan "als " freie Conception eines allmächtigen Verstandes " ansehen, 》welche in dessen Gedanken gereift ist, beror sich dieselbe in greifbaren, äusseren Formen offenbarte", als blosse La un e des Schöpfers erscheinen, da sie weder aus dem Gesichtspuncte praktischer Zweckmässigkeit, noch aus dem "typischen Bauplane" erklärbar ist. Von DARwix's Lehre aus 
erhält dagegen diese Thatsache Sim und Bedeutung, und sie scheint hinwiederum geeignet, Licht zu werfen auf eine Frage, in der Brosi "den ersten und erheblichsten Einwand gegen die neue Theorie " erblickte, - wie es möglich sei, dass aus der Häufung in verschiedenen Richtungen auseinanderlaufender kleinster Abänderungen, Abarten und Arten entstehen, die von der Stammform nett und scharf wie ein gestieltes Dicotyledonenblatt sich abheben und nicht mit ihr und untereinander, wie der unregelmässige krause Lappen einer Blätterflechte mit der übrigen Flechtenmasse rerfliessen.

Lassen wir die noch gleichgebildeten Männchen unserer Scheerenassel, -- meinetwegen, wie Broxx will, nach allen beliebigen Richtungen hin, -- abzuändern beginnen. War die Art ihren Lebensrerhältnissen angepasst, war in dieser Beziehung bereits durch natürliche Züchtung das Beste erreicht und gesichert, so hatten neue die Art als Art berührende Abänderungen, als Rückschritte keine Aussicht sich geltend zu machen, mussten viehmehr, wie sie auftauchten, wieder rerschwinden und nụ für die geschlechtlichen Beziehungen blieb den abändernden Männchen der Kampfplatz geöffinet. Hier konnten sie Vortheile über ihre Mitbewerber erlangen, indem sie entweder ihre Weibchen besser aufzuspüren oder besser zu fassen rermochten. Die besten Riecher besiegten alle, die ihnen in dieser Beziehung nachstanden, wenn sie nicht andere Torzüge, etwa kräftigere Scheeren, entgegenzustellen hatten. Die besten Packer besiegten alle schwächer bewaffneten Kämpen, wenn sie nicht andere Vorzüge, etwa schärfere Sinne, ihnen entgegenstellten. Man begreift, wie auf diese Weise einerseits alle in der Ausbildung der Riechfäder, andrerseits alle in der Ausbildung der Scheeren minder begünstigten Zwischenstufen rom Kampfplatze rerschwinden und zwei scharf geschiedene Formen, die besten Riecher und die besten Packer als einzige Gegner übrig bleiben konnten. Zur Zeit scheint sich der Kampf zu Gunsten der letzteren entscheiden zu wollen, da sie in weit überwiegender Mehrzahl, vielleicht zu Hundert auf Einen Riecher vorkommen.

Wenn daher Broxx, um auf dessen Einwand zurückzukommen, "gerne zu Gunsten der Darwlx'schen Theorie und zur Erklärung, 
warum nicht viele Arten durch Zwischenglieder in einander verfliessen, noch irgend ein äusseres oder inneres Princip entdecken möchte, welches die Abänderungen jeder Art nur in einer Richtung weiter drängte, statt sie in allen Richtungen blos zu gestatten ", - so wird ein solches, wie in diesem, so in vielen anderen Fällen einfach darin zu finden sein, dass eben nur wenige Richtungen offen stehen, nach denen hin die Veränderungen zugleich Verbesserungen sind, in denen also sie sich häufen und befestigen können, während sie in allen anderen als gleichgültig oder nachtheilig " wie gewonnen, so zerronnen " sein werden.

Das Vorkommen von zweierlei Männchen bei derselben Art mag vielleicht eine nicht allzu seltene Erscheinung sein bei Thieren, wo sich dieselben weit von der Bildung der Weibchen entfernen. Doch nur bei solchen, die man sich in genügender Menge verschaffen kann, wird es möglich sein, sich zu überzeugen, dass man nicht etwa verschiedene-Arten oder verschiedene Altersstufen vor sich habe. Ich kann aus dem Bereiche meiner wenig ausgedehnten Erfahrung ein zweites Beispiel geben. Es betrifft einen Strandhüpfer (Shore-hopper. Orchestia). Das

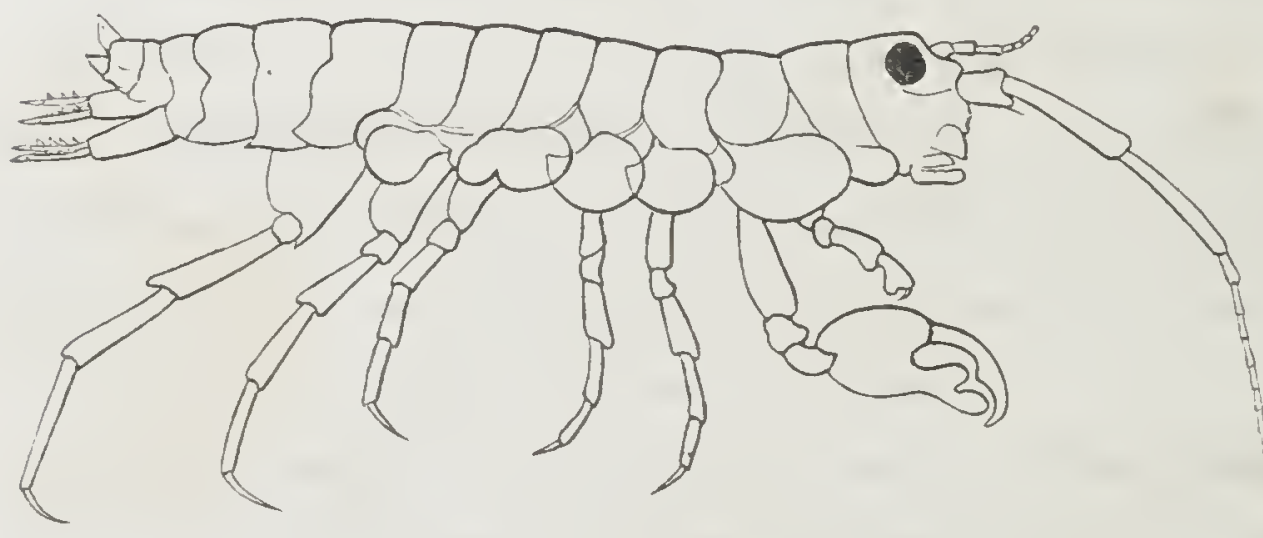

Fig. 7 .

Thier (Fig. 7) lebt an sumpfigen Stellen in der Nähe des Meeres, unter moderndem Laube, in der lockeren Erde, welche die Sumpfkrabben (Gelasimus, Sesarma, $\mathrm{Cy}$ -

clograpsus u. s. w.) um den Eingang ihrer Höhlen aufwerfen, ja unter trockenem Kuh - und Pferdedung. Wie es sich so weiter vom Strande entfernt, als die Mehrzahl seiner Gattungsgenossen, - (einige freilich gehen meilenweit in's Land, bis auf tausend Fuss hohe Berge, wie O. tahitensis, telluris, sylvicola) —, so entfernt sich das Männchen noch mehr von allen bekannten Arten durch die gewaltigen Scheeren des zweiten Fusspaars. Nur die Orchestia Gryphus, von der sandigen Küste

Fig. i. Orchestia Darwinii n. sp. Männchen. 
von Mönchgut, zeigt eine entfernt ähnliche Bildung, während sonst die gewöhnliche Handform der Amphipoden sich findet. Namentlich in der
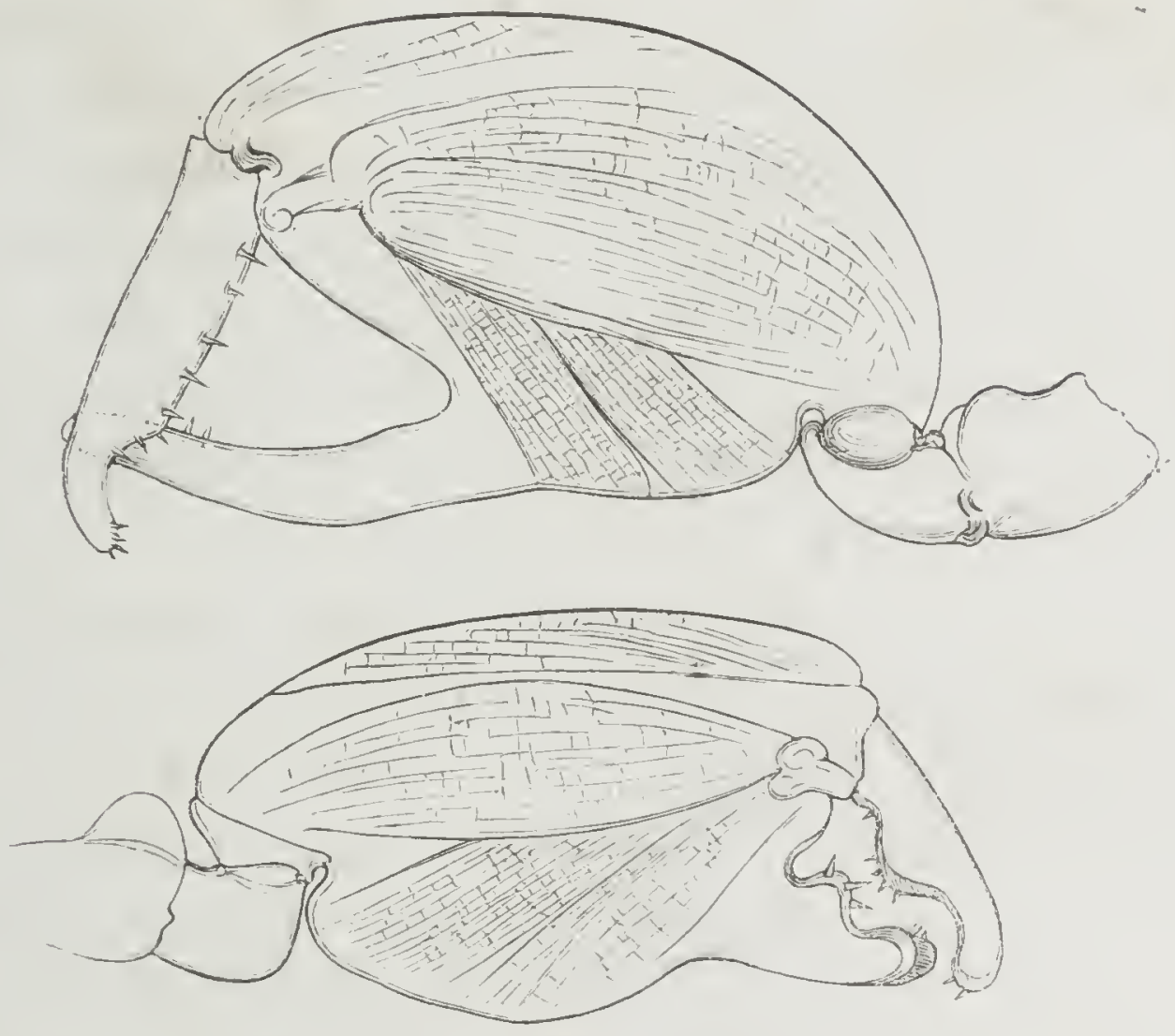

Fig. S. u. 9.

Bildung dieser Scheeren nun findet eine erhebliche Verschiedenheit zwischen den Männchen statt, so gross als sie sonst kaum zwischen zwei Arten der Gattung wiederkehrt, und wie bei der Scheerenassel trifft man nicht etwa eine lange Reihe in einander verfliessender Bildungen, sondern nur zwei durch keinerlei Zwischenglieder verbundene Formen (Fig. 8 u.9). Man würde die Männchen unbedenklich als zwei wohl geschiedene Arten betrachten, wenn sie nicht an gleicher Stelle mit ununterscheidbaren Weibchen zusammenlebten. Dass nun gerade bei dieser Art die doppelte Scheerenform der Männchen vorkommt, ist insofern beachtenswerth, als die weit von der gewöhnlichen Bildung der anderen Arten abweichende Gestaltung der Scheeren darauf hinweist, dass sie noch neuerdings beträchtliche Veränderungen erlitten habe, und als daher von rornherein gerade bei ihr eher als bei anderen ein solches Vorkommen zu erwarten war.

Fig. u. 9. Jie zweierlei scheeren der Männchen ron Orchestia Darwinit. 45 mal vergr.

r. 3 iillr, Fiir Darwin. 
Ich kann mich nicht enthalten, bei dieser Gelegenheit darauf' hinzuweisen, dass man (soviel Spexce Bate's Katalog ersehen lässt) zu zweierlei verschiedenen Männchen (Orchestia telluris und sylvicola), die zusammen in den Wäldern von Neuseeland gesammelt wurden, erst einerlei Weibchen kennt, und die Vermuthung zu wagen, dass hier ein ähulicher Fall vorliege. Es ist mir nicht wahrscheinlich, dass von diesen gesellig lebenden Amphipoden zwei nahe verwandte Arten unter den gleichen Lebensbedingungen mit und durcheinander vorkommen sollten.

Wie die Männchen mehrerer Melita-Arten durch die mächtige unpaare Kneifzange, so sind die Weibchen einiger anderen Arten dersclben Gattung dadurch vor allen anderen Amphipoden ausgezeichnet, dass bei ihnen eine besondere Vorrichtung entwickelt ist, die dem Männchen das Halten derselben erleichtert. Die Hüftblätter des vorletzten Fusspaares sind in hakenförmige Fortsätze ausgezogen, an die sich das Männchen mit den Händen des ersten Fusspaares festklammert. Die beiden

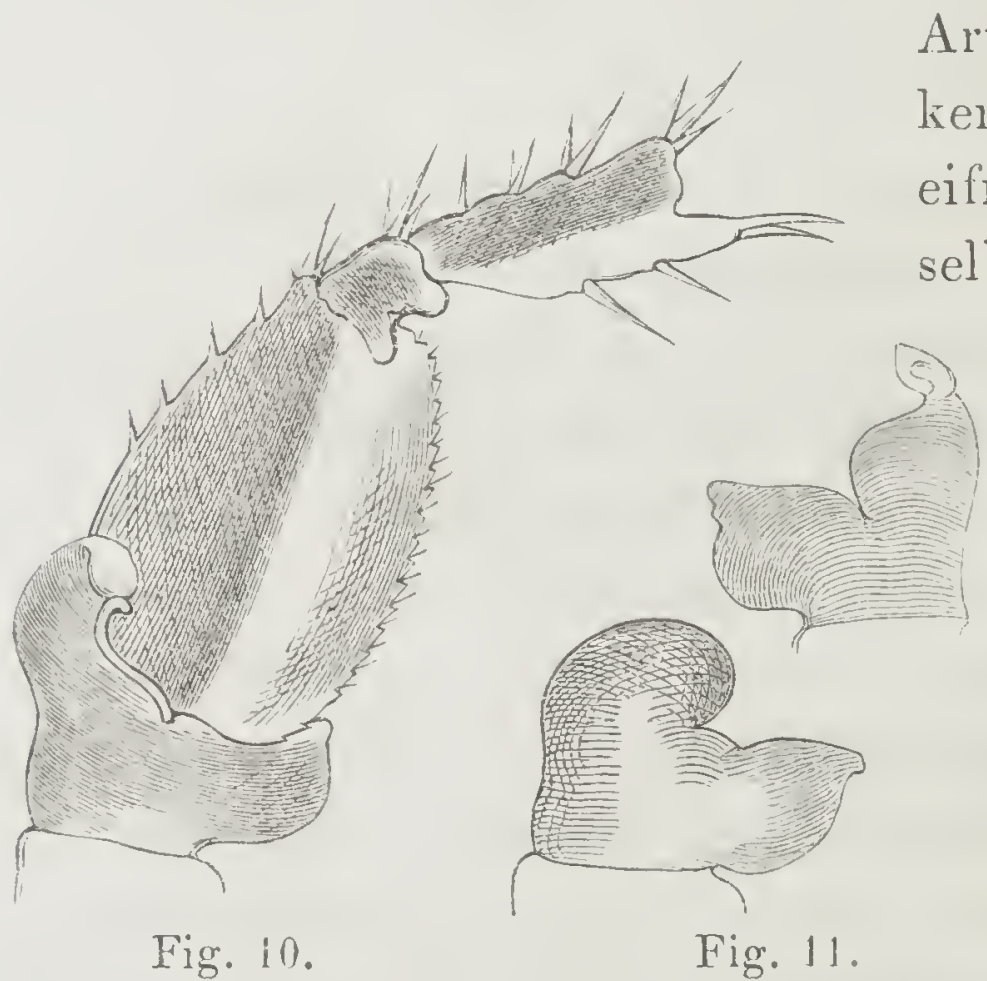
Arten, ron denen ich diese Bildung: kenne, gehören zu den begattungseifrigsten Thieren ihrer Ordnung, selbst Weibchen, die mit Eiern auf beliebiger Entwicklungsstufe beladen sind, haben nicht selten ihr Männchen auf' dem Rücken. Beide Arten sind nahe verwandt mit der an den europäischen Küsten weit verbreiteten und häufig untersuchtel Melita palmata Leach (Gam. marus Dugesii Enw.); leider aber finde ich keinen Aufschluss darüber, ob auch die Weibchen dieser oder einer' andern europäischen Art eine ähnliche Vorrichtung besitzen; bei Melita exilii sind alle Hüftblätter von gewöhnlicher Bildung. Doch,

Fig. 10. Hüftblatt des vorletzten Fusspaars rom? Männchen, sowie Hüftblatt nebst den drei folgenden Gliedern desselben Fusspaares vom Weibchen der Melita Messalina. $15 \mathrm{mal}$ vergr. - Fig. 11. Hüftblatt desselben Fusspars rom Weibchen der Melita insatiabilis. 
wie dem auch sei, mögen sie nun bei zwei oder bei zwanzig Arten sich finden, jedenfalls ist das Vorkommen jener eigenthümlichen hakenförmigen Fortsätze ein sehr beschränktes.

Unsere beiden Arten nun leben geschützt unter flach aufliegenden Steinen in der Nähe des Ufers, die eine, Melita Messalina, so hoch, dass sie nur selten vom Wasser bedeckt wird, die andere, Melita insatiabilis, ein wenig tiefer; beide Arten leben in zahlreichen Schaaren beisammen. Weder ist also zu erwarten, dass häufiger als bei anderen Arten den Liebespaaren störende Einflüsse drohen, noch auch würde es dem Männchen, das etwa sein Weibchen verlöre, schwerer werden als denen anderer Arten, ein neues zu finden. Ebensowenig ist abzusehen, wie diese das Begattungsgeschäft sichernde Vorrichtung am Körper des Weibchens anderen Arten nachtheilig sein könnte. So lange aber weder nachgewiesen ist, dass unsere Arten dieser Vorrichtung besonders bedürftig sind, oder dass dieselbe anderen Arten mehr schädlich als nützlich sein würde, so lange wird man iln Vorhandensein nur bei diesen wenigen Amphipoden als Werk nicht einer voraus berechnenden W $\mathrm{W}$ eisheit, sondern eines von der natürlichen Züchtung benutzten glücklichen Zufalls ansprechen dürfen. Bei letzterer Annahme ist das so vereinzelte Vorkommen begreiflich, während man nicht absieht, warum der Schöpfer mit einer Torrichtung, die er doch mit dem nallgemeinen Bauplane « der Amphipoden rereimbar fand, gerade nur diese wenigen Arten beglückte und sie anderen versagte, die unter gleichen äusseren Verhältnissen leben und selbst in dem ungewöhnlichen Begattungseifer ihnen gleichen. In Gesellschaft oder nächster Nachbarschaft der beiden Melita leben nämlich zwei Allorchestes, von denen man ebenfalls fast mehr Pärchen, als einzelne Thiere trifft und deren Weibchen doch nichts von jenen Fortsätzen der Hüftblätter zeigen.

Wie diesen, so wird man, meine ich, gegen die ron AGAssiz mit so viel Geist und Sachkemntniss vertretene Auffassung der Arten als verkörperter Gedanken des Schöpfers alle ähnlichen Fälle geltend machen dürfen, in welchen Einrichtungen, die allen Arten einer Gruppe gleich nützlich sein würden, der Mehrzahl fehlen und nur einzelnen bevor- 
zugten Günstlingen, die deren nicht mehr als andere bedürftig erscheinen, sich zugetheilt finden.

\section{V.}

Unter den auch in der Naturgeschichte der Kruster zahlreichen 'Thatsachen, auf die von DARwix's Lehre aus ein neues helles Licht fällt, ist mir neben den zwiefältigen Männchen unserer Scheerenassel und der Orchestia Darwinii noch einc besonders wichtig erschienen, das Verhaltcn der Kiemenhöhle bei den luftathmonden Krabbcn, von denen ich leider einige der merkwürdigsten (Gecarcinus, Ranina) noch nicht untersuchen konnte. Da dies Verhalten, das Vorhandensein eines hinter den Kiemen gelegenen Eingangs, selbst als Thatsache bisher nur bci Ranina beachtet wurde, will ich etwas näher darauf eingchen. Ich erwähnte schon, dass wie es DARwry's Lehre fordert, diese Eingangsoffnung bei den verschiedenen Familien in verschiedener Weise zu Stande kommt.

Bei dcr Froschkrabbe (Ranina) des indischen Mecres, die sich nach Runpr bis auf die Dächer der Häuser zu versteigen liebt, fehlt nach Minae Edwards die gewöhnliche vordere Eingangsöffnung ganz und der Eingang eines in den hintersten 'Theil der Kiemrenhöhle mündendcn Canales findet sich unter dem Anfang des Hinterleibes.

Am einfachsten ist die Sache bei mehreren Grapsoïden. So bei Aratus Pisonii, einer allerliebsten, lebhaften Krabbe, die auf die Manglcbüsche Rhizophora' steigt und deren Blätter benagt. Mit ihren kurzen, aber ungemein spitzcn Klauen, die wie Stecknadeln prickeln, wenn sie einem über die Hand läuft, klettert sie mit grosser Behendigkeit die dünnsten Zweiglein hinauf. Als ich einmal ein solches Thier auf meiner Hand sitzen hatte, sah ich, wie es den hinteren Theil seines Panzers hob, und wie sich dadurch jederseits über den letzten Füssen eine breite Spalte erschloss, durch die ich tief in die Kiemenhöhle hineinsehen konnte. Ich habe scitdem das merkwürdige Thier mir nicht wieder verschaffen können, dagegen konnte ich diesclbe Beobachtung oft wiederholen an einem anderen Thiere derselben Fanilie, (cinem echten 
Grapsus, wie es scheint) das häufig an den Felsen unserer Küste lebt. Während der hintere Theil des Panzers sich hebt und die erwähnte Spalte sich bildet, scheint zugleich der vordere Theil sich zu senken und die vordere Eingangsöffnung zu verengen oder ganz zu schliessen. Unter Wasser findet das Heben des Panzers nie statt. Das Thier öffnet also seine Kiemenhöhle vorn oder hinten, je nachdem es Wasser oder Luft zu athmen hat. - Wie das Heben des Panzers zu Stande kommt, weiss ich nicht, doch glaube ich, dass es dadurch geschieht, dass cin häutiger Sack der unter dem hinteren Theile des Panzers aus der Leibeshöhle weit in die Kicmenhöhle hineinragt, durch Hineintreiben der Leibesflüssigkeit angeschwellt wird. -

Dasselbe Heben des Panzers beobachtete ich auch bei einigen Arten der verwandten Gattungen Sesarma und Cyclograpsus, die in sumpfigem Boden tiefe Löcher graben und manchmal auf dem feuchten Schlamme herumlaufen, oder wie lauernd vor ihren Löchern sitzen. Man muss aber bei diesen Thieren sich oft lange gedulden, ehe sie, dem Wasser entnommen, ihre Kiemenhöhle der Luft erschliessen, denn es besteht bei ihnen eine wundervolle Vorrichtung, vermöge deren sie auch ausser Wasser noch eine Zeitlang Wasser zu athmen fortfahren können. Die Oeffnungen zum Austritt des Wassers, das der Athmung gedient hat, liegen bekanntlich bei diesen, wie bei den meisten Krabben in den rorderen Ecken des Mundrahmens (cadre buccal EDw.), während von dessen hinteren Ecken aus die Eingangsspalten der Kiemenhöhle über dem ersten Fusspaare sich hinziehen. Der Theil des Panzers nun, der zu den Seiten des Mundes zwischen den beiderlei Oeffnungen sich hinzieht (die régions ptérygostomiennes), erscheint bei unseren Thieren, und schon Milane Edwarids hat das als eine besonders auffallende Eigenthümlichkeit derselben hervorgehoben, in kleine quadratische Feldchen von äusserster Regehmässigkeit getheilt. Dieses Aussehen ist bedingt theils durch kleine warzenförmige Erhöhungen, theils und vorzugsweise durch eigenthümlich knieförmig gebogene Haare, die gewissermaassen ein dicht über der Oberfläche des Panzers ausgespanntes feines Netz od'r Haarsieb bilden. Tritt nun eine Wasserwelle aus der Kiemenhöhle an *, so verbreitet sie sich $\mathrm{im} \mathrm{Nu}$ in diesem Haarnetze und wird durch ange- 
strengte Bewegungen des in der Eingangsspalte spielenden Anhanges der äusseren Kieferfüsse der Kiemenhöhle wieder zugeführt. Während das Wasser so als dünne Schicht über dem Panzer hingleitet, wird es sich wieder mit Sauerstoff sättigen und dann aufs Neue der Athmung dienen können. Zur Vervollständigung dieser Einrichtung tragen die äussern Kieferfüsse, wie ebenfalls längst bekannt, eine vorspringende, mit dichtem Haarsaum bedeckte Leiste, die rorn nahe der Mittellinie beginnt und nach hinten und aussen zur hintern Ecke des Mundrahmens sich hinzieht. Die beiden Leisten der rechten und linken Seite bilden also zusammen ein Dreieck mit nach vorn gewandter Spitze, einen Wogenbrecher, durch welchen das der Kiemenhöhle entströmende Wasser vom Munde abgehalten und der Kiemenhöhle wieder zugeleitet wird. - In recht feuchter Luft kann der in der Kiemenhöhle enthaltene Wasserrorrath stundenlang vorhalten und erst, wenn er zu Ende geht, hebt das Thier seinen Panzer, um von hinten her Luft zu den Kiemen treten zu lassen.

Bei Eriphia gonagra liegen die der Luftathmung dienenden Eingangsöffnungen der Athemhöhle nicht wie bei den Grapsoiden über, sondern hinter dem letzten Fusspaare, zu den Seiten des Hinterleibes.

Bei den schnellfüssigen Sandkrabben (Ocypoda), ausschliesslichen Landthieren, die in Wasser kaum einen Tag sich lebend erhalten, während weit früher schon ein Zustand gänzlicher Erschlaffung eintritt und alle willkürlichen Bewegungen aufhören ${ }^{1}$, kennt man schon längst, ohne jedoch ihren Zusammenhang mit der Kiemenhöhle zu ahnen, eine eigenthümliche Vorrichtung an den Füssen des dritten und vierten Paares. Fig. 12). Diese beiden Fusspaare sind dichter als die übrigen aneinandergerückt; die einander zugewendeten Flächen ihrer Grundglieder, also die hintere Fläche am dritten, die vordere am vierten Fusse:

1) Da dies nicht im Meere, sondern in Gläsern mit Seewasser beobachtet wurde, konnte man denken, dass die Thiere ermatten und sterben, nicht weil sie unter Wasser sind, sondern weil sie den darin enthaltenen Sauerstoff aufgezehrt. Ich brachte daher in dasselbe Wrasser, aus dem ich eben eine bewusstlose Ocypoda genommen hatte, deren Beine schlaff niederhingen, eine Lupea diacantha, die durch Verweilen an der Luft in gleichen Zustand gerathen war, und wie jene in der Luft, erholte sich diese im Wasser. 
sind eben, glatt, und ihre Ränder tragen einen dichten Besatz langer seidenglänzender, eigenthümlich gestalteter Haare (Fig. 13). Munse EDwaris, der ihrem Aussehen nach diese Flächen passend mit Gelenkflächen vergleicht, meint, dass sie dazu dienen, die Reibung zwischen den beiden Füssen zu vermindern. Man musste sich bei dieser Deutung fragen, wie denn gerade bei diesen Krabben und gerade nur zwischen diesen beiden Füssen eine solche die Reibung mindernde Vorrichtung nöthig werde, abgesehen

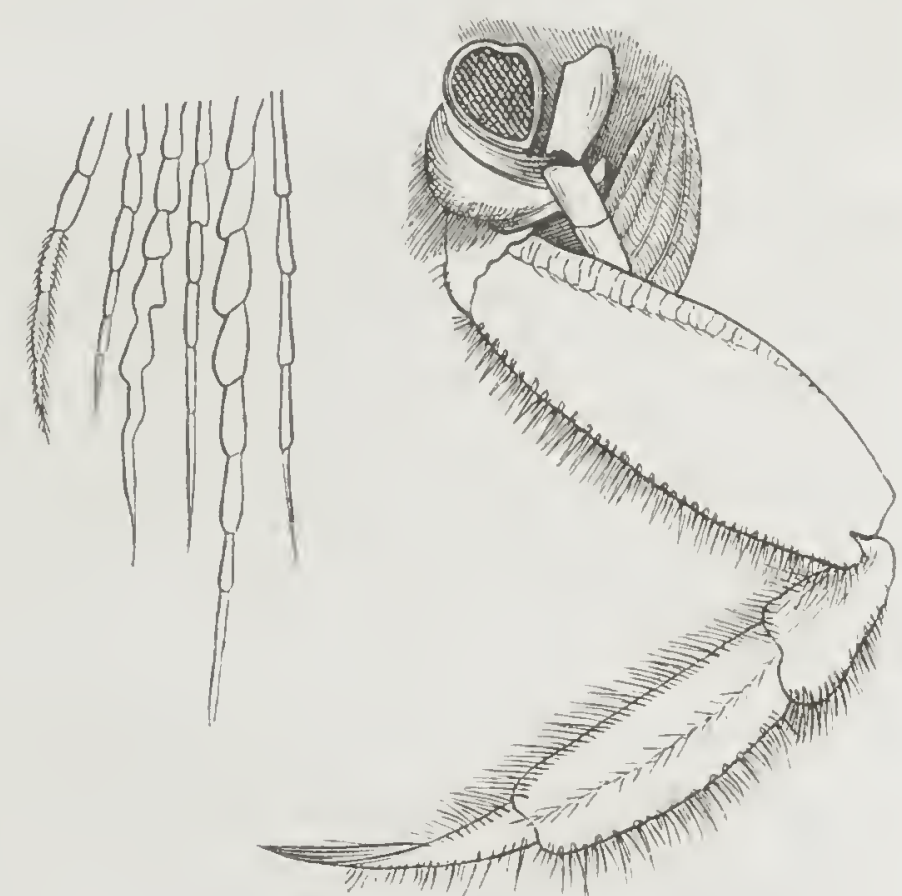

Fig. 13.

Fig. 12. davon, dass die sonderbaren Haarbürsten, die ja im Gegentheil die Reibung mehren mussten, unerklärt bleiben. Indem ich nun die Füsse einer grossen Sandkrabbe in mancherlei Richtungen hin und herbog, un zunächst zu sehen, bei welchen Bewegungen des Thieres Reibung an der bezeichneten Stelle stattfinde, und ob dies vielleicht ihm besonders wichtige, oft wiederkehrende Bewegungen seien, - bemerkte ich, als ich die Füsse weit auseinander gespreizt hatte, in der Tiefe zwischen ihnen eine ansehnliche runde Oeffnung, durch die sich leicht Luft in die Kiemenhöhle einblasen, oder auch ein feines Stäbchen einführen liess. Die Oeffnung mündet in die Kiemenhöhle hinter einem kugelförmigen Zapfen, der an Stelle einer bei Ocypoda fehlenden Kieme über dem dritten Fusse steht. Sie wird seitlich begrenzt von Leisten, die sich oberhalb der Einlenkung der Füsse erheben und an die sich der untere Rand des Panzers anlegt. Auch nach aussen wird sie bis auf eine schmale Spalte von diesen Leisten überwölbt. Ueber diese Spalte legt sich der Panzer, der gerade hier weiter als sonst nach unten vor-

Fig. 12. Hinterer Eingang in die Kiemenhöhle von Ocypoda thombea FABR. Nat. Gr. Der Panzer und der 4. Fuss der rechten Seite sind entfernt. -

Fig. 13. Spitzen einiger Haare vom Grundglied des 3. Fusses, 45 mal vergr. 
springt, und so wird eine vollständige Röhre gebildet. Während Grapsus Wasser immer nur von vorn her zu seinen Kiemen treten lässt, sah ich dasselbe bei Ocypoda auch durch die soeben besprochene Oeffnung einströmen.

Mit Ocypoda stimmen in der Lage der hinteren Eingangsöffnung. und den sie begleitenden Eigenthümlichkeiten des dritten und vierten Fusspaares zwei andere dem Wasser entfremdete Arten derselben Familie ïberein, die ich zu untersuchen Gelegenheit hatte. Die eine, vielleicht der Gelasimus vocans, die in Manglesümpfen lebt, und die Oeffnung ihrer Höhle mit einem dicken, mehrere Zoll hohen, walzenförmigen Schornstein zu versehen liebt, hat die Bürsten am Grundgliede der betreffenden Füsse aus gewöhnlichen Haaren gebildet. Die andere, ein kleinerer Gelasimus, in M. EDwards' Naturgeschichte der Kruster nicht verzeichnet, die trocknere Stellen liebt und sich nicht scheut, unter der scheitelrechten Mittagssonne eines Decembertages im glühenden Sande umherzuschweifen, aber auch im Wasser wenigstens mehrere Wochen lang auszudauern vermag, hat dagegen in diesen Bürsten, wie Ocypoda, borstenlose, zarte, ja noch zartere und regelmässiger eingeschnürte Haare. ' Was diese eigenthümlichen Haare bedeuten mögen, ob sie nur fremde Körper von der Kiemenhöhle abhalten, ob sie der vorbeiströmenden Luft Feuchtigkeit geben, oder ob sie etwa, wie ihr Ansehen namentlich bei dem kleinen Gelasimus an die Riechfäden der Krabben erinnert, so auch ähnliche Dienste leisten, das gebührend zu erörtern würde uns zu weit von unserem Gegenstande abführen. Doch sei bemerkt, dass bei beiden Arten, besonders bei Ocypoda, die Riechfäden an der gewöhnlichen Stelle sehr verkümmert sind, und ihre Fühlergeisseln im Wasser nie die eigenthümlichen schlagenden Bewegungen ausführen, wie man sie bei anderen Krabben und auch bei den grösseren Gelasimus sieht, und dass allerdings wohl bei diesen luftathmenden

i) Dieser kleinere Gelasimus ist auch dadurch merkwürdig, dass bei ihm besonders augenfällig der chamäleontische Farbenwechsel herrortritt, den manche Krabben zeigen. Der Panzer eines Männchens, das ich eben vor mir habe, prangte vor fünf Minuten, als ich es fing, in seinem hinteren Theile in blendendem Weiss; jetzt zeigt er an derselben Stelle ein mattes Grau. 
Krabben, wie bei den luftathmenden Wirbelthieren, der Sinn des Geruchs am Eingange der Athemhöhle zu suchen sein dürfte.

Soweit das Thatsächliche in Betreff des Luftathmens der Krabben. Es ist schon oben angedeutet worden; weshalb DARwr's Lehre fordert, dass wenn überhaupt besondere Einrichtungen für die Luftathmung bestanden, dieselben verschieden in den verschiedenen Familien gebildet seien. - Dass die Erfahrung mit dieser Forderung in vollem Ein. klang steht, wird um so schärfer zu Gunsten DaRwix's betont werden dürfen, als die Schule, weit entfernt, so tieforgeifende Verschiedenheiten roraussehen oder erklären zu können, dieselben vielmehr als etwas höchst Verwunderliches wird betrachten müssen. Wenn bei den nahe verwandten Familien der Ocypodiden und Grapsoïden die grösste Uebereinstimmung herrscht in allen wesentlichen Verhältnissen ihres Baues, wenn für alles Andere, für die Sinne, für die Gliederung der Gliedmassen, für jedes Stäbchen und Haarbüschelchen des verwickelten Magengerüstes, für das Herz und den Kreislauf, wenn für die der Wasserathmung dienenden Einrichtungen bis auf die mikroskopischen Häkchen an den Haaren der die Kiemen abfegenden Geisseln derselbe Bauplan sklarisch festgehalten ist, woher nun auf einmal diese Ausnahme, diese völlige Verschiedenheit für die Luftathmung?

Die Schule wird kaum eine Antwort haben auf diese Frage, sie müsste sich denn auf den mit Recht unter uns in Verruf gekommenen theologisch-teleologischen Standpunct stellen wollen, ron dem aus das Zustandekommen einer Einrichtung als erklärt gilt, wenn man ihre "Zweckmässigkeit " für das Thier nachweisen liann. Von diesem aus würde man allerdings sagen liönnen, dass eine über den hinteren Füssen weitklaffende Spalte, die für Aratus Pisonii zwischen dem Laube der Manglebüsche nichts Bedenkliches hatte, nicht passte für die im Sande lebende Ocypoda; dass um dem Eindringen des Sandes vorzubeugen, hier die Oeffnung der Kiemenhöhle an deren tiefster Stelle angebracht, dass sie von ihr aus abwärts gerichtet, dass sie tief zwischen breiten mit schützenden Haarbürsten umsäumten Flächen verborgen sein musste. -Es liegt diesen Blättern fern, im Allgemeinen auf eine Zurückweisung jener Zweckmässigkeitslehre einzugehen. Dem vielen Trefflichen, was 
seit Sproza hierüber gesagt ist, wäre auch kaum etwas Wesentliches nachzutragen. Nur das möge bemerkt sein, dass ich es gerade als eine der wichtigsten Leistungen der Darwin'schen Lehre ansehe, die nun einmal auf dem Gebiete des Lebens unabweisbaren Nützlichkeitsbetrachtungen ihrer mystischen Ueberschwenglichkeit entkleidet zu haben. - Für den rorliegenden Fall genügt es, auf den Gelasimus der Manglesümpfe hinzuweisen, der hier mit verschiedenen Grapsö̈den dieselben äusseren Verhältnisse theilt, und doch nicht mit ihnen, sondern mit der sandbewohnenden Ocypoda übereinstimmt.

\section{VI.}

Kaum minder schlagend als das Beispiel der luftathmenden Krabben ist das Verhalten des Herzens in der Abtheilung der Edriophthalmen, die man billig nach dem Vorgange von Daxa und Sperce Bate, nur in zwei Ordnungen, die Amphipoden und die Asseln, theilt.

Bei den Amphipoden, denen die genannten Forscher mit Recht auch die Caprellen und Wallfischläuse, die Lämodipoden Latreille's zuzählen, hat das Herz unveränderlich dieselbe Lage; es dehnt sich als langer Schlauch durch die sechs dem Kopfe folgenden Ringe und hat drei Paar mit Klappen versehener Spalten zum Eintritt des Blutes, die im zweiten, dritten und rierten dieser Ringe liegen. So fanden es $\mathrm{LA}_{\mathrm{A}}$ ValeT'Te bei Niphargus (Gammarus puteanus) und Clads bei Phronima, und ebenso fand ich es bei einer ansehnlichen Zahl von Arten aus den verschiedensten Familien. ${ }^{1}$ Die einzige, unerhebliche Ausnahme, auf

1) Besonders bequem für die Beobachtung der Herzspalten pflegen die Jungen im Ei. kurz ror dem Ausschlüpfen, zu sein; sie sind meist genügend durchsichtig, die Bewegungen des Herzens sind weniger stürmisch, als später, und sie liegen still selbst ołne den Druck eines Deckglases. - Bei der herkömmlichen Ansicht von der Verbreitung der Amphipoden, dass sie an Mannichfaltigkeit polwärts zu-, nach dem Aequator hin abnehmen, mag man es befremdlich finden, wenn ich von einer ansehnlichen Artenzahl an einer subtropischen Küste rede. Ich bemerke also, dass ich in wenigen Monaten und ohne grössere, vom Strande aus unzugängliche Tiefen auszubeuten, 35 verschiedene Arten auffand, darunter 34 neue, - was mit den früher, namentlich durch DaNa bekannt gewordenen schon 60 brasilianische Amphipoden ergiebt, während KRörER in seinen "Grönlands Amfipoder" aus dem damals schon 
die ich bis jetzt gestossen bin, bietet die Gattung Brachyscelus ': hier besitzt das Herz nur zwei Spaltenpaare, indem es nach vorn nur bis in den zweiten Leibesring reicht und des sonst in diesem Ringe liegenden Spaltenpaares entbehrt. ${ }^{2}$

Dieser Einförmigkeit gegenüber, die das Herz in der ganzen Ordnung der Amphipoden zeigt, muss es sehr auffallen, es in der nächststehenden Ordnung der Asseln als eines der veränderlichsten Organe wiederzufinden.

Bei den Scheerenasseln (Tanais) gleicht das Herz durch seine langstreckige Schlauchform, sowie durch Zah] und Lage der Eingangsspalten dem Amphipodenherzen, mit dem Unterschiede jedoch, dass die beiden Spalten jedes Paares nicht genau einander gegenüberliegen.

Bei allen übrigen Asseln ist das Herz nach dem Hinterleibe hingegerückt. Bei derı wunderlich missgestalteten Binnenasseln der Porzellankrebse (Entoniscus Porcellanae) ist das kuglige Herz des Weibchens auf eine kurze Strecke des langgezogenen ersten Hinterleibsringes be-

von weit zahlreicheren Forschern durchsuchten arctischen Meere mit Einschluss ron 2 Lämodipoden nur 24 Arten kannte.

1) Nach Midne EDwards' Anordnung würden die Weibchen dieser Gattung zu den Hypérines ordinaires, die bisher unbekannten Männchen, zu den Hypérines anormales gehören, deren unterscheidendes Merkmal, die wunderlichen zickzackförmig zusammengelegten unteren Fühler, überhalipt eben nur eine Geschlechtseigenthümlichkeit männlicher Thiere ist. Bei dem Systematisiren nach einzelnen todten Exemplaren, über deren Geschlecht, Alter u. s. w. man nichts weiss, sind ähnliche Missgriffe unvermeidlich. So hat, um ein anderes Beispiel aus neuester Zeit zu geben, ein berühmter Fischkenner, BLEEKEl, kürzlich zwei Gruppen der Cyprinodonten dadurch unterschieden, dass die einen, Cyprinodontini, eine pinna analis non elongata, die andern, Aplocheilini, eine pinna analis elongata haben sollen; danach würden ron einem hier sehr häufigen Fischchen die Weibchen zur ersten, die Männchen zur zweiten Gruppe gehören. Solche Missgriffe sind, wie gesagt, für den "dry skin philosopher" unvermeidlich und deshalb verzeihlich; sie beweisen aber immerhin, wie grundsatz- und haltlos vielfach noch die heutige Systematik ins Blaue hinein geht, und wie sehr sie des untrüglichen Prüfsteins für den Werth der verschiedenen Merkmale bedürftig ist, den 1)ARwin's Lehre ihr zu geben verspricht.

2) In Milve Enwaros' Leçons sur la physiol. et l'anat. comp. III. p. 197 finde ich die Angabe, dass nach FREY und LEuchart das Her'z der Caprella linearis fü nf Paar Spalten besitze; ich habe vollkommen durchsichtige junge Caprellen untersucht, - wahrscheinlich Junge der Caprella attenuata DANA, mit der sie zusammen vorkamen, - aber nur die gewöhnlichen drei Spaltenpaare finden können. 
schränkt und scheint ein einziges Spaltenpaar zu besitzen. Bei deın Männchen des Entoniscus Cancrorum n. sp. liegt das Herz in dritten

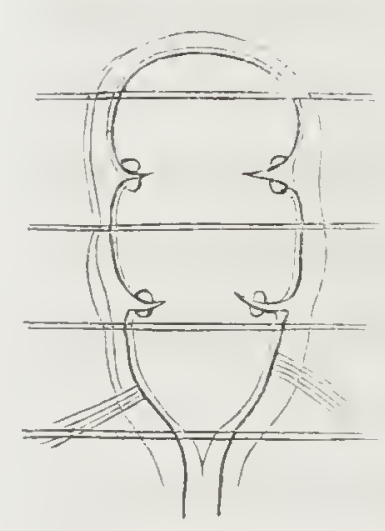

Fig. 14. Hinterleibsringe. Bei den Schildasseln (Cassidina) ist das Herz ebenfalls kurz und mit zwei Spaltenpaaren versehen, die im letzten Ringe des Mittelleibes und dem ersten des Hinterleibes liegen. Bei einer jungen Fischassel (Anilocra) endlich sehe ich das Herz durch die ganze Länge des Hinterleibes sich erstrecken und mit vier (oder fünf?) Spalten versehen, die nicht paarweise, sondern abwechselnd in dem einen Ringe links, imnächsten rechts gelegen sind. Bei anderen Thieren dieser Ordnung; die

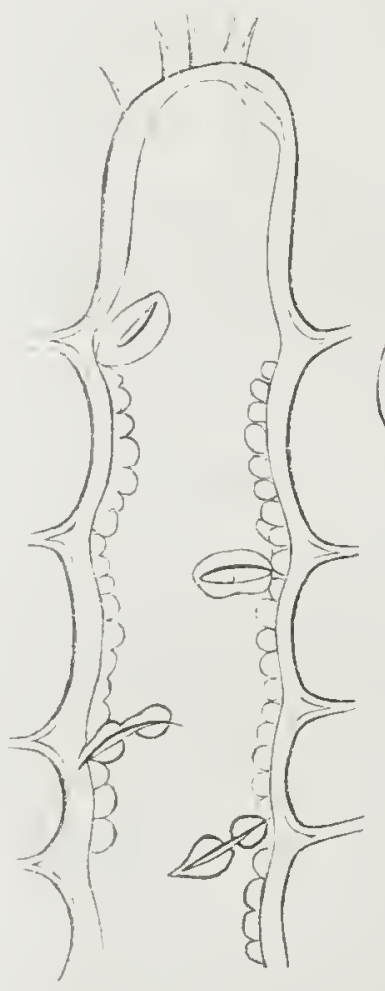

Fig. 15. ich bis jetzt nur beiläufig untersuchte, werden sich voraussichtlich noch weitere $V$ erschiedenheiten finden lassen.

Woher nun in zwei einander so nahe stehenden Ordnungen dort jene Beständigkeit, hier diese Veränderlich-

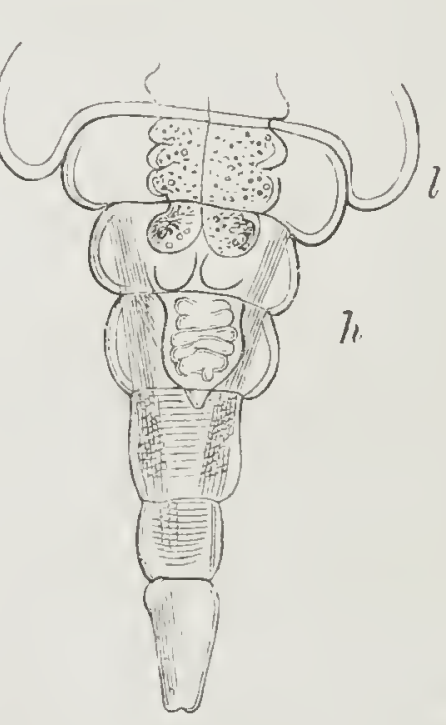

Fig. 16. keit desselben hochwichtigen Organes? Von der Schule wird man keine Erklärung erwarten dürfen, sie wird entweder die Erörterung des Woher als ihrem Gebiete fremd, als jenseit der Grenzen der Naturwissenschaft liegend ablehnen, - oder auch durch eine hochtönende, mit griechischen Worten reich durchspickte Umschreibung des Thatbestandes den zudringlichen Frager zu verblüffen suchen. Da ich leider mein Griechisch vergessen, ist mir der zweite Ausweg verschlossen; da ich aber zum Glück nicht zu den zünftigen Meistern, sondern, mit Freiherrn vox Liebig zu reden, zu den "Spaziergängern an den Grenzen der Naturwissenschaft « zähle, kann mich jenes zimperliche Bedenken der Schule nicht abhalten, eine Antwort zu suchen, die sich denn auch ron DARwin's Standpuncte aus in ungezwungenster $W$ eise bietet.

Fig. 14. Herz einer jungen Cassidina. - Fig. 15. Herz einer jungen Anilocra. - Fig. 16. Hinterleib des Männchens von Entoniscus Cancrorum. h. Herz. l. Ieber. 
Da ausser den Scheerenasseln, welche anderweite Gründe als der Urassel besonders nahestehend anzusehen berechtigen (s.o.), und ausser den Amphipoden auch die Krabben und Krebse ein Her\% mit drei Spaltempaaren und in wesentlich gleicher Lage besitzen, - da dieselbe Lage des Herzens sogar bei den Embryonen der Heuschreckenkrebse (Squilla wiederkehrt (s. u.), wo das Herz des erwachsenen Thieres und selbst schon, wie ich anderwärts zeigte, das weit von der Reife entfernter Larven als langer Schlauch mit zahlreichen Oeffnungen sich weit durch den Hinterleib streckt, - so darf man unbedenklich das Amphipodenherz als Urform des Edriophthalmenherzens ansehen. Da ferner bei diesen Thieren das Blut ron den Athemwerkzengen ohne Gefässe dem Herzen zuströnt, liegt es auf der Hand, wie vortheilhaft eine möglichst genäherte Lage dieser Organe ihnen sein muss. Als Urform der Athmungsweise hat man Grund, das bei den Scheerenasseln bestehende Ver. hältniss (s. o.) zu betrachten. Wo nun später, wie bei der Mehrzahl der Asseln, Kiemen am Hinterleibe sich entwickelten, änderte sich, inden es ihnen näher rückt, Lage und Bildung des Herzens, ohne dass für diese jüngere Bildungsweise sich wieder ein gemeinsamer Plan herausstellte, entweder weil diese Umwandlung des Herzens erst nach der Scheidung der Stammform in untergeordnete Gruppen stattfand, oder weil wenigstens zur Zeit dieser Scheidung das abändernde Herz sich noch in keiner neuen Form befestigt hatte. Wo dagegen die Athmung dem vorderen Theile des Leibes verblieb, - sei es in der ursprünglichen W eise der Zoëa, wie bei den Scheerenasseln, sei es, indem Kiemen am Mittelleibe sick entwickelten, wie bei den Amphipoden, - da vererbte sich unverändert auch die Urform des Herzens, weil etwa auftauchende Abweichungen eher Nachtheil, statt Tortheil brachten und sofort wieder untergingen.

Ich schliesse diese Reihe vereinzelter Beispiele mit einer Beobachtung, die freilich nur zur Hälfte ins Bereich der Kruster fällt, auf das sich diese Blätter beschränken wollen, und auch mit den eben besprochenen Verhältnissen keinen weiteren Zusammenhang hat, als den, nur von DARwTx's Lehre aus eine »verständliche und Verständniss bringende Thatsache " zu sein. Als ich dieser Tage eine Lepas anatifera öfnete, um das Thier mit der Beschreibung in Darwix's "Monograph on the 
Subclass Cirripedia " zu vergleichen, stiess ich im Gehäuse dieses Rankenfüssers auf einen blutrothen Ringelwurm mit kurzem, flachen Leibe, etwa $1 / 2$ Zoll lang bei 2 Linien Breite, mit 25 Leibesringeln, ohne vorspringende Borstenhöcker und ohne Gliedfäden. Der kleine Kopflappen trug 4 Augen und 5 Fühler; jeder Leibesring jederseits am Rande ein schief aufwärts gerichtetes Büschel einfacher Haarborsten und ziemlich entfernt davon auf der Bauchseite eine Gruppe dickerer Borsten mit stark hakig gebogener zweizackiger Spitze. Ausserdem fand sich über jedem der seitlichen Borstenbüschel eine Kieme, einfach an wenigen der vordersten Ringe, weiterhin und bis zum Ende des Leibes stark baumförmig verästelt. Das Thier, ein mit Eiern gefülltes Weibchen, gehört nach alledem offenbar in die Familie der Amphinomiden, die einzige Familie, deren Angehörige als treffliche Schwimmer im offenen Meere leben. - Dass dasselbe sich nicht zufällig zur Lepas verirrt habe, sondern ihr als regehmässiger bleibender Gast zugehöre, dafür bürgt seine im Verhältniss zu dem schmalen Eingange des Lepasgehäuses erhebliche Grösse, der vollständige Mangel des Regenbogenschimmers, der' die Haut freilebender Ringelwürmer und namentlich auch der Amphinomiden auszuzeichnen pllegt, die Bildung und Stellung der unteren Borsten u. s. w. -- Dass nun aber gerade ein Wurm aus der Familie der im hohen Meere lebenden Amphinoniden in der ebenfalls an Holz, Rohr u. dgl. im Meere fluthenden Lepas als Gast sich findet, ist ohne Weiteres verständlich vom Standpuncte der DARwIx'schen Lehre aus, während die Verwandtschaft diescs Schmarotzers mit den freilebenden Würmern des offenen Meeres völlig umbegreiflich bleibt bei der Annahne, dass er selbstständig für den Aufenthalt in der Lepas geschaffen wurde.

Wie günstig nun auch für Darwrs sich die besprochenen Beispiele ausnehmen, man wird ihnen, und das mit vollem Recht, das Bedenken entgegenstellen dürfen, dass es eben nur vereinzelte Thatsachen sind, die bei weit über das unmittelbar Gegebene hinausgehenden Betrachtungen nur zu leicht mit dem täuschenden Schimmer des Irrlichts von der rechten Bahn abziehen. Je hochragender der Bau, um so breitcr muss die sichernde Unterlage wohl gesichteter Thatsachen sein. 
Wenden wir uns denn zu einem weiteren Felde, der Entwicklungsgeschichte der Kruster, auf dem die Wissenschaft bereits eine bunte Fülle merkwürdiger Thatsachen zusammengetragen hat, die aber für sie ein wüstes Haufwerk unhandlichen Rohstoffs geblieben sind, und sehen wir, wie unter DARwr's Hand diese zerstreuten Werkstücke zu einem wohlgefügten Baue sich zusammenschliessen, in den jedes, tragend und getragen, seine bedeutsame Stelle findet. Unter DArwn's Hand, -denn ich werde Nichts zu thun haben, als eben die Bausteine an die stelle zu setzen, die seine Lehre ihnen anweist. "Wenn die Könige baun, haben die Kärmer zu thun. "

\section{VII,}

Ueberblicken wir zunächst die vorliegenden Thatsachen.

Unter den stieläugigen Krustern (Podophthalma) kennt man nur äusserst wenige Arten, die in der Gestalt der Eltern, mit vollzähligen, wohlgegliederten Leibesanhängen das Ei verlassen. So nach Ratmke ${ }^{1}$ der europäische Flusskrebs und nach WEstwood eine westindische Landkrabbe (Gecarcinus). Beide Ausnahmen gehören also zu der geringen Zahl in süssen Wasser oder auf dem Lande lebender Krabben und Krebse, - wie ja auch in manchen anderen Fällen Süsswasser - und Landthiere der Verwandlung entbehren, während ihre Verwandten im Meere eine solche durchlaufen. Ich erinnere an die vorwiegend dem süssen Wasser und dem Lande angehörigen Regenwürmer und Blutegel unter den Ringelwürmern, an die Plattwürmer des süssen $W$ assers und das Tetrastemma der salzarmen Ostsee unter den Strudelwürmern, an die Lungenschnecken und an die Flusskiemenschnecken, deren Junge nach 'Trosches's Handb. der Zoologie) keine mit Wimpern besetzte Mundlappen tragen, während die der so ähnlichen Strandschnecken (Littorina) sie besitzen.

Alle Meerbewohner dieser Abtheilung scheinen eine mehr oder minder beträchtliche Verwandlung zu bestehen. Nur unerheblich scheint dieselbe beim Hummer zu sein, dessen Brut nach rax Bexedex sich

1) Gewährsmänner sind nur angeführt bei Thatsachen, die ich selbst zu bestätigren keine Gelegenheit hatte. 
dadurch vom erwachsenen Thiere unterscheidet, dass ihre Füsse nach Art der Mysis einen frei nach aussen ragenden Schwimmast besitzen. Auch scheinen, nach einer von $\mathrm{CoucH}$ gegebenen Abbildung die Anhänge des Hinterleibes und Schwanzes noch zu fehlen.

Weit tiefer greifend ist die Verschiedenheit der jüngsten Brut vom geschlechtsreifen 'Thiere bei der weit überwicgenden Mehrzahl der Podophthalmen, die als Zoëa das Ei verlassen. Diese Jugendform findet sich, soweit die bisherigen Erfahrungen reichen, bei allen Krabben, mit alleiniger Ausnahme jener einen von Westwood untersuchten Art. Ich sage Art und nicht Gattung, denn Vaughax Thompsox fand bei derselben Gattung Gecarcinus Zoëabrut, ${ }^{1}$ die auch bei anderen landbewohnenden Krabben (Ocypoda, Gelasimus etc.) getroffen wird. Alle Anomuren scheinen ebenfalls als Zoëa ihren L nen; so die Porcellanen, die Tatuira (Hippa emerita) und die Einsiedlerkrebse. Unter den langschwänzigen Krebsen kennt man dieselbe früheste Jugendform namentlich von zahlreichen Garneelen; so ron Crangon (Du C ANe), Caridina (JoLy), Hippolyte, Palaemon, Alpheus u. s. w. Endlich ist es nicht unwahrscheinlich, dass auch die jüngste Brut der Heuschreckenkrebse (Squilla) sich hier anschliesst. -

Die wichtigsten Eigenthümlichkeiten nun, welche diese Zoëabrut vom erwachsenen Thiere unterscheiden, sind die folgenderi:

Der Mittelleib nit seinen Anhängen, jenen fünf Fusspaaren, denen Krabben und Krebse den Namen der Zehnfüsser danken, fehlt noch vollständig, oder ist doch kaum angelegt; Hinterleib und Schwanz sind

1) BELL (Brit. Stalk-eyed C'rust. pg. XIV) hält sich berechtigt, 'THompson's Beobachtung ohne Weiteres zu "eliminiren ", weil derselbe nur vier tragende Weibchen in Weingeist habe untersuchen können. Wer sich aber so viel mit der Entwicklung dieser'Thiere beschäftigt, wie Thompsor, musste sehr wohl auch an Eiern, die ron der Reife wicht allzufern und nicht allzuschlecht erhalten waren, unzweideutig erkemen können, ob daraus eine Zoëa ausschlüpfen werde. Zudem spricht zu THoupsox's Gunsten die L,ebensweise der Landkrabben. "Jährlich einmal " erzählt 'Troscuel's Handb. der Zoologie, "wandern sie in grossen Schaaren zum Meere, um ihre lier abzulegen, und nachher sehr entkräftet zu ihren Wohnplätzen zurück, welche nur von Wenigen erreicht werden." - Wozu diese aufreibenden Wanderungen zum Meere bei Arten, deren Junge als Tandthiere das Ei und die Mutter verlassen? - 
anhanglos; letzterer besteht aus einem einzigen Stücke. Den Kinnbacken (mandibulae) fehlen, wie bei den Insecten, die Taster. Die Kieferfüsse, von denen das dritte Paar oft noch fehlt, sind noch nicht in den Dienst des Mundes gezogen, sondern erscheinen als zweiästige Schwimmfüsse. Kiemen fehlen, oder wo sich deren erste Anlagen als kleine warzenförmige Vorsprünge erkennen lassen, sind dieses dichte vom Blute noch nicht durchströmte Zellenmassen, die also mit der Athmung nichts zu thun haben. Ein Austausch zwischen den Gasen des Wassers und des Blutes wird überall an der dünnhäutigen Oberfläche des Leibes statthaben können; als Hauptsitz der Athmung aber darf man unbedenklich die Seitentheile des Panzers bezeichnen. Sie bestehen ganz wie es Lerdig von den Daphnien beschreibt ans einem äussern und einem inneren Blatte, deren Zwischenraum von zahlreichen an den Enden verbreiterten Querbälkchen durchsetzt ist; die Lücken zwischen diesen Bälkchen werden von reicheren Blutströmen durchflossen, als sie sonstwo im Leibe der Zoëa sich finden. Dazu kommt, dass ein beständiger Strom frischen Wassers in der Richtung von hinten nach vorn unter dem Panzer hinzieht, unterhalten, wie beim erwachsenen Thiere, durch einen blattoder zungenförmigen Anhang des zweiten Kieferpaares (Fig. 1's.). Zusatz feiner Farbtheilchen zu dem Wasser lässt selbst bei den kleineren Zoëa leicht diesen Athemstrom wahrnehmen.

Die Zoc̈a der Krabben (Fig. 17.) pflegen sich auszuzeichnen durch lange stachelförmige Fortsätze des Panzers; ein solcher ragt von der Mitte des Rückens empor, ein zweiter von der Stirn

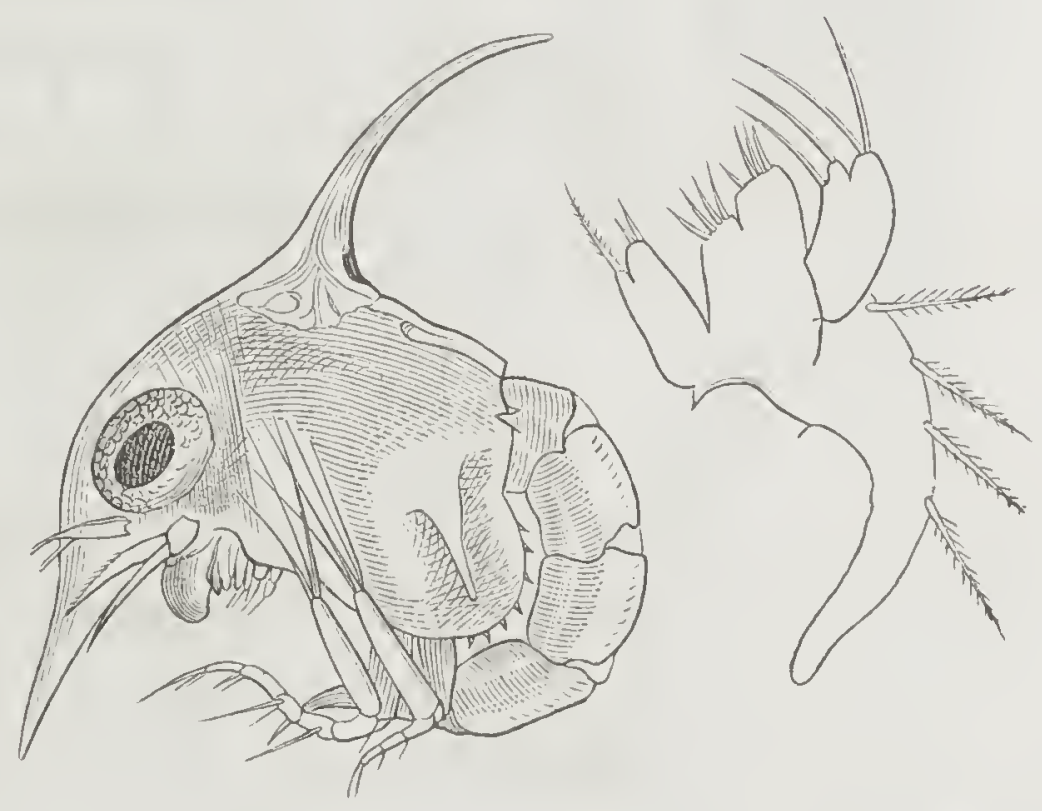

Fig. 17.

Fig. 15. nach unten und häufig steht noch ein kürzerer jederseits nahe der

Fig. 17. Zoëa einer Sumpfkrabbe [Cyclograpsus (?)] $45 \mathrm{mal}$ vergr. - Fig. 15. Kiefer (maxilla) des zweiten Paares von derselben, 180 mal vergr.

F. Müller, Für Darwin. 
hinteren, unteren Ecke des Panzers. Alle diese Fortsätze fehlen jedoch nach Couch bei Maia, nach Kinahax bei Eurynome, und bei einer dritten Art aus derselben Gruppe der Oxyrhynchen (der Gattung Achaeus zugehörig oder nahestehend) finde ich ebenfalls nur einen unbedeutenden Rückenstachel, während Stirn und Seiten unbewehrt sind. Wieder ein Beispiel, das zur Vorsicht mahnt beim Schliessen nach Analogie. Nichts schien näher zu liegen, als die schnabelförmige Bildung der Stirn bei den Oxyrhynchen zurückzuführen auf den Stirnfortsatz der Zoëa, und nun findet sich, dass gerade den Jungen der Oxyrhynchen ein solcher Stirnfortsatz völlig abgeht. - Wichtigere Eigenthümlichkeiten der Krabbenzoëa, wenn auch weniger augenfällig als jene Fortsätze des Panzers, die im Verein mit den grossen Augen ihnen oft ein so wunderliches Ansehen verleihen, sind die folgenden: die vorderen (inneren) Fühler sind einfach, ungegliedert, an Ende mit 2 bis 3 Riechfäden versehen; die hinteren (äusseren) Fühler laufen in einen oft ungemein langen stachelförmigen Fortsatz (styliform process, Spence Bate) aus, und tragen aussen einen bisweilen sehr winzigen

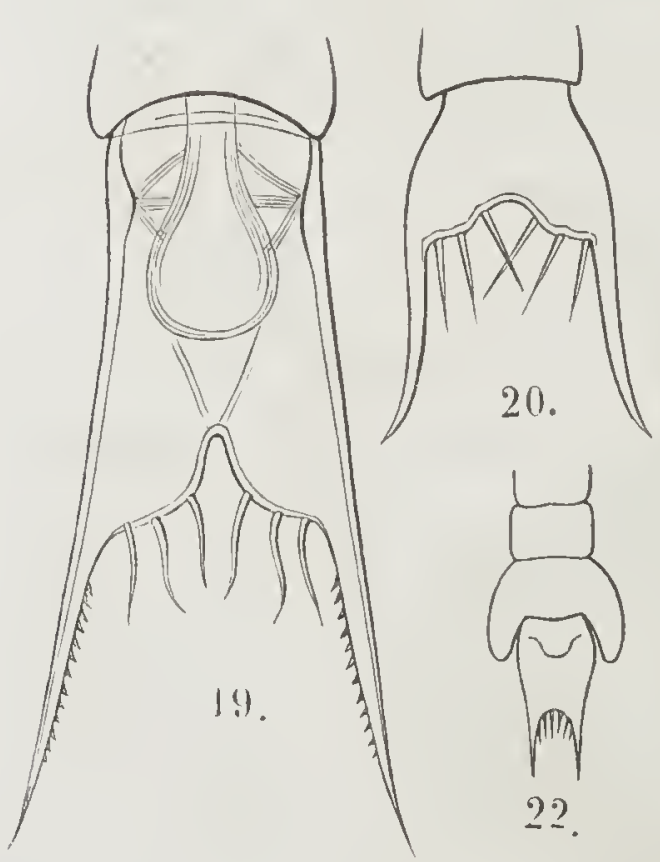

Fig. $19-23$.

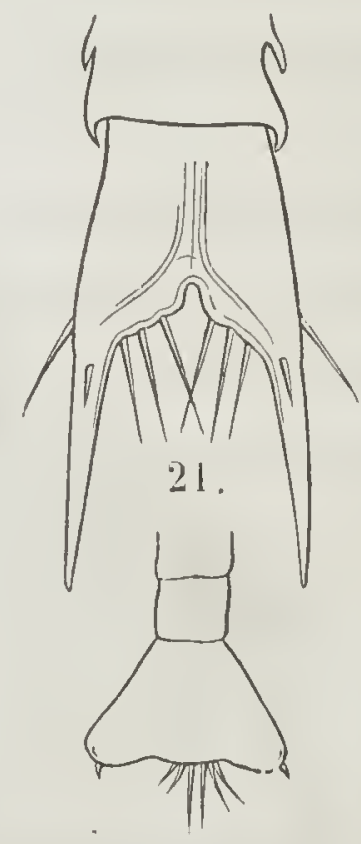

23. Anhang (squamiform process, Sr. B.), der Schuppe des Garneelenfühlers entsprechend; ${ }^{1}$ daneben ist oft schon die erste Anlage der späteren Fühlergeissel erkennbar. Schwimmfüsse, (später Kieferfüsse) sind nur zwei Paare vorhanden; es fehlt das dritte, (nicht, wie Syence Bate will, das erste) vollständig, oder ist wie die fünf fol-

1) In einem Aufsatze über die Verwandlung der Porcellanen habe ich diesen Anhang irrthümlich als " Geissel " bezeichnet.

Schwänze verschiedener Krabbenzoëa. Fig. 19. von Pinnotheres. - Fig. 20. von Sesarma. - Fig. 21, von Xantho. - Fig. 22. 23. von unbekannter Herkunft. 
genden Fusspaare nur als winzige Knospe vorhanden. Der Schwanz, von sehr wechselnder Form, trägt immer drei $\mathrm{P}$ a ar Borsten an seinem Hinterrande. Die Krabbenzoëa pflegen im Wasser sich so zu halten, dass der Rückenstachel nach oben steht, der Hinterleib nach vorn gekrümmt, der innere Ast der Schwimmfüsse nach vorn, der äussere nach aussen und oben gerichtet ist.

$\mathrm{Zu}$ bemerken ist noch, dass die Zoëa der Krabben, wie auch der Porcellanen, der Tatuira, der Garneelen beim Ausschlüpfen aus dem Eic von einer die Stachelfortsätze des Panzerss, die Borsten der Füsse und Fühler verhüllenden Haut umschlossen sind, die sie schon nach wenigen- Stunden abstreifen. Bei Achaeus habe ich mir angemerkt, dass der Schwanz dieser jüngsten Larvenhülle an die Garneelenlarven erinnert und dasselbe scheint bei Maia der Fall zu sein. (S. BeLt, Brit. Stalk-eyed Crust. pg. 44).

So weit sie beim ersten Anblick sich von ihnen zu entfernen scheinen, so eng schliessen sich an die Zoëa der Krabben die der Porcellanen (Fig. 24.) an. Fühler, Mundtheile, Schwimmfüsse zeigen dieselbe Bildung. Der Schwanz aber trägt fü $\mathrm{n} f$ Paar Borsten, der Rückenstachel fehlt, der Stirnfortsatz dagegen und die Seitenstacheln sind von abenteuerlicher Iänge und gerade nach vorn und hinten gerichtet.

Auch die Zoëa der Tatuira (Fig. 25.) scheint nur wenig von denen der Krabben abzuweichen, denen sie auch in ihrer Bewegungsweise gleicht. Der Panzer besitzt nur einen kurzen, breiten Stirnfortsatz; der Hinterrand des Schwanzes ist mit zahlreichen kurzen Borsten besetzt.

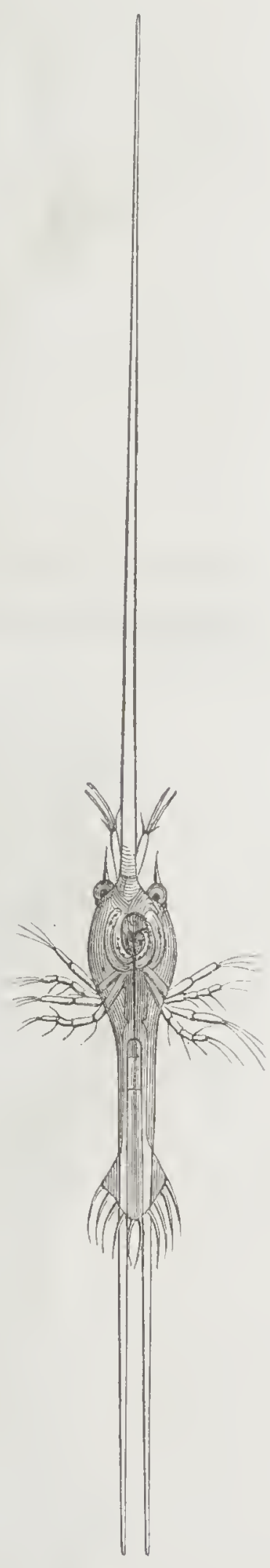

Fig. 24.

Die Zoëa der Einsiedlerkrebse (Fig. 26.) besitzt die einfachen inneren Fühler der Krabbenzoëa; die äusseren Fühler tragen auf kurzem Fig. 24. Zoëa der Porcellana stellicola F. MÜLL. $15 \mathrm{mal}$ vergr. 
Stiele aussen ein ansehnliches der Schuppe der Garneelenfühler ähnliches Blatt, innen einen kurzen dornförmigen Fortsatz und zwischen

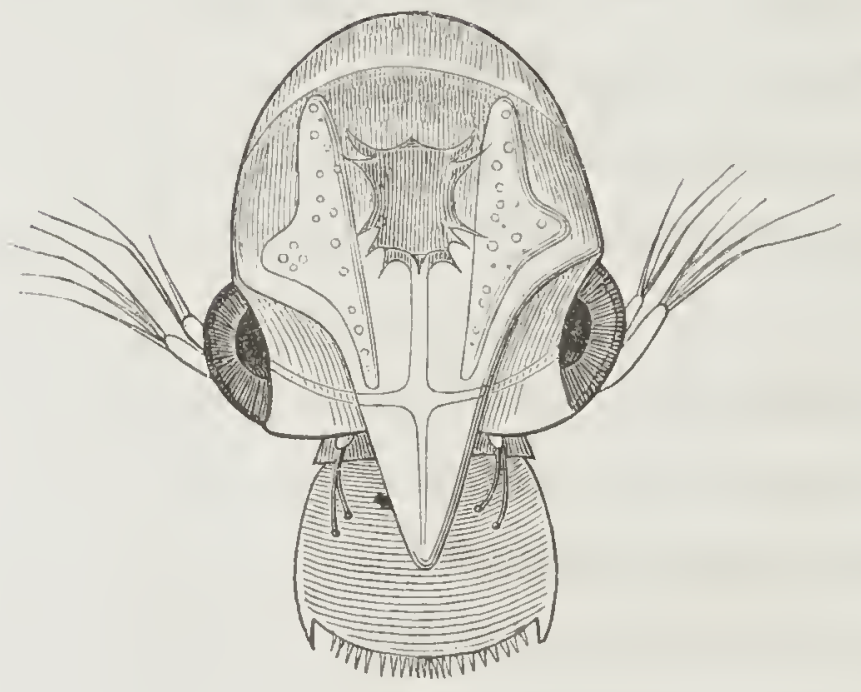

Fig. 25. beiden die noch kurze aber schon mit zwei Endborsten bewehrte Geissel. Wie bei den Krabben finden sich nur zwei Paar wohl entwickelte Schwimmfüsse (Kieferfüsse); aber auch das dritte Paar ist schon als ansehnlicher, zweigliedriger, wenn auch nóch borstenloser Stummel vorhanden. Der Schwanz trägt fünf Paar

Borsten. Das Thierchen pflegt sich im Wasser gerade äusgestreckt zu halten mit abwärts gerichtetem Kopfe.

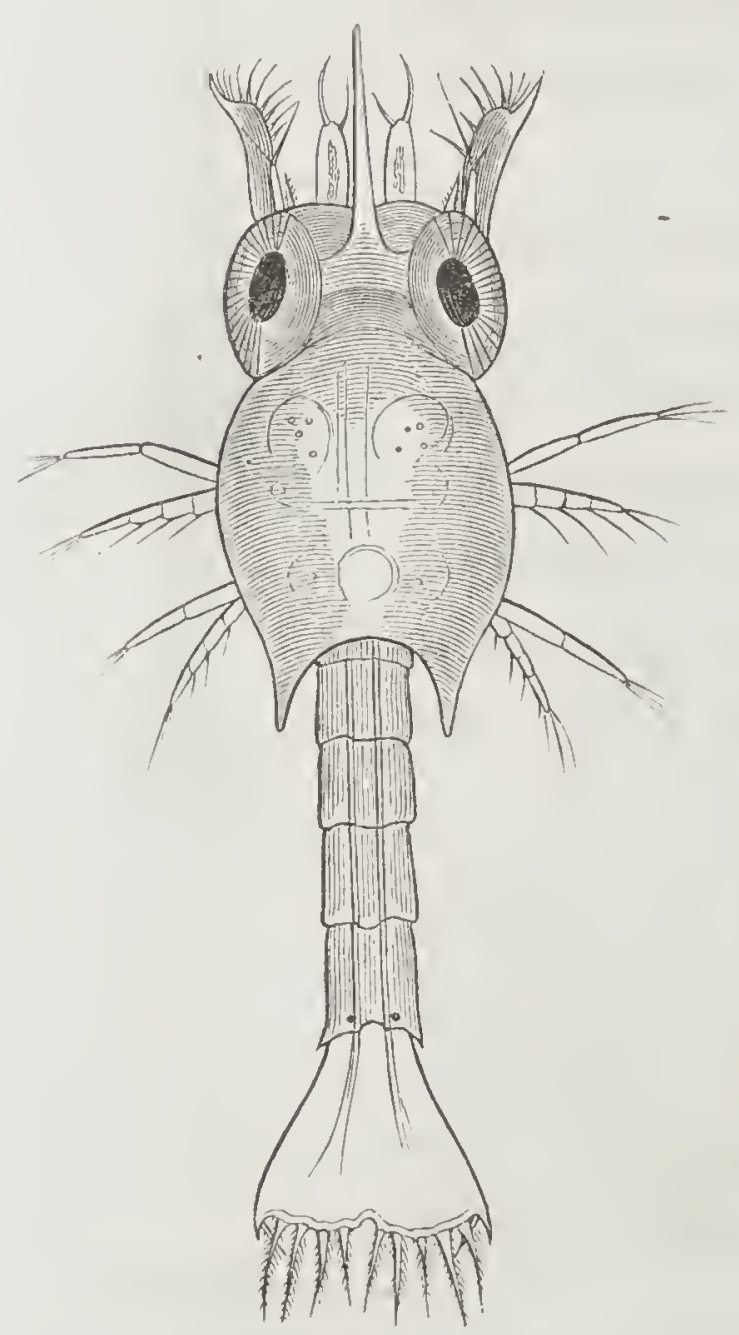

Fig. 26.

In derselben Haltung sieht man gewöhnlich die Zoëa der Garneelen (Fig. 27.), die überhaupt im allgemeinen Ansehen mit denen der Einsiedlerkrebse übereinstimmen. Zwischen den grossen zusammengesetzten Augen findet sich bei ihnen ein kleines unpaares Auge. Dic inneren Fühler tragen am Ende eines bisweilen ansehnlich langen Grundgliedes innen eine gefiederte Borste, die auch schon bei den Einsiedlerkrebsen sich findet, aussen ein kurzes Endglied mit cinem oder einigen Riechfäden. Die äusseren Fühler zeigen eine wohlentwickelte, bisweilen deutlich gegliederte Schuppe und meist nach innen daran einen dornartigen Fortsatz; die Geissel scheint in der Regel noch zu

Fig. 25. Zoëa der Tatuira (Hippa emerita). $45 \mathrm{mal}$ vergr.

Fig. 26. Zoëa eines kleinen Einsiedlerkrebses. 45 mal vergr. 
fehlen. Das dritte Paar der Kieferfüsse scheint stets, wenigstens als ansehnlicher Stummel schon vorhanden zu sein. Das spatelförmige Schwanzblatt trägt fünf bis sechs Borstenpaare am Hinterrande. -

Die Entwicklung der Zoëabrut zum geschlechtsreifen Thiere verfolgte Spence Bate bei Carcinus Maenas; er wies nach, dass die Umwandlung eine ganz allmähliche ist, dass sich in ihr keine scharfgeschiedenen Entwickelungsstufen, wie etwa beim Schnetterlinge Raupe und Puppe abgrenzen lassen. Leider besitzen wir nur diese einzige vollständige Beobachtungsreihe und ihre Ergebnisse dürfen nicht ohne Weiteres als allgemein giltig betrachtet werden; so bewahren die jungen Einsiedlerkrebse das allgemeine Aussehen und die Bewegungsweise der Zoëa, während die Anlagen der Füsse des Mittel- und Hinterleibes heranwachsen, und erscheinen dann auf einmal, indem diese in Thätigkeit treten, in ganz neuer Gestalt, die von der des erwachsenen Thieres hauptsächlich durch vollkommene Symmetrie des Leibes und durch vier Paar wohlgebildèter Schwimmfüsse an Hinterleibe sich unterscheidet. ${ }^{1}$

Sehr eigenthümlich scheint die Entwicklung der Panzerkrebse zu sein. Claus fand in den Eiern der Languste (Palinurus) Embryonen mit vollständig gegliedertem Leibe, denen die Anhänge des Schwanzes, des Hinterleibes, und der beiden letzten Ringe des Mittelleibes fehlen; sie besitzen ein einfaches unpaares und ansehnliche zusammengesetzte Augen; die vorderen Fühler sind einfach, die hinteren mit einem kleinen Nebenaste versehen; die Kinnbacken tasterlos; das dritte

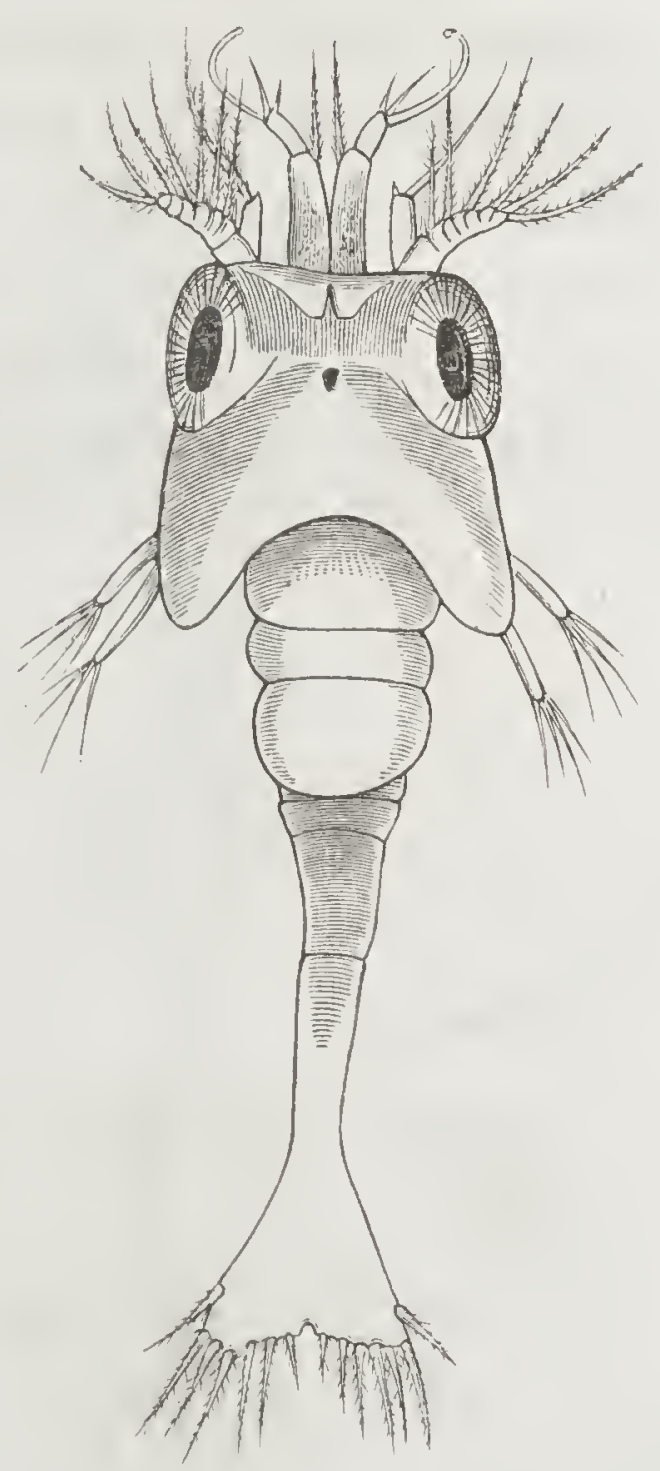

Fig. 27 .

1) Die Glaucothoë Peronii EDw. mag ein solcher junger noch symmetrischer Pagurus sein.

Fig. 27. Zoëa eines an Rhizostoma cruciatum LEss. sich aufhaltenden Palaemon. 4 mal vergr. 
Paar der Kieferfüsse wie die beiden folgenden Fusspaare in zwei fast gleichlange Aeste gespalten, während das letzte der vorlandenen Fusspaare und das zweite Paar der Kieferfüsse nur einen unbedeutenden Nebenast tragen. Coste will bekanntlich aus den Eiern desselben Krebses junge Phyllosomen gezogen haben, - eine Angabe, die um so mehr einer nähern Begründung bedarf, als die neueren Untersuchungen von Claus über Phyllosoma ihr keineswegs günstig scheinen. --

Die grossen zusammengesetzten Augen, die früh bewegt zu werden pflegen und bisweilen schon in frühester Zeit auf langen Stielen stehen, sowie der Panzer, der den ganzen Vorderleib deckt, weisen bei aller Verschiedenheit den bisher betrachteten Larven sofort ihre Stelle unter den Podophthalmen an. Nicht ein bezeichnendes Merkmal aber dieser Abtheilung bleibt der Brut einiger zur Gattung Penēus oder in deren Nähe gehörigen Garneelen. Dieselben verlassen das Ei mit ungegliedertem eiförmigen Leibe, unpaarigem Strirnauge und drei Paar Schwimmfüssen, von denen die vorderen einfach, die beiden anderen zweiästig sind, - in jener unter niederen Krustern so häufigen Larvenform also, der O. F. Mültur den Namen Na u plius gab. Keine Spur eines Panzers,

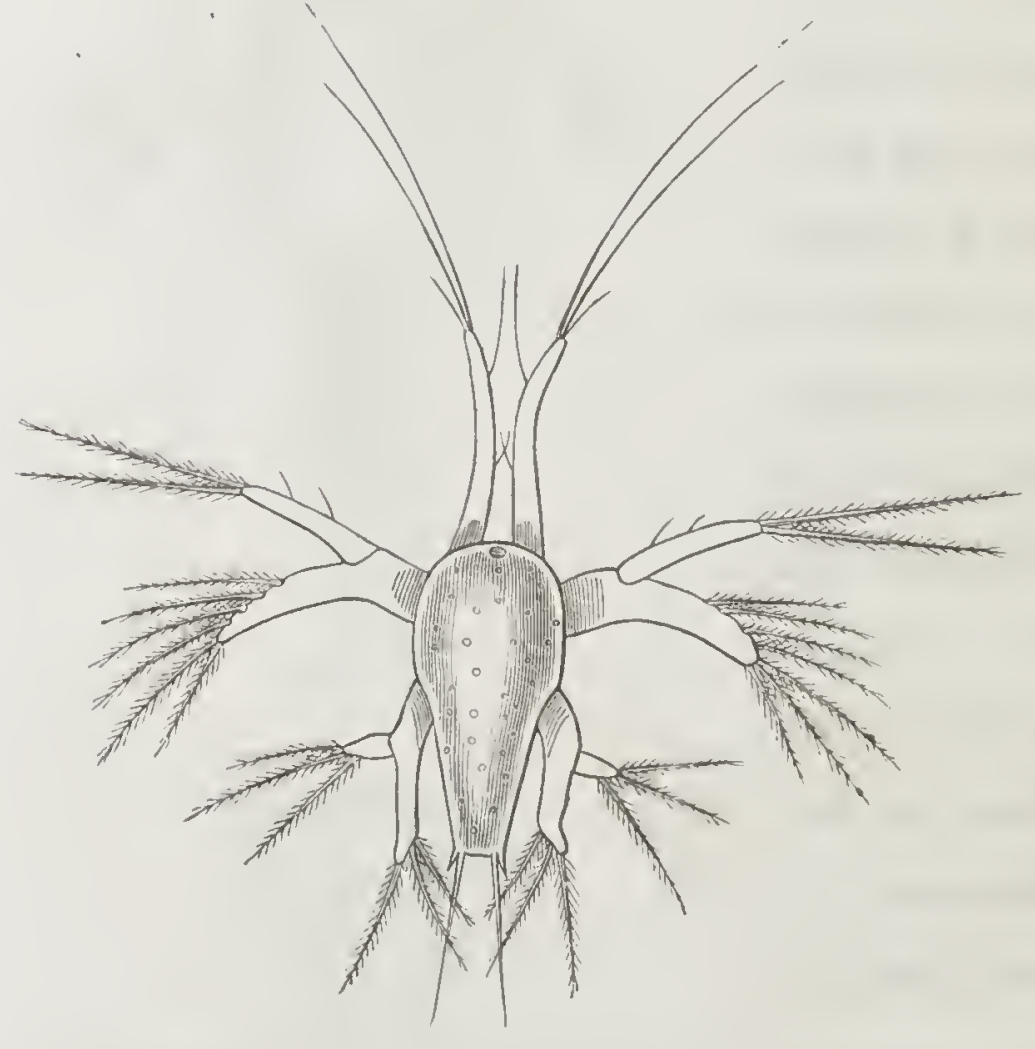

Fig. 28. keine Spur der paarigen Augen, keine Spur von Kauwerkzeugen neben dem von einer helmförmigen Kappe überwölbten Munde!

Für eine dieser Arten wurden bereits dieZwischenformen, die vom Nauplius zur Garneele führen, in ziemlich enggeschlossner Reihe aufgefunden.

An die jüngsten Nauplius (Fig. 28.) schliessen sich Formen, bei denen hinter dem dritten Fusspaare

Fig. 29. Nauplius einer Garneele. $45 \mathrm{mal}$ vergr. 
eine Hautfalte als erste Andeutung des Panzers quer über den Rücken zieht und auf der Bauchseite vier Paar plumpe Zapfen herrorspriessen, - Anlagen neuer Gliedmassen. Innerhalb des dritten Fusspaares bilden sich kräftige Kinnbacken aus.

Bei einer folgenden Häutung treten die neuen Gliedmassen, Kiefer, vordere und mittlere Kieferfüsse, - in Thätigkeit und damit ist aus dem Nauplius eine Z o ëa geworden (Fig. 29.), völlig übereinstimmend mit der Zoëa der Krabben in der Zahl der Leibesanhänge, wenn auch freilich sehr abweichend in Gestalt und Bewegungsweise und selbst in manchen Verhältnissen des inneren Baues. Als hauptsächlichste Bewegungswerkzeuge dienen noch die schlanken langbeborsteten beiden vorderen Fusspaare, die späteren Fühler; das dritte Fusspaar verliert seine Aeste und wird zu tasterlosen Kinnbacken. Die Oberlippe erhält einen ansehnlichen vorwärts gerichteten Stachel, der sich bei allen verwandten Zoëaarten wiederfindet. Die zweiästigen Kieferfüsse scheinen wenig bei der Bewegung mitzuwirken. Del gablige Schwanz erinnert mehr

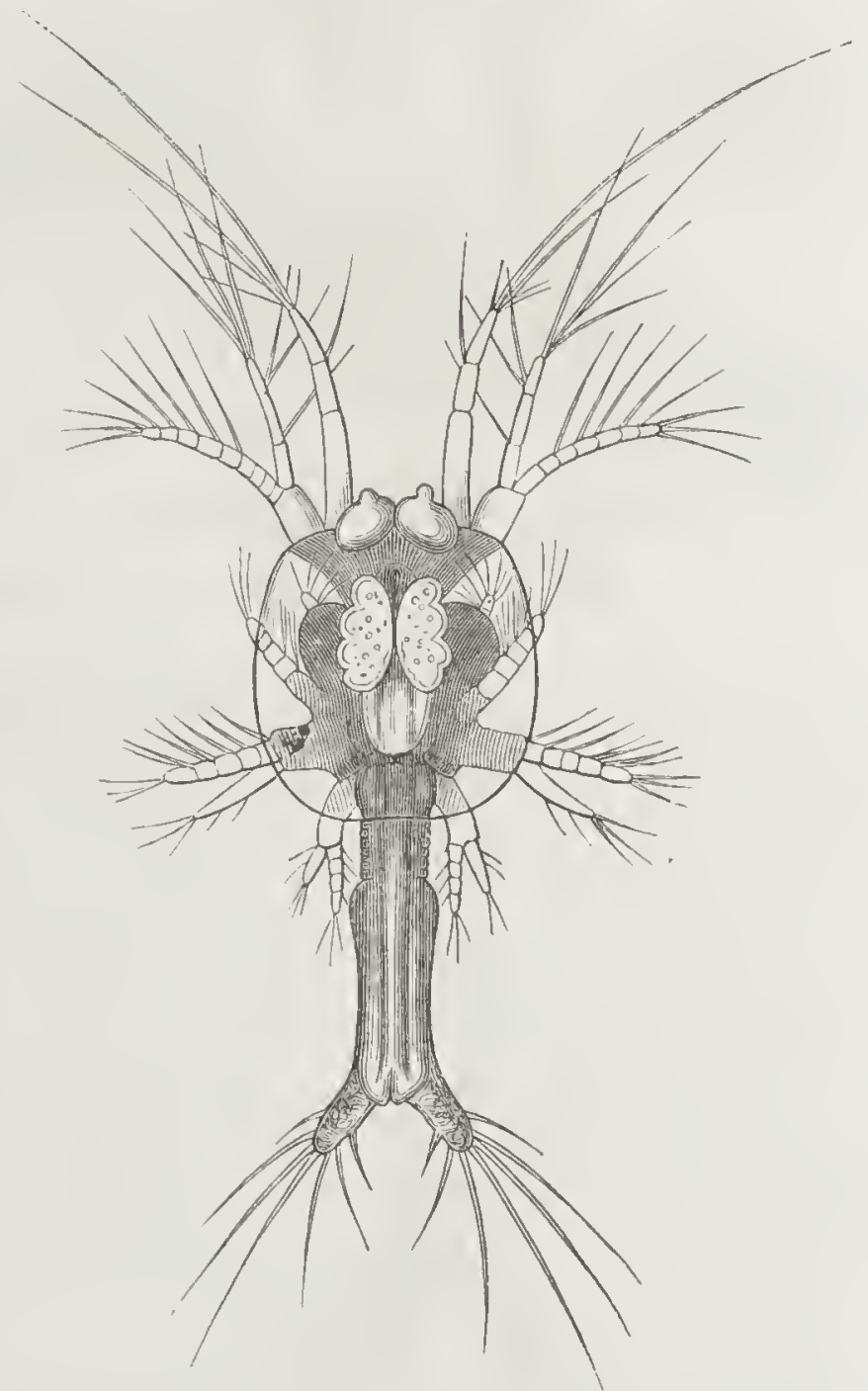

Fig. 29. an die bei niederen Krustern, namentlich den Copepoden vorkommenden Formen, als an das spatelförmige Schwanzblatt, das die Zoëa der Alpheus, Palaemon, Hippolyte und andrer Garneelen, der Einsiedlerkrebse, der Tatuira, der Porcellanen auszeichnet. Das Herz besitzt nur ein Spaltenpaar und keine sein Innres balkenartig durchsetzenden

Fig. 29. Jüngere Zoëa derselben Garneele. $45 \mathrm{mal}$ vergr. 
Muskchn, während bei andercn Zoëa zwei Spaltenpaare und cin innres Balkcnwcrk stets deutlich crkennbar sind.

Während dieses Zoc̈azeitraums

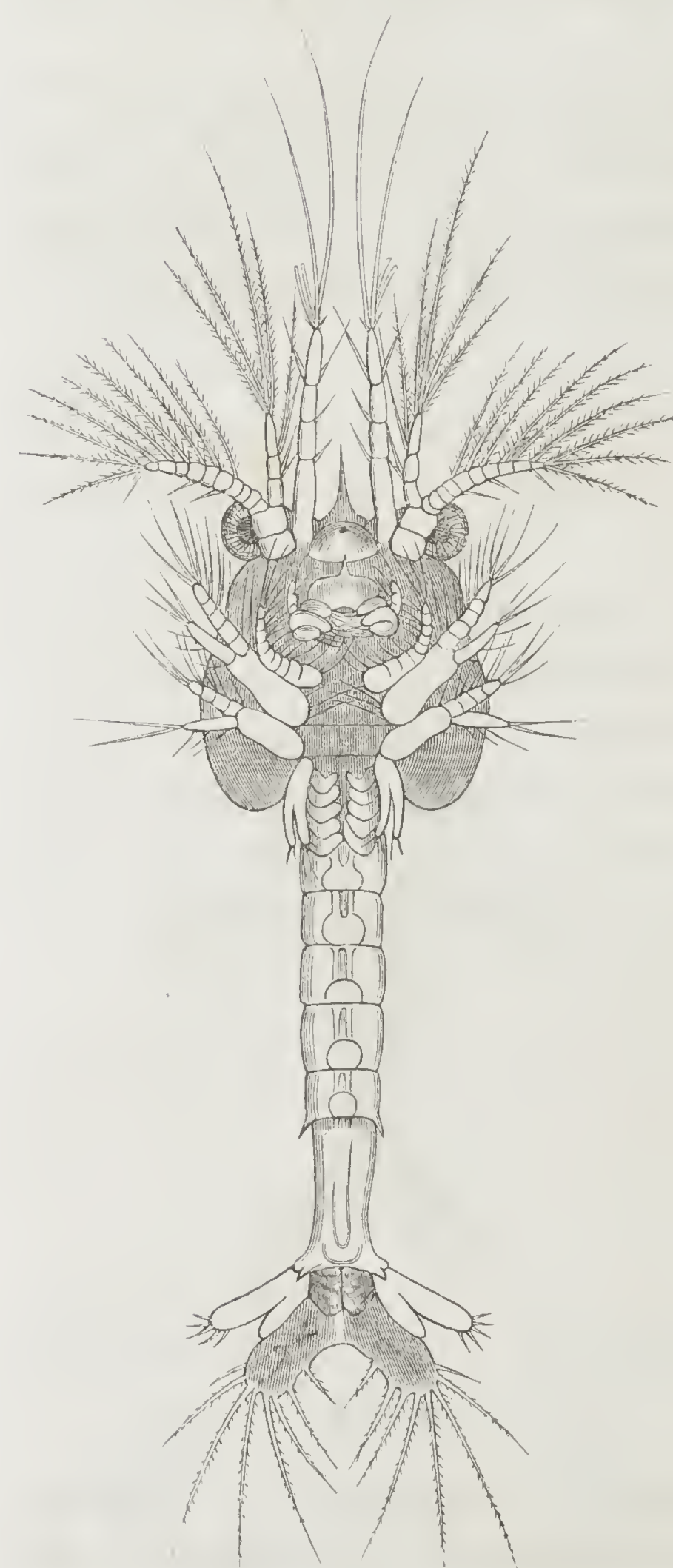

Fig. 30. bilden sich ( $\mathrm{Fig}$. 30.) die paarigen Augen, es bilden sich die Ringc des Mittel- und Hintcrleibes, die hinteren Kicferfüsse, die seitlichcn Schwanzanhänge und die stummelförmigen Anlagen der Füsse des Mittelleibes. Die Schwanzanhänge spriesscn wie andere Gliedmassen frei an der Bauchfläche hervor, während sie bei anderen Garneelen, bei den Porcellanen u. s. w. im Innern des spatelförmigen Schwanzblattes angelegt werden.

Indem die Füsse des Mittelleibes in Thätigkeit treten, geht, unter gleichzeitigen anderen tiefgreifenden Veränderungen, die Zoëa in die Mysis-oder Schizopodenform über (Fig. 31.). Die Fühler hören auf, der Bewegung zu dienen; sie werden abgelöst durch den langen Hinterleib, der vor Kurzem noch als unnütze Last mühsam nachgeschleift wurde und dessen kräftige Muskeln jetzt das Thier in munteren Sprüngen durch's Wasser schnellen und durch die langgeborsteten Brustfüssc. Die vorderen Fühler haben ihre langen Borsten verloren und neben dem letzten (vierten) mit Riechfäden

Fig. 30. Aeltere Zoëa derselben Garneele, 45 mal vergr. 
ausgestattelen Gliede erscheint cin zweiter anfangs ungegliederter Ast. Der äussere bisher viclgliedrige Ast der hinteren Fühler ist zu einem einfachen Blatte, der Schuppe des Garneelenfühlers geworden; daneben erscheint die stummelförmige Anlage der Geissel, wahrscheinlich als Neubildung, indem der innere Ast vollständig schwindet. Die fünf neuen Fusspaare sind zweiästig, der innere Ast kurz, einfach, - der äussere länger, am Ende geringelt, langbeborstet und wie bei den Mysis in beständiger strudelnder Bewegung. Das Herz erhält neue Spalten und innere Muskelbalken.

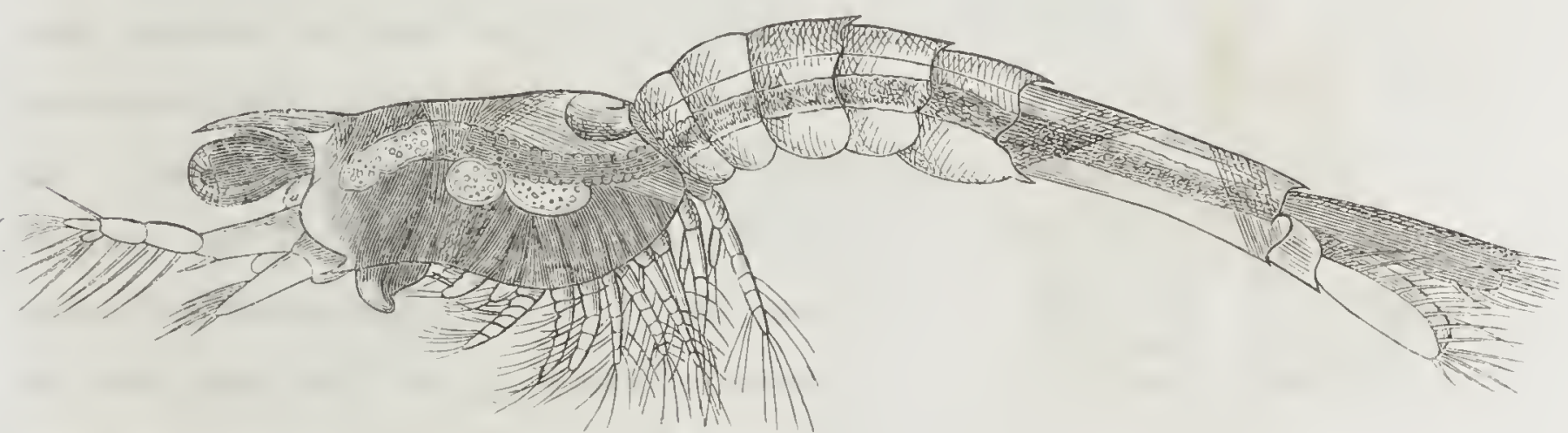

Fig. 31 .

Während der Mysiszeit bilden sich Gehörwerlszeuge in Grundgliede der vorderen Fühler, die inneren Aeste der drei vorderen Fusspaare entwickeln sich zu Scheeren, die der zwei hinteren zu Gangfüssen; an den Kinnbacken sprosst ein Taster, am Mittelleibe sprossen Kiemen, an Hinterleibe Schwimmfüsse hervor. Der Dorn der Oberlippe bildet sich zurück. - Das Thier nähert sich so allmählich der Garneelenform, in der das unpaare Auge undeutlich geworden, der Dorn der Oberlippe, die äusseren Aeste der Scheeren - und Gangfüsse verloren gegangen sind, die Taster der Kinnbacken und die Hinterleibsfüsse deutliche Glieder und Borsten erhalten haben und die Kiemen in Thätigkeit treten.

Bei einer anderen Garneele, deren verschiedene Larvenzustände leicht als zusammengehörig erkannt werden an einem dunkelgelben scharfumschriebenen Fleck, der das unpaare Auge umgiebt, stimmen die jüngsten wahrscheinlich aus Nauplius hervorgehenden Zoëa (Fig. 32) in allen wesentlichen Verhältnissen mit der eben besprochenen Art über-

Fig. 31. Mysisform derselben Garneele, tõ mal vergr. 
ein; dagegen ist die weitere Entwicklung namentlich dadurch sehr abweichend, dass weder die Füsse des Mittelleibes noch die des Hinterleibes sich gleichzeitig bilden und dass eine mit Mysis in Zahl und Bildung der Gliedmassen vergleichbare Entwicklungsstufe fehlt.

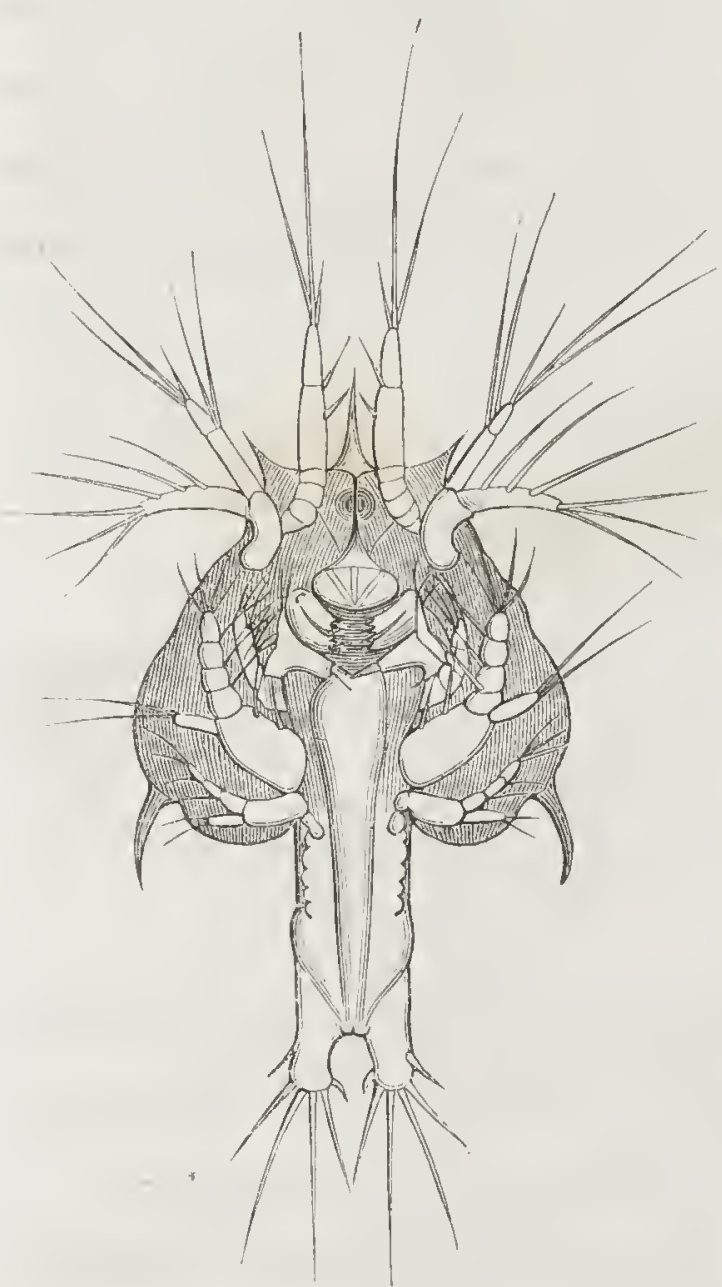

Fig. 32.

Zeitig zeigen sich Spuren der äusseren Kieferfüsse. Dann erscheinen Füsse an vier Ringen des Mittelleibes und zwar zweiästig an den drei vorderen, einfach, indem der innere Ast fehlt, an dem vierten Ring. An den inneren Aesten entwickeln sich Scheeren, die äusseren Aeste gehen verloren, ehe noch ein innerer Ast am vierten Ringe aufgetreten ist (Fig. 32.). Letzterer erscheint wieder anhanglos, so dass also hier in früherer Zeit vier, in späterer nur drei Ringe des Mittelleibes Gliedmassen tragen. Der fünfte Ring fehlt noch vollständig, während inzwischen auch sämmtliche Hinterleibsringe Gliedmassen erhalten haben und zwar einer nach dem anderen, ron vorn nach hinten. Das erwachsene Thier wird jedenfalls, darauf weisen die drei Scheerenpaare hin, dem der vorigen Art sehr nahe stehen. ${ }^{1}$

1) Die ältesten beobachteten Larven zeichnen sich aus (s. Fig. 33.) durch ungewöhnliche Länge der Geissel der äusseren Fühler, und gleichen hierin der von CLaus bei Messina gefundenen Sergesteslarve (Zeitschr. für wiss. Zool. Bd.XIII. Taf.XXVII, Fig. 14). Diese ungemeine Länge der Fühler lässt vermuthen, dass sie unserer gemeinsten, vielverspeisten, dem Peneus setiferus ron Florida nächstverwandten Garneele zugehören. Das Acanthosoma ron CuAus (a. a. O. Fig. 13) ist der jüngern Mysisform der von mir im Archiv für Naturgesch.1563. 'Taf. II. Fig. 18 abgebildeten Larve ähnlich, die ich auf Sicyonia carinata zu beziehen geneigt bin.

Fig. 32. Jüngste (beobachtete) Zoëa einer anderen Garneele. Man bemerkt die winzigen Knospen des dritten Paares der Kieferfüsse. Die Hinterleibsringe beginnen sich zu bilden. Paarige Augen werden noch vermisst. Vergr. 45 mal. 
Der jüngsten Zoëa unsercr Garneclen sehr nahe steht dic jüngste der von Cuaus beobachteten Larven der Schizopodengattung Euphausia; aber während ihre vorderen Fühler schon zweiästig sind, und sic hierin sich weiter vorgeschritten zeigt, fehlen ihr noch die mittleren Kieferfüsse. Auch bei ihr fand Cusus das Herz mit eincm einzigen Spaltenpaare versehen. Ob nicht auch hier der Zoëa naupliusähnliche Zustände vorausgehen?

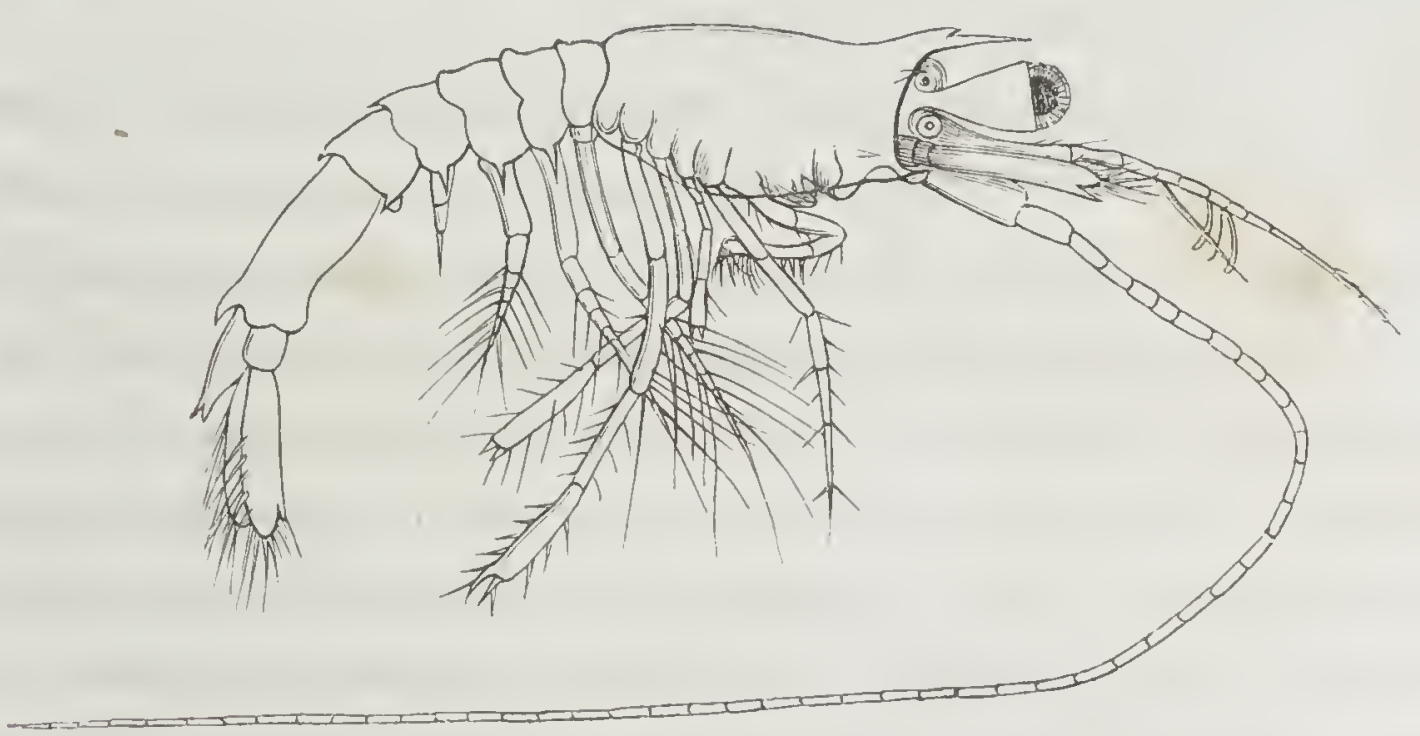

Fig. 33.

Die Entwicklungsgeschichte der Mysis, deren nahe Verwandtschaft mit den Garneelen neucrdings wieder allgemein anerkannt wird, hat van Beneden ausführlich geschildert. Soweit ich sie auch prüftc, kann ich dessen Angaben nur bestätigen. - Die Entwicklung des Embryo beginnt mit der Bildung des -- Schwanzes! Derselbe tritt auf als einfacher Lappen, dessen Rückenfläche der Rückenfläche des Embryo zugewandt ist und dicht anliegt. (Die Jungen anderer stieläugiger Kruster sind bekanntlich im Ei so gekrüınmt, dass die Bauchflächen der vorderen und hinteren Körperhälfte einander zugekehrt sind, bei ihnen erscheint also der Rücken, bei Mysis die Bauchseite gewölbt). Bald nimmt der Schwanz die Gabelform an, die wir bei der zuletzt betrachteten Garneelenzoëa kennen lernten. Dann sprossen am entgegengesetzten Leibesende zwei Paar plumpe säbelförmige Anhängc hervor und dahinter ein Paar leicht zu übersehender Höcker, -- Fühler und Kinnbacken. Jetzt birst die Eihaut, ehe noch irgend ein inneres Organ,

Fig. 33. Aeltere Larve, aus der Fig. 32 gezeichneten Zoëa hervorgehend. Es fehlt der letzte Ring und die beiden letzten Fusspaare des Mittelleibes. Vergr. 20 mal. 
irgend ein Gewebe ausser den Zellen der Hautschicht gebildet ist. Man könnte das Junge einen Nauplius nennen; eigentlich freilich ist nichts da, als eine rohe Nachbildung einer Naupliushaut, gewissermassen eine neue Eihaut, innerhalb deren die Mysis sich entwickelt. Die zehn Paar Anhänge des Vorderleibes (Kiefer, Kieferfüsse) und des Mittelleibes treten gleichzeitig auf; später mit einem Male die fünf Paar Hinterleibsfüsse. Kurz nachdem die junge Mysis die Naupliushülle abgestreift, verlässt sie die Bruttasche der Mutter. ${ }^{1}$

Aus der Entwicklungsgeschichte der Maulfüsser, denen man, den Mangel einer besonderen Kiemenhöhle einseitig betonend, eine Zeitlang auch die Mysis, die Leucifer, die Phyllosomen zuzählte, die man aber jetzt wieder, wie ursprünglich Latreille, auf die Heuschreckenkrebse (Squilla) die Glaskrebse (Erichthus) und ihre nächsten Verwandten beschränkt, sind bisher nur sehr. vereinzelte Bruchstücke bekannt geworden. Die Verfolgung der Entwicklung im Ei wird erschwert durch den Unstand, dass die Heuschreckenkrebse nicht wie Krabben und Krebse ihr Laich mit sich herumtragen, sondern in die ron ihnen bewohnten unterirdischen Gänge absetzen in Gestalt dünner, runder, dottergelber Platten. Das Laich ist deshalb überhaupt schwierig zu erhalten und leider verdirbt es in Tagesfrist; wenn es seiner natürlichen Brutstätte entnommen wird, während man an den Eiern einer einzigen gefangen gehaltenen Krabbe wochenlang den Fortschritten der Entwicklung nachgehen kann. Die Eier der Squilla sterben, wie vom Leibe der Krabbe entfernte Eier, weil ihnen der lebhafte Strom frischen Wassers fehlt, den die Mutter behufs ihrer eigenen Athmung durch ihre Höhle treibt.

Beistehende Abbildung eines Squillaembryo zeigt dass derselbe einen langen, gegliederten, anhanglosen Hinterleib, einen zweilappigen Schwanz, sechs Paar Gliedmassen und ein kurzes Her'z besitzt; letzteres pulsirt nur schwach und langsam. Erhält er vor dem Ausschlüpfen nicht noch weitere Gliedmassen, so dürfte die jüngste

1) VAx Beneden, der selbst die Augenstiele als Gliedmassen betrachtet, kann doch nicht umhin, bei Mysis zu bemerken: "Ce pedicule n'apparaît aucunement comme les autres appendices et parait avoir une autre valeur morphologique." 
Larve auf gleicher Stufe mit der jüngsten Craus'schen Euphausialarve stehen.

Von den beiden bis jetzt bekannt gewordenen Larvenformen, die mit Sicherheit wenn auch nicht dem Heuschreckenkrebse, so doch einem Maulfüsser zuzutheilen sind, übergehe ich die jüngere, ${ }^{1}$ da deren Gliedmassen sich nicht zurerlässig deuten lassen und erwähne nur, dass bei ihr die drei letzten Hinterleibsringe noch anhanglos sind. Der älteren Larve (Fig. 35), die namentlich durch die Gestalt

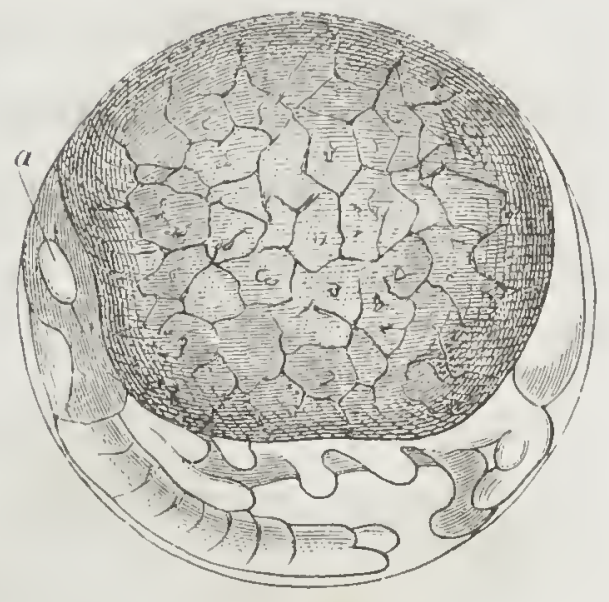

Fig. 34 . der grossen Raubfüsse und des vorhergehenden Fusspaares an die erwachsenen Heuschreckenkrebse erinnert, fehlen noch die sechs den Raubfüssen folgenden Fusspaare. Die en tsprechenden Leibesringe sind schon wohl entwickelt, ein unpaares Auge ist noch vorhanden, die vorderen Fühler sind schon zweiästig, während den hinteren die Geissel fehlt, die Kinnbacken sind tasterlos; die vier vorderen Hinterleibsringe tragen zweiästige, kiemenlose Schwimmfüsse; der fünfte Hin-

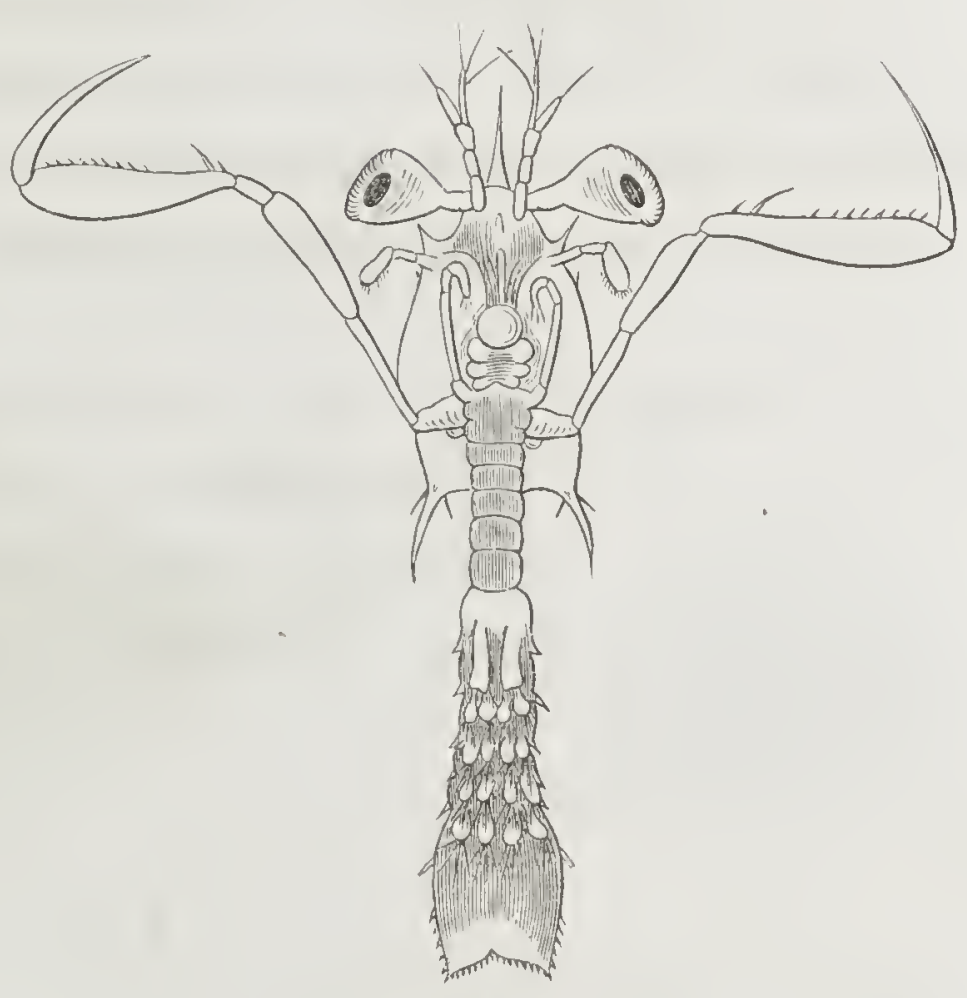

Fig. 3j. terleibsring ist anhanglos; ebenso der Schwanz, der noch als einfaches am Hinterrande mit zahlreichen kurzen Zähnchen besetztes Blatt erscheint. Man sieht, die Larve steht im Wesentliehen auf der Stufe der Zoëa.

1) Archiv für Naturgeschichte, 1563 , 'T'af. I.

Fig. 31. Embryo einer Squilla. 45 mal vergr. a. Herz.

Fig. 35. Aeltere Larve (Zoëa) eines Maulfüssers. 15 mal vergr. 


\section{VIII.}

Minder mannichfaltig, als die der stieläugigen Kruster ist die Entwicklungsweise der Asseh (Isopoda) und Flohkrebse (Amphipoda), die Leach in der Abtheilung der Edriophthalmen, der Kruster mit Sitz. augen vereinigte.

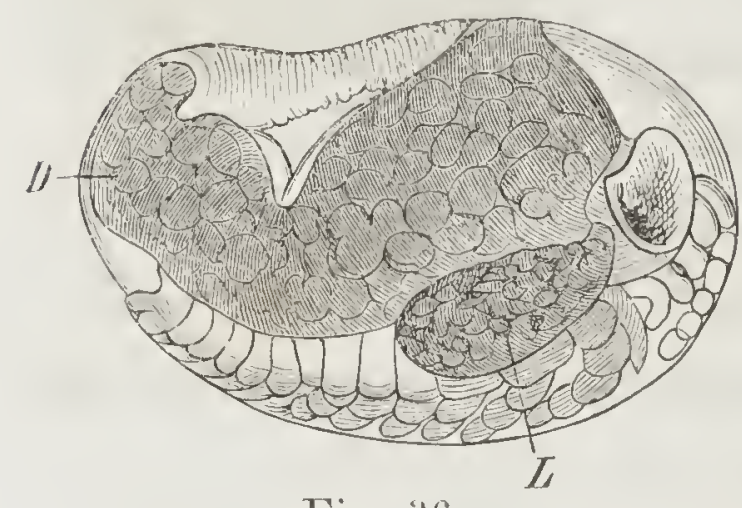

Fig. 36.

Als Beispiel für die Entwickluug der Isopoden mögen die Felsenasseln (Ligia) dienen. Wie bei Mysis ist bei ihnen der Schwanztheil des Embryo nicht nach unten, sondern nach oben gekrümmt; wie dort, bildet sich zunächst eine Larrenhaut, innerhalb deren damn die Assel sich entwickelt. Bei Mysis liess sich diese erste Larvenhaut einem Nauplius vergleichen; bei Ligia erscheint sie als völlig anhanglose Made, die in einen langen einfachen

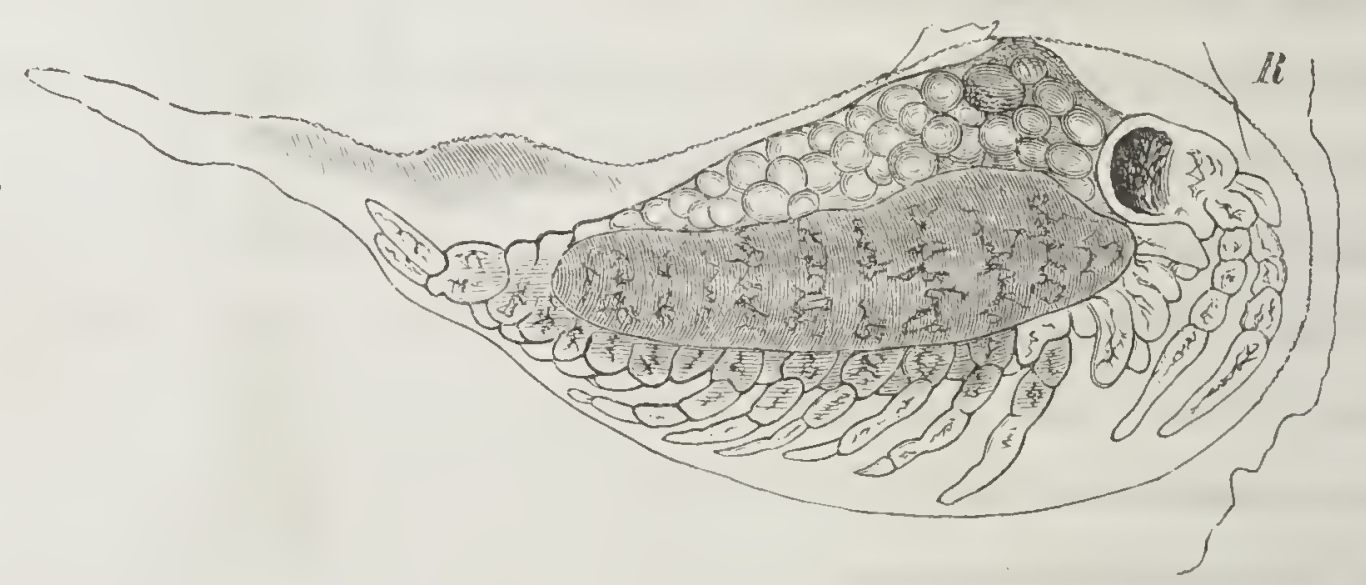

Fig. 37.

Schwanz ausläuft. Die Eihaut bleibt länger erhalten, als bei Mysis; sie birst, wenn schon die Gliednassen der jungen Assel vollzählig angelegt sind. Die Rückenfläche der Assel ist etwas hinter dem Kopfe mit der Larvenhaut verwachsen. An dieser Stelle findet sich, nachdem die Verbindung nicht lange vor der Häutung gelöst ist, ein blattförmiger

Fig. 36. Embryo von Ligia im Ei. - Fig. 37. Madenförmige Larve derselben. 1.5 mal vergr. $D$. Dotter. $L$. Leber. $R$. Rest der Eihaut. Man sieht an der Bauchseite von vorn nach hinten: vordre, hintre Fühler, Kinnbacken, vordre, hintre Kiefer, Kieferfüsse, sechs Gangfüsse, den letzten auhanglosen Ring des Mittelleibes, fünf Hinterleibsfüsse, Schwanzfüsse. 
Anhang, der nur kurze Zeit besteht und schon geschwunden ist, ehe noch die junge Assel die Bruttasche der Mutter verlässt.

Das Junge gleicht, wenn es für sich selbst zu sorgen anfängt, den Alten fast in allen Stücken, bis auf einen wichtigen Unterschied: statt sieben besitzt es nur sechs Paar Gangbeine; der letzte Ring des Mittelleibes ist nur wenig entwickelt und anhanglos. Dass auch die geschlechtlichen Eigenthümlichkeiten noch nicht ausgebildet sind, dass den Männchen noch die handförmigen Verdickungen an den vorderen Gangbeinen und die der Begattung dienenden Anhänge fehlen, bedarf' kaum besonderer Erwähnung.

Auf die Frage, inwieweit die Entwicklung der Felsenasseln bei den übrigen Isopoden sich wiederholt, kann ich nur ungenügende Antwort geben. Die Krümmung des Embryo nach oben statt nach unten fand ich wie RAthke auch bei Idothea, und ebenso bei Cassidina, Philoscia, 'Tanais und den Bopyriden, vermisste sie überhaupt bei keiner der darauf untersuchten Asseln. Bei Cassidina ist auch die erste anhanglose Larvenhaut leicht zu erkennen; es fehlt ihr der lange Schwanz, doch ist sie innerhalb des Eies stark gekrümmt, wic bei Ligia, und deshalb nicht mit einer » inneren Eihaut « zu verwechseln. Letzteres könnte man bei Philoscia, wo sie sich eng an die Eihaut anschliesst und nur im Hinblick auf Ligia und Cassidina als Larvenhaut zu deuten ist. - Den blattförmigen Anhang am Rücken kennt man seit lange an den Jungen der gemeinen Wasserassel (Asellus). ${ }^{1}$ -

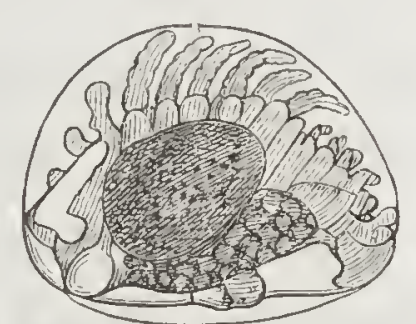

Fig. 3s. Dass den Jungen der Landasseln (Porcellionides Eıw.) und Fischasseln

1) LEYDIG hat diesen blattförmigen Anhang der Wasserasseln der ngrünen Drüse " oder "Schalendrüse " anderer Kruster verglichen; er nimmt dabei an, dass die grüne Drüse ohne Ausführungsgang sei und beruft sich darauf, dass beiderlei Organe "an derselben Stelle " sich finden. 1)ie Deutung ist keine glückliche. Einmal überzeugt man sich, wie auch CLAUS fand, bei Leucifer sehr leicht, dass die "grüne Drüse" wirklich am Ende des von MiLne EDwards als "tubercle auditif" von SPENCE BATE als "olfactory denticle " bezeichneten Vorsprunges ausmündet. Und zweitens ist die Stelle eine so verschiedene, als sie nur irgend sein kann. Dort eine parige Drüse, am Grunde der hinteren Fühler, also an der Unterseite des. $z$ weit en

Fig. 35. Embryo einer Philoscia in Ei, 25 mal vergr. 
(Cymothoadiens EDw.) das letzte Fusspaar des Mittelleibes fehle, hat schon Milne Edwards bemerkt. Das Gleiche gilt für die Schachtasseln (Idothea), für die lebendig gebärenden Kugelasseln (Sphaeroma) und Schildasseln (Cassidina), für die Bopyriden (Bopyrus, Entoniscus, Cryptoniscus n. g.) und für die Scheerenasseln ('Tanais), also wahrscheinlich für die überwiegende Mehrzahl der Isopoden. Alle übrigen Gliedmassen pflegen bei den jungen Asseln wohlentwickelt zu sein. Nur bei den Scheerenasseln fehlen sämmtliche Füsse des Hinterleibes, (aber nicht des Schwanzes); sie entwickeln sich gleichzeitig mit dem letzten Fusspaare des Mittelleibes.

Das letzte Fusspaar an Mittelleibe der Larve, das vorletzte also des erwachsenen Thieres, ist fast immer dem vorhergehenden gleichgebildet;

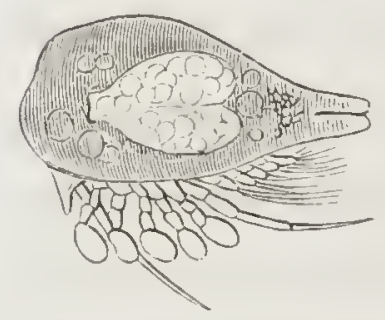

Fig. 39.

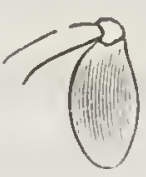

Fig. 10 . eine beachtenswerthe Ausnahme machen jedoch hierin Cryptoniscus und Entoniscus; - beachtenswerth als Beleg zu Darwin's Satze, dass "in ungewöhnlicher Weise entwickelte Theile sehr veränderlich « sind; denn für das abweichend gebildete Fusspaar besteht die grösstmögliche Verschiedenheit zwischen den drei bisher beobachteten Arten. Bei Cryptoniscus (Fig. 39) ist dieser letzte Fuss dünn, ruthenförmig; bei Entoniscus Cancrorum ungemein lang, mit stark verdickter Hand und eigenthümlich gebildeter Scheere versehen; bei Entoniscus Porcellanae sehr kurz, unvollständig gegliedert mit grossem eiförmigen Endgliede (Fig. 40).

Einige Asseln erleiden unmittelbar vor dem Eintritte der Geschlechtsreife eine erhebliche Verwandlung ; so die Männchen der Schee-

Ringes ausmündend; hier ein unpaares Gebilde in der Mittellinie des Rückens hinter dem siebenten Ringe ("hinter der Grenzlinie des ersten Brustsegments “ LEYDIG) sich erhebend.

Fig. 39. Embryo von Cryptoniscus planariö̈les, $90 \mathrm{mal}$ vergr.

Fig. 40. Tetzter Fuss vom Mittelleibe von der Larve des Entoniscus Porcellanae, $150 \mathrm{mal}$ rergr. 
renasseln, von denen schon oben die Rede war und nach Hesse die Praniza, bei denen beide Geschlechter in die als Anceus bekannte Form übergehen sollen. Doch will Spence BA'TE, ein sorgfältiger Beobachter, mit. weit in der Entwicklung vorgeschrittenen Eiern beladene Weibchen in Pranizaform gesehen haben.

Wir treffen in dieser Ordnung zum ersten Male eine weitgehende rückschreitende Verwandlung als Folge des Schmarotzerlebens. Schon bei einigen Fischasseln (Cymothoa) sind die Jungen muntere Schwimmer, die Alten blödsichtige, steife, phumpe Gesellen, deren kurze Kilammerfüsse nur noch geringer Bewegung fühig sind. Bei den Lausasseln, Bopyrus, Phryxus, Kepone u. s. w., die man füglich in einer Gattung hätte beisammen lassen können), Schmarotzern der Krabben und Krebse, die hauptsächlich in deren Kiemenhöhle ihren Wohnsitz nchmen, pflegen den erwachscnen Weibchen dic Augen ganz zu fehlen; die Fühler verkümmern; der breite Leib ist häufig in Folge des beschränkten Raumes unsymmetrisch entwickelt, seine Ringe sind mehr oder minder verschmolzen, die F'üsse verkrüppelt, die Anhänge des Hinterleibes aus langbeborsteten Schwimmfüssen zu blatt- oder zungenförmigen, bisweilen verästelten Kiemen geworden. Bei den zwerghaften Männchen pflegen Augen, Fühler, Füsse besscr erhalten zu sein, als bei den Weibchen; dagegen sind am Hinterleib nicht selten alle Anhänge und bisweilen jede Spur von Gliederung verschwunden. Bei den Weibchen der Binnenasseln (Entoniscus), welche in der Lcibeshöhle von Krabben und Porcellanen gefunden werden, schwinden Augen, Fühler, Mundtheile, schwindet die Gliederung des wurmförmigen Leibes, schwinden bei einer Art (Fig. 41) sämmtliche Gliedmassen fast spurlos und den Cryptoniscus planarioïdes end-

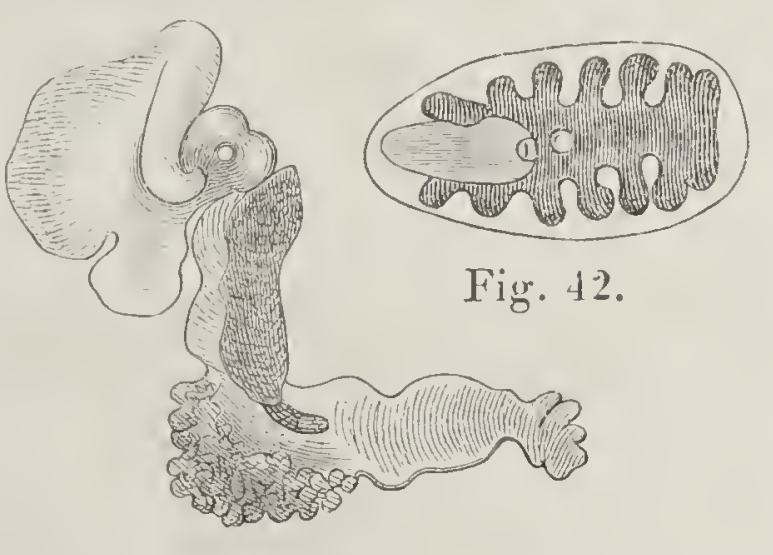

Fig. 41. lich würde man, wenn nicht Eier und Junge die Krebsnatur verriethen,

Fig. 41. Entoniscus Cancrorum, Weibchen, 3 mal vergr. - Fig. 42. Cryptoniscus planarioïdes, Weibchen, 3 mal vergr. 
fast eher für einen Plattwurm als für eine Assel halten. Unter den Männchen dieser verschiedenen Bopyriden nimmt das des Entoniscus Porcellanae die niedrigste Stelle ein; es bleibt lebenslänglich auf sechs Fusspare beschränkt, die zu ungestalten kugligen Klumpen verkrüppeln.

Die Flohkrebse (Amphipoda) sind

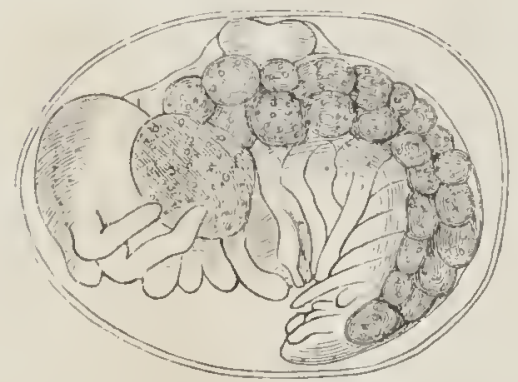

Fig. 43. schon zeitig im Eie von den Asseln zu unterscheiden durch die abweichende Lagerung des Embryo, dessen Hinterende nach unten gekrümmt ist. Ebenfalls sehr früh zeigt sich bei allen Thieren dieser Ordnung die bis jetzt darauf untersucht wurden, ${ }^{1}$ ein eigenthümliches Gebilde am vorderen Theile des Rückens, durch welches der Embryo an die »innere Eihaut « befestigt ist, und das man, unpassend wie mir scheint, als » Mikropylapparat " bezeichnet hat. ${ }^{2}$ Man wird durch dasselbe erinnert an die Verbindung der jungen Asseln mit der Larvenhaut, und an das umpare "Haftorgan " im Nacken der Wasserflöhe (Cladocera), welches bei Evadne besonders entwickelt ist und während des ganzen Lebens sich erhält, bei Daphnia pulex aber, nach Lexisic, ebenfalls nur bei jüngeren 'Thieren vorhanden, bei ausgewachsenen spurlos geschwunden ist.

Das Junge erhält schon in Eie die volle Zahl seiner Leibesringe

1) Bei den Gattungen Orchestoidea, Orchestia, Allorchestes, Montagua, Batea n. g., Amphilochus, Atylus, Microdeutopus, Leucothoe, Melita, Gammarus (nach Mrissxeli und La Valestre), Amphithoe, Cerapus, Cyrtophium, Corophium, I)ulichia, Protella, Caprella.

2) So wenig am Ende der Name zur Sache thut, sollte man doch den Namen "Mikropyle auf Canäle der Eihaut beschränken, die dem Eintritte des Samens dienen. Ueber den "Mikropylapparat "der Amphipoden aber geht die äussere Eihaut, nach den eigrenen Angaben von Mrissner und IA VALE'TE undurchbohrt hinweg, er scheint nie vor der Befruchtung vorhanden zu sein, erreicht seine grösste Entwicklung in einer späteren Zeit des Eilebens und die ihn durchsetzenden zarten Canäle scheinen sogar nicht immer vorhanden zu sein; überhaupt scheint er mehr dem Fimbryo als der Eihaut anzugehören. Ich vermochte mich noch nicht zu überzengen, dass überhaupt die sogenannte "innere Eihaut" wirklich eine solche sei und nicht etwa eine erst nach der Befruchtung gebildete früheste Larvenhaut, wie man im Hinblick auf Ligia, Cassirlina und Philoscia annehmen möchte.

Fig. 43. Embryo eines Corophium, 90 mal vergr. 
und Gliedmassen; wo Leibesringe mit einander verschmelzen, wie die beiden letzten Ringe des Mittelleibes bei Dulichia, die beiden letzten Hinterleibsringe mit dem Schwanze bei Gammarus ambulans und Corophium dentatum n. sp., der letzte Hinterleibsring mit dem Schwanze bei Brachyscelus, ${ }^{\prime}$, oder wo ein oder mehrere Ringe fehlen, wie bei Dulichia und den Caprellen, da findet man dieselbe Verschmelzung, denselben Mangel schon bei den der Bruttasche der Mutter entnommenen Jungen. Auch Eigenthümlichkeiten in der Bildung der Gliedmassen, sofern sic beiden Geschlechtern zukommen, pflegen schon bei den ausschlüpfenden Jungen ausgeprägt zu sein, so dass diese in der Regel nur durch plumpere Gestalt, geringere Zahl der Fühlerglieder, der Riechfäden, sowic der Borsten und Zähne, mit denen Lèib oder Füsse bewaffnet sind, auch wohl durch verhältnissmässig grössere Nebengeissel von ihren Eltern abweichen.

Eine Ausnahme von dieser Regel machen die meist an Quallen lebenden Hyperinen; bei ihnen haben Junge und Alte oft ein ausserordentlich verschiedenes Aussehen; aber auch bei ihnen findet keine Ncubildung von Leibesringen und Gliedmassen, sondern nur eine allmähliche Umwandlung derselben statt. ${ }^{2}$ So gehen, um einige Beispiele

1) Nach SPENcE Ba'ce soll bei Brachyscelus crusculum der fünfte Hinterleibsring nicht mit dem sechsten (dem Schwanze), sonchern mit dem vierten verschmolzen sein, was ich bei der grossen Uebereinstimmung, clie sonst diese Art mit den beiden ron mir untersuchten zeigt, bezweifeln möchte.

2) Spence Bate vermisste bei den Jungen der Hyperia gaba sämmtliche Füsse des Hinterleibes und die zwei letzten Fusspaare des Mittelleibes; clie sehr auffallende Angabe bedarf um so mehr cler Bestätigung, da er diese winzigen 'Thierchen nur in getrocknetem Zustande untersuchte. Nachträglich wurde mir die erwünschte Gelegenheit, die Entwicklung einer an Rippenquallen, besonders Beroë gilva Eschsch. nicht seltenen Hyperia zu verfolgen. Die jüngsten Larven, aus der Bruttasche cler Nutter, besitzen schon sämmtliche Füsse des Mittelleibes; dagegen vermisse ich wie Spence Bate, die des Hinterleibes. Anfangs ziemlich einfach, werden diese Fússe bald sämmtlich wie die Vorderfüsse zu reichgezähnelten Greiffüssen und zwar von dreifach verschiedener Form, indem die Vorderfüsse (Fig. 44), die beiden folgenden (Fig. 45) und endlich die drei letzten Fusspaare (Fig. 46) unter sich ähnlich und von den übrigen abweichend gebilchet sind. In dieser Gestalt erhalten sich die Füsse sehr lange, während die Hinterleibsanhänge zu kräftigen Schwimmwerkzeugen, und die anfangs, wie mir schien, ganz fehlenden Augen zu gewaltigen Halbkugehn heranwachsen. Bei dem Uebergang in die Gestalt des erwachsenen Thieres erleiclen namentlich die drei letzten Fiusspare (Fig. 49) eine bedeu- 
zu geben, die gewaltigen Scheeren am drittletzten Fusspaare der Phronima sedentaria nach PAGExstecher aus einem einfachen Fusse von

tende Veränderung. Die Verschiedenheit der beiden Geschlechter ist bedeutend; die Weibchen sind durch einen sehr breiten Mittelleib, die Männchen (Lestrigonus) durch sehr lange Fühler ausgezeichnet, von denen die vorderen ungemein reichliche Riechfäden tragen.

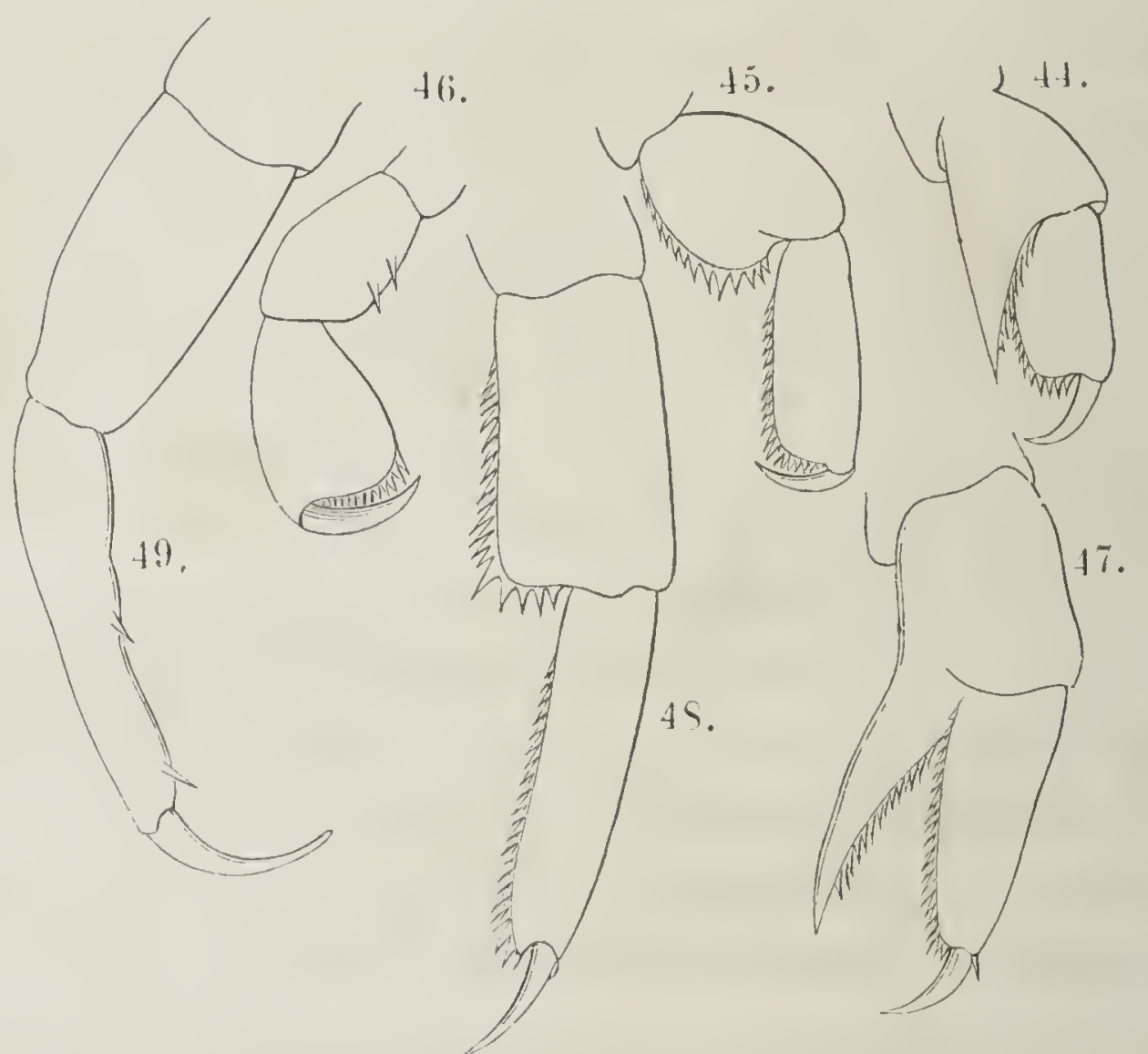

Fig. $44-49$.

1)ie jüngsten Larren können natürlich nicht schwimmen; es sind unbehilfliche Thierchen, die sich namentlich an die Schwimmblättchen des Wirthes festklammern; die erwachsenen Hyperien, die man nicht selten frei in Meere trifft, sind, wie man weiss, die trefflichsten Schwimmer ihrer Ordnung. ("Il nage avec une rapidité extrême" sagt vaN BENEDEN von Hyp. Latreillii FDw.).

Offenbar ist die Verwandlung der Hyperien als eine er wo r bene, nicht als eine ererbte zu betrachten, $c$. .h. das späte Auftreten der Hinterleibsanhänge und die eigenthümliche Fussbildung der Jungen sind nicht mit der geschichtichen Entwicklung der Amphipoden in Verbindung zu bringen, sondern auf Rechnung des Schmarotzerlebens der Jungen zu setzen.

Fig. 4t-46. Füsse einer halbwüchsigen Hyperia Nartinezii ${ }^{1}$ n. sp. - Fig. 47-49. Füsse eines ziemlich erwachsenen Männchens derselben Art; und zwar 44 u. 47 vom ersten Paare der Vorderfüsse (gnathopoda), $45 \mathrm{u}$. 45 vom ersten, 46 u. 49 vom letzten Fusspare des Mittelleibes, 90 mal vergr.

1) Benannt nach meinem geschätaten Freunde, dem liebenswürdigen spanischen Zoologen, Herm Francisco de Paula Martinez Y Sass, zur Zeit auf einer Reise um die Erde. 
gewöhnlicher Bildung hervor, und umgekchrt bildet sich die Scheere am vorletzten Fusspaare des jungen Brachyscelus zu einem einfachen Fusse um. Bei den Jungen der letztgenannten Gattung ist der lange Kopt in eine kegelförmige Spitze ausgezogen und trägt auffallend kleine Augen; beim Heranwachsen erreichen diese, wie bei den meisten $\mathrm{Hy}_{\mathrm{y}}$ perinen, einen ungeheneren Unfang und füllen fast vollständig den nun kuglig erscheinenden Kopf, u. s. w.

Die Verschiedenheit der Geschlechter, die bei den Gammarinen besonders in der Bildung der Vorderfüsse (gnathopoda Sp. BATE), bei den Hyperinen in der Bildung der Fühler ausgesprochen zu sein pflegt, und oft so beträchtlich ist, dass man Männchen und Weibchen als verschiedene Arten beschrieben und mehrfach sogar in verschiedene Gattungen (Orchestia und Talitrus, - Cerapus und Deocothoë, - Lestrigonus und Hyperia) und selbst Familien (Hypérines anormales und Hypérines ordinaires) gestellt hat, bildet sich erst aus, wenn die Thiere ziemlich herangewachsen sind. Bis dahin gleichen die Jungen im A.llgemeinen den Weibchen, sogar in einigen Fällen, wo diese sich weiter als die Männchen von dem "Typus « der Ordnung entfernen. So ist das zweite Paar der Vorderfüsse bei den männlichen Strandhüpfern (Orchestia) mit einer kräftigen Hand versehen, wie bei der Mehrzahl der Am. phipoden, bei den Weibchen in höchst abweichender Weise gebildet. Die Jungen gleichen dennoch den Weibchen. - So fehlen, -- ein äusserst seltner Fall ${ }^{1}$ - , den Weibchen von Brachyscelus die hinteren (oder unteren) Fühler, das Männchen besitzt dieselben, wie andere Amphipoden, bei den Jungen finde ich, wie Spenca Bate keine Spur davon.

Wie bei Brachyscelus ist hier gegen die gewöhnliche Weise der Schmarotzer dem Alter und nicht der Jugend die freiere Beweglichkeit geblieben. Noch auffallender ist ein ähnliches Verhalten bei Caligus unter den schmarotzenden Copepoden. Das junge Thier, von Burueister als eigene Gattung, Chalimus, beschrieben, liegt mittelst eines von seiner Stirn entspringenden Taues, dessen Fnde in der Haut eines Fisches festsitzt, an diesem vor Anker. Beim Eintritt der Geschlechtsreife wird das Tau gekappt, und nicht selten fängt man die erwachsenen Caligus, vortrefliche Schwimmer, frei im Meere. - (S. Archiv für Naturgesch. 1552. I, S.91).

1) "I know of no case in which the inferior (antennae) are obsolete, when the 
Hervorzuheben ist noch, dass die Ausbildung der geschlechtlichen Eigenthümlichkeiten mit crlangter Geschlechtsreife nicht stille steht.

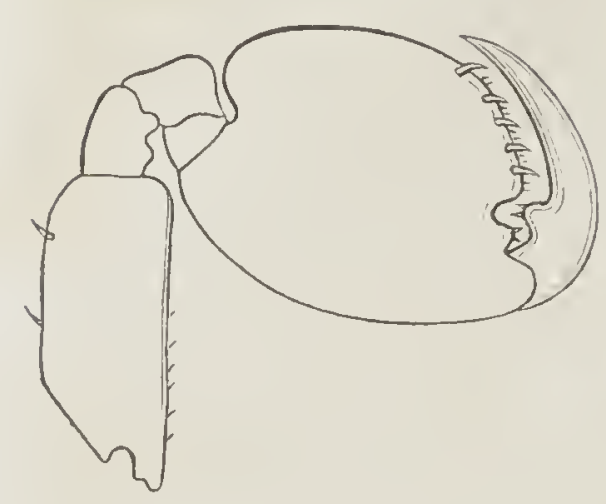

Fig. 51$)$.

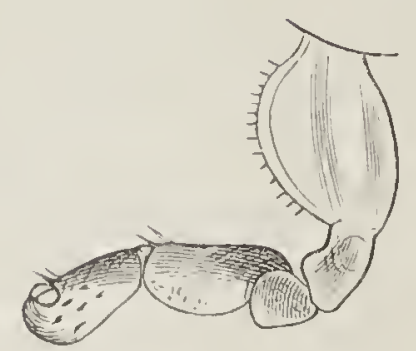

Fig. j1.

Jüngere geschlechtsreife Männchen von Orchestia Tucurauna n. sp. z. B. haben schlanke untere Fühler mit unverschmolzenen Geisselgliedern, der Greifrand (palm Sp. B.) der Hand des zweitenFusspaares ist gleich-

mässig gewölbt, das letzte Fusspaar ist schlank, den vorhergehenden ähnlich. Später verdicken sich die Fühler, die zwei, drei, vier ersten Glieder der Geissel verschmelzen, der Greifrand der Hand erhält nahe seiner unteren Ecke eine tiefe Bucht, die mittleren Glieder des letzten Fusspaares schwellen zu einer ansehnlichen Verdickung an. Kein Museumszoolog würde anstehen, zwei besondere Species zu fabriciren, wenn ihm die ältesten und jüngsten geschlechtsreifen Männchen ohne die verbindenden Zwischenformen übersandt würden. Bei jüngeren, aber wie die mikroskopische Untersuchung der Hoden lehrt, schon geschlechtsreifen Männchen der Orchestia Tucuratinga n. sp. fehlt die in Fig. 50 gezeichnete Bucht des Greifrandes der Hand, sowie der ent. sprechende Vorsprung des Fingers noch vollständig. - Aehnliches kann man bei Cerapus, bei Caprella und wahrscheinlich überall beobachten, wo überhaupt erbliche Geschlechtsverschiedenheiten vorkommen.

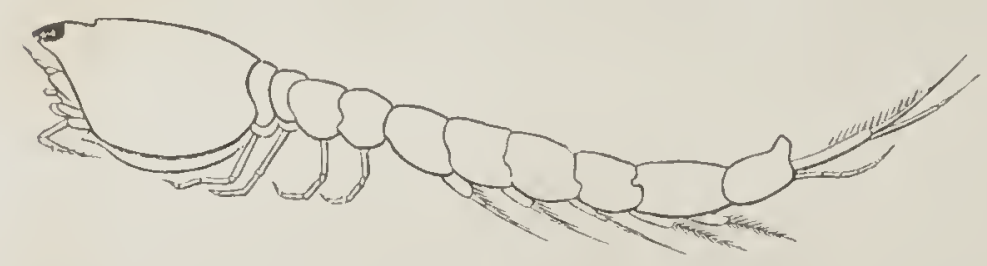

Fig. 52.

An die artenreichen $\mathrm{Ab}$ theilungen der stieläugigen und der sitzäugigen Kruster reiht sich, ersteren wohl näher verwandtals letzteren,

superior are developed " DANA. (DARWIN, Monograph on the Subclass Cirripedia. Lepadidae. pg. 15.).

Fig. 50. Vorderfuss des zweiten Paares (second pair of gnathopoda) vom Männchen und Fig. 51. vom Weibchen der Orchestia Tucuratinga, 15 mal vergr.

Fig. 52. Männchen einer Bodotria, 10 mal vergr. Man beachte die langen unteren Fühler, die dem Leibe dicht anliegen, und deren. Spitze unter den Schwanzanhängen sichtbar ist. 
die merkwürdige Familie der einängigen Diastyliden oder Cumac e en. Die Jungen, die KroyFu der Bruttasche der Weibchen entnahm und die ein Viertel der Länge der Mutter erreichten, glichen dem erwachsenen Thiere fast in allen Stücken. Ob innerhalb der ähnlich wie bei Mysis gebildeten Bruttasche eine Verwandlung stattfinde, wie bei Mysis oder Ligia, weiss man nicht. ${ }^{1}$

Gleich dürftig ist unsere Kenntniss der Entwicklungsgeschichte der Muschelkrebschen (Ostracoda). Man weiss kaum mehr, als dass ihre vorderen Gliedmassen sich früher als die hinteren entwickeln (ZENKRr).

\section{IX.}

Die Abtheilung der Kiemenfüsser (Branchiopoda) umfasst zwei auch durch ihre Entwicklung geschiedene Gruppen, die Blattfüsser (Phyllopoda) und die Wasserflö he (Cladocera). Die letzteren, mit vier bis sechs Paar blattförmiger Füsse ausgestattete winzige 'Thierchen, die hauptsächlich dem süssen Wasser angehören und in ähnlichen Formen über alle Welt verbreitet sind, verlassen das Ei mit vollzähligen

1) Ein zurerlässiger englischer Forscher, Goodsin, beschrieb schon 1943 die Bruttasche und die Eier von Cuma. Krøy ER, dessen peinliche Sorgfalt und Gewissenhaftigkeit bewundernd anerkennt wer je mit ihm auf gleichem Arbeitsfelde zusammentraf, bestätigte $1 \$ 46$ GoodsiR's Angaben und entrahm, wie oben erwähnt, der Bruttasche weit entwickelte, den Eltern ähnliche Enibryonen. Damit ist die Frage ob die Diastyliden erwachsene Thiere oder Larven seien, vollständig und für immcr entschieden, und nur die berühmten Namen eines Agassiz, Dara, Milne Fdwards, die sie trotzdem neuerdings wieder zu Larven stempeln möchten (s. vaN BFNEDEs, Rech. sur la faune littor. de Belgique Crustacés. pg. 73. 74), veranlassen mich, auf Grund zahlreicher eigener Untersuchungen mit vas BENEDEx's Worten zu erklären : "Parmi toutes les formes embryonnaires de podophthalmes ou d'édriophthalmes que nous avons observées sur nos côtes, nous n'cn avons pas vu une seule qui eût même la moindre ressemblance avec un $\mathrm{C} u \mathrm{~m}$ a quelconque. "Das $\mathrm{E}$ in zige, was aus den von KRøYER aufgestellten, drei Seiten füllenden Familiencharakteren der Cumaceen (KRørkk, Nat. 'Tidsskrift. Ny Raekke. Bd. II. S. 203-206) auf die Jarven von Hippolyte, Palaemon und Alpheus passt, ist: "Duo antennarum paria." Und das passt bekanntlich so ziemlich auf alle Kruster. Wie wohlherechtigt war man also, diese mit jenen zu identificiren. Es genügt übrigens, pinen Blick auf die Palacmonlarve (Fig. 31) und auf die Cumacee (Fig. 52) zu werfen, um sich von deren ungeheurer Aehnlichkeit zu überzeugen. 
Glicdmassen. Die Blattfüsser dagegen, deren Fusszahl zwischen 10 und 60 l'aaren schwankt, und von denen einige zwar in der gesättigten Soole der Salzwerke und der Natronseen leben, aber nur eine, ziemlich abweichende Gattung (Nebalia) im Meere gefunden wird, ${ }^{1}$ haben eine Verwandlung zu bestehen. Die jüngsten Larven sind Nauplius, die wir schon einmal ausnahmsweise bei einigen Garneelen trafen und die wir von nun ab fast ohne Ausnahme wiederfinden werden. Die bisweilen so zahlreichen Leibesringe und Füsse bilden sich nach und nach von vorn nach hinten, ohne dass durch die Zeit ihres Auftretens oder durch ihre Gestalt scharfgeschiedene Leibesabschnitte bezeichnet werden. Alle Füsse sind im Wesentlichen gleich gebaut und erinnern an die Kiefer der höheren Kruster. ${ }^{2}$ Man könnte die Phyllopoden als Zoëa betrachten, die nicht zur Bildung eines eigenthümlich ausgestatteten Hinterund Mittelleibes gekommen sind, und statt dessen die den Naupliusgliedmassen zuerst folgenden Anhänge in vielfacher Wiederholung erzeugt haben.

Die Entwicklungsgeschichte, wie die ganze Naturgeschichte der Copepoden, - die theils frei lebend das süsse Wasser und in weit mannichfacheren Formen das Meer bevölkern, theils als Schmarotzer Thiere der verschiedensten Klassen belästigen und dabei oft zu wunderlicher Missgestalt verkümmern, - lag bis vor Kurzem sehr im Argen. Man wusste zwai längst, dass die Cyclopen des süssen Wasser's in Naupliusform ausschlüpfen und kannte einige andere Jugendzustände derselben; man hatte durch Nordrans dieselbe früheste Jugendform für mehrere Schmarotzerkrebse kennen gelernt, die bis dahin fast allgemein als Würmer gegolten hatten; -- aber es fehlten die verbindenden Mittelglieder, welche die Leibesabschnitte und Gliedmassen der Larven auf die des erwachsenen Thieres zurückzuführen erlaubt hätten. Die um-

1) 1) ürfte man die Phyllopoden als nächste Verwand te der Trilobiten bctrachten, worüber ich kein Urtheil wage, so würden sie neben Lcpidosteus und Polypterus, Tappidosiren und Protopterus ein weiteres Beispiel liefern für die Erhaltung im Mecre längst erloschener Formen im Binnenwasser. Das Vorkommen der Artemien in übersalzenem Wasser würde dabei zeigen, dass sie nicht durch das süsse Wasser, sondern durch die hicr geringere Nitbewerbung der Vernichtung entgingen.

2) "Der Kiefer der Krebslarve ist eine Art Phyllopodenfuss "Claus. 
fassenden und sorgfältigen Untersuchungen von CuArs haben diese Lücke ausgefüllt und die Abtheilung der Copepoden zu einer der bestgekannten der ganzen Klasse erhoben. Den Arbeiten dieses wackeren Forschers sind die folgenden Angaben entnommen. Ich hebe aus der Fülle wichtiger Thatsachen, die darin niedergelegt sind, nur das für das Verständniss der Krusterentwicklung im Allgemeinen Unentbehrliche hervor, weil, was dic Copepoden in Besonderen anlangt, schon durch die Darstellung ihres neuesten Bearbeiters die 'Thatsachen in's rechte Licht gestellt sind, und Jedem, der offene Augen hat, als wichtige Belege für die DARwrs'sche Lehre erscheinen müssen. ${ }^{1}$

Alle von Clays untersuchten Larven der freilebenden Copepoden haben in frühester Zeit drei Gliedmassenpaarc (die späteren Fühler und Kinnbacken), die vorderen mit cinfacher, die zwei nachfolgenden mit zweifachen Gliederreihen oder Aesten. Das unpare Auge, Oberlippe, Münd nehmen schon ihre bleibende Stelle ein. Die hintere, meist kurze, gliedmassenlose Leibespartie trägt zwei Endborsten, zwischen denen der After licgt. Dic Gestalt dieser Naupliusbrut ist äusserst mannichfaltig, bald seitlich comprimirt, bald flach, - bald langstreckig,
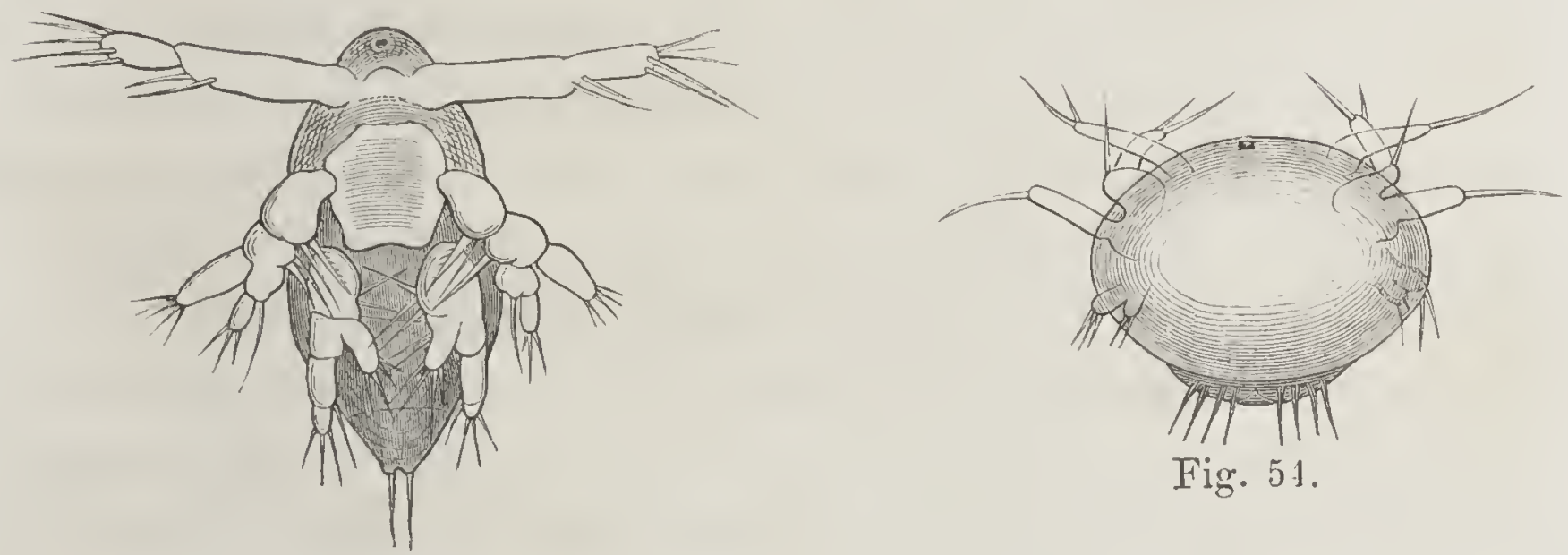

Fig. 51.

Fig. 53.

bald oval, bald rund oder selbst breiter als lang u. s. w. Die Veränderungen, welche die ersten Larvenstadien mit dem weiteren Wachsthume erlciden, beruhen in Wesentlichen auf einer Streckung des Lcibes und

1) 1)as neueste grössere Werk von Claus äber Copepoden kenne ich noch nicht; doch wird sich von 1 ihm ohne Zweifel dasselbe sagen lassen.

Fig. 53. 54. Nauplius von Copepoden, erstere 90, letztere 180 mal vergr. 
Hervorsprossen neuer Gliedmassen (. ") Das nachfolgende Stadium weist schon ein viertes Extremitätenpaar, die späteren Maxillen, auf. "Dann folgen auf einmal drei neue Glicdmassenpaare (dic Kieferfüsse und die zwei anderen Schwimmfusspaare). Noch bleibt die Larve Nauplius-ähnlich, indem dic drei vordern Glied massenpaare Ruderfüsse darstellen; bei einer neuen Häutung verwandelt sie sich in den jüngsten Cyclops-ähnlichen Zustand, sie gleicht nun im Bau der Fühler und Mundtheile dem erwachsenen Thiere, wenn auch die Zahl der Gliedmassen und Leibesringe noch eine vicl geringere ist, denn es sind nur, in Form mit Borsten besetzter Wülste, die Anlagen des dritten und vierten Schwimmfuss paares hinzugekommen und der Leib besteht aus dem ovalen Kopfbruststück, dem zweiten bis vierten Thoracalsegment und einem langgestreckten Endgliede. Bei den Cyclopiden haben die hinteren Fühler ihre Nebenäste verloren, die Kinnbacken vollständig den früheren Schwimmfuss abgeworfen, während bei den übrigen Familien diese Anhänge mehr oder weniger verändert fortbestehen. "Ueber diese Stufe der freien Entwicklung gelangen vicle Formen der parasitischen Copepoden z. B. Lernanthropus und Chondracanthus, nicht hinaus, indem sie weder die Gliedmassen des dritten und vierten Paares erhalten, noch cine Sonderung des fünften Thoracalsegments vom Abdomen zu Stande kommt; andere (Achtheres) sinken sogar durch den späteren Verlust der beiden Schwimmfusspaare auf eine ticfere Stufe zurück. Alle freilebenden Copepoden aber und die meisten Schmarotzerkrebse durchlaufen noch eine grösscre oder geringere Reihe von Entwicklungsstadien, in welchen in continuirlicher Aufeinanderfolge die Gliedmassen eine höhere Gliederung erhalten, die hinteren Fusspaare zur Entwicklung kommen und aus dem gemeinsamen Endabschnitt sich der Reihe nach das letzte Thoracalsegment und die einzelnen Abdominalsegmente sondern."

Aus der Entwicklungsgeschichte der S ch marotzer kre bse sei nur noch hervorgehoben, dass einige derselben z. B. Achtheres percarum zwar auch wic dic andern in Nauplius-ähnlicher Gestalt das Ei verlassen, indem der plumpe, ovale, mundlose Leib zwei Paar einfache Ruderfüsse und dahinter als Rest des dritten Paares zwei mit ciner langen Borste 
versehene Auftreibungen trägt, dass aber unter dieser Naupliushaut schon eine weit verschiedene Lare fertig liegt, dic nach wenig Stunden ihre unbeholfene Hülle sprengt und nun in einer Gestalt auftritt, ") welche in der Gliederung des Körpers und in der Ausbildung der Extremitätenpaare mit dem ersten Cyclopsstadium übereinstimmt. " (Cı,aus). Die ganze Reihe von Naupliusstadien, welche die freilebenden Copepoden durchlaufen, wird hier vollständig übersprungen.

Eine letzte sehr eigenthümliche Abtheilung der Kruster bilden die beiden Ordnungen der Rankenfüsser (Cirripedia) und der Wurzelkrebse (Rhizocephala). ${ }^{1}$

Auch hier schwärmt die Brut in Naupliusgestalt aus und streift nach Kurzem eine früheste durch keine crwähnenswerthen Eigenthümlichkeiten ausgezeichnete Larvenhaut ab. Auch hier kehrt diesclbe Birnform des ungegliederten Leibes, dieselbe Zahl und

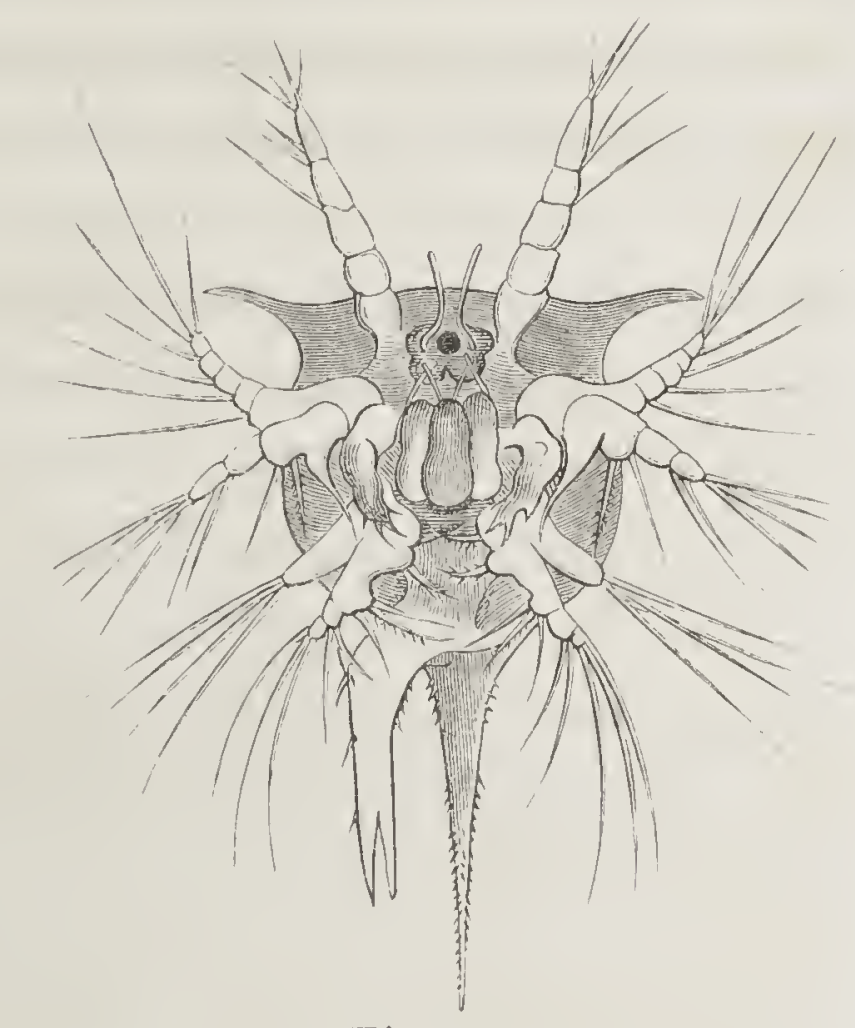

Fig. 55.

1) Ueber die Stellung der Rankenfüsser herrschen die abweichendsten Ansichten. Die Finen weisen ihnen eine sehr untergeordnete Stellung unter den Copepoden an; so H. Milne EDwards (1552). Im geraden Gegensatz zu dieser Auffassung seines Vaters stellt sie Alpir. MILne Edwatids als Basinotes allen übrigen Krustern (Fileuthéronotes) gegenüber. DARWin betrachtet sie als besondere den Podophtlialmen, Edriophthalmen u.s.w. gleiehwerthige Unterklasse. Dies seheint mir das Passendste. Die Wurzelkrebse möchte ich nicht den Rankenfüssern einverleiben, wie LILJEBORG, sondern als gleiehwerthig gegenüberstellen, wie die Amphipoden den Isopoden. - Man sprieht aueh wohl von der nahen Verwandtschaft der Rankenfüsser mit den Ostracoden; die Aehnliehkeit aber der sogenannten »cyprisähnlichen Larven " oder Rankenfüsserpuppen, wie sie DAlwin nemnt, mit den Cypris ist eine so rein äusserliche, selbst was die Schale anlangt, dass mir die Verwandtsehaft kaum grösser seheint, als etwa die des Peltogaster socialis (Fig. 59, nit der Familic der Schlack- und Teberwürste.

Fig. 55. Nauplius der Tetraelita porosa, nach der ersten Häutung, 90 mal vergr. Man sieht um das Auge das Gehirn, von dem die Rieehfäden entspringen, und dahinter einige zarte zur Mundkappe gehende Muskeln. 
Bildung der Füsse, dieselbe Lage des unpaaren Auges (das indess bei Sacculina purpurea und nach DARwn bei einigen Lepas vermisst wird), dieselbe Lage der "Mundkappe " wieder, wie sie bei den Nauplius der Garneelen und der Copepoden sich findet. Unterschieden von letzteren sind die Nauplius der Rankenfüsser und Wurzelkrebse durch den Besitz eines Rückenschildes oder Panzers, der bisweilen (Sacculina purpurea) den Körper ringsum weit überragt; unterschieden nicht nur von anderen Nauplius, sondern soviel mir bekannt von allen anderen Krustern dadurch, dass Gebilde, die sonst mit den beiden vorderen Gliedmassenparen (Fühlern) verbunden sind, hier von ihnen getrennt auftreten.

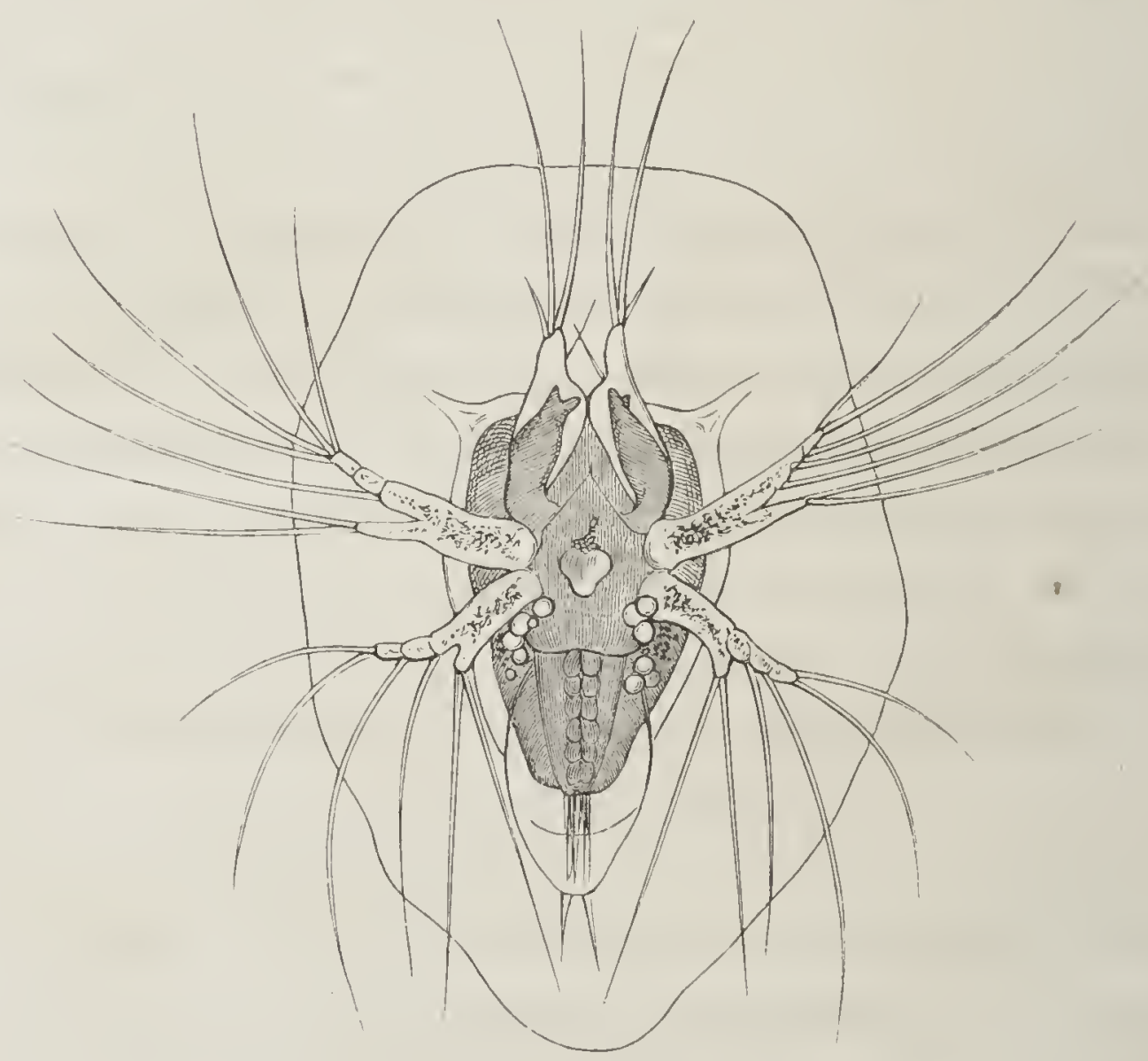

Fig. 56.

Die vorderen Fühler der Copepoden, der Cladoceren, der Phyllopoden (Lerdig, Claus), der Ostracoden (wenigstens der Cypridinen), der Diastyliden, der Edriophthalmen und der Podophthalmen tragen - mit wenigen, Landthiere oder Schmarotzer betreffenden Ausnahmen, cigrenthümliche Fäden, deren ich schon mehrmals als »Riechfäden "

Fig. 56. Nauplius der Sacculina purpurea, kurz vor der zweiten Häutung, 1 50 mal vergr. Im ersten Fusspaare sind die späteren Haftfüsse, im Hinterleibe sechs Paar langborstiger Schwimmfüsse zu erkennen. 
Erwähnung gethan. Ein Paar ganz ähnliche Fäden entspringen bei den Larven der Rankenfüsser und Wurzelkrebse unmittelbar vom Gehirn.

Am Grunde der unteren Fühler mündet bei Krabben und Krebsen, bei letztern an Ende cines kugelförmigen Vorsprunges die sogenannte "grüne Drüse " aus. Ein ähnlicher kegelförmiger Vorsprung mit dem ihn durchsetzenden Ausführungsgange ist bei den meisten Amphipoden sehr augenfällig. Bei den Ostracoden beschreibt Zexrer eine im Grunde der unteren Fühler gelegene Drüse, die an Ende eines ungemein langen "Stachels « ausmündet. Bei den Nauplius der Cyclops und Cyclopsine findet Claus helle "Schalendrüsen ", die am mittleren Gliedmassenpaare (den hinteren Fühlern) beginnen. Dagegen münden bei den Nauplius der Rankenfüsser und Wurzelkrebse die "Schalendrüsen " am Ende liegelförmigcr Fortsätze von bisweilen abenteuerlicher Länge, die von den Ecken des breiten Stimrandes ausgehen und bald als Fühler (BukMIEISTER, DARwiN), bald als blosse » Hörner des Rückenschildes ( (KROHN) gedeutet worden sind. Die Verbindung der wSchalendrüse " mit den Stirnhörnern wurde bei Lepaslarven in unzweidentiger Weise erkannt, wie denn überhaupt die Aehnlichkeit der Stirnhörner mit dem kegelförmigen Vorsprung an den unteren Fühlern der Amphipoden oder des Leucifer eine vollständige ist. ${ }^{1}$

Uebereinstimmend in diesen wichtigen Eigenthünlichkeiten bieten die Nauplius der beidèn Ordnungen in manchen anderen Stücken erhebliche Unterschiede. Der Hinterleib der jungen Rankenfüsser läuft unterhalb des Afters in einen langen am Ende gablig getheilten schwanzförmigen Anhang aus und über dem After steht ein zweiter langer Stachelfortsatz; der Tinterleib der Wurzelkrebse endet in zwei liurze Spitzen, in cine »bewegliche Schwanzgabel, wie bei den Räderthieren " (Oscar Schinit). Die jungen Rankenfüsser haben Mund, Magen, Darm, After und ihre beiden hinteren Gliedmassenpaare sind mit mannichfachen Zacken, Borsten und Haken besetzt, die jedenfalls bei der Nahrungsaufnahme mitwirken. Dies Alles vermisst man bei den jungen

1) Es mag bei dieser Gelegenheit erwähnt werden, dass bei den Weibchen ron Brachyscelus, denen die hinteren Fühler fehlen, doch die kegelförmigen Vorsprünge mit dem sie durchsetzenden Canale erhalten bleiben. 
Wurzelkrebsen. Die Nauplius der Rankenfüsser haben als solche mehrfache Häutungen zu bestehen; die Nauplius der Wurzelkrebse können, - mundlos, wie sie sind, - natürlich nicht lange als solche leben und schon nach wenigen 'Tagen verwandeh sie sich in ebenfalls mundlose „Puppen «, wie sie Dakwin nennt.

Der Panzer klappt sich zusammen, so dass das Thierchen ein muschelähnliches Aussehen erhält, die vordersten Gliedmassen verwandeln sich in sehr eigenthümliche Haftfüsse (" prehensile antennae (DArw.), die bciclen folgenden Paare werden abgeworfen, wie die Stimhörner. Am Hinterleibe haben sich unter der Naupliushaut sechs Paar kräftiger, zweiästiger, langborstiger Schwimmfüsse gebildet, und dahinter stehen zwei kurze borstentragende Schwanzanhänge. (Fig. 58.)

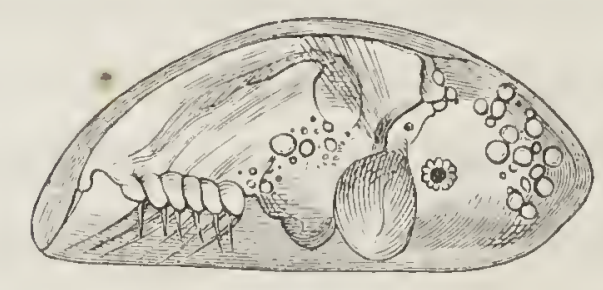

Fig. 5i.

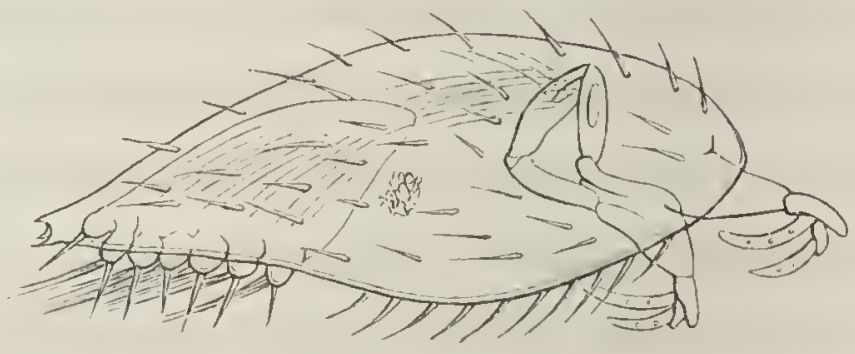

Fig. 5 s.

Die Puppen dcr Rankenfüsser (Fig. 57), die gleichfalls mundlos sind, stimmen in allen diesen Stücken vollständig mit denen der Wurzelkrebse überein, bis ins Einzelnste der Gliederung und Beborstung der Schwimmfusspaare; ${ }^{1}$ sie unterscheiden sich von ihnen besonders durch den Besitz paariger zusammengesetzter Augen. Bisweilen scheinen auch Spuren der Stimhörner zu bleiben. ${ }^{2}$

1) Man vergleiche die Abbildung, welche 1) ARwin (Balanidae, Pl. XXX, Fig. 5) vom ersten Schwimmfusse der Puppe von Lepas australis gibt mit der im Archiv für Naturgeschichte (IS63, Taf. III, Fig. 5) mitgetheilten von Lernaeodiscus Porcellanae. )er einzige Unterschied, dass bei letzteren am Ende des äusseren Astes 11 ur 3 Borsten stehen, bei den Rankenfüssern 4 am ersten, 5 an den folgenden Schwinmfüssen, mag auf einem Irrthum meinerseits beruhen.

2) 1)Aliwis beschreibt als "acoustic orifices" kleine Oeffnungen in der Schale der Rankenfüsserpuppen, die öfter von einem Rande umgeben, bei Lepas pectinata

Fig. 57. Puppe eines Balaniden (Chthamalus ?), 50 mal vergr. -- Die Haftfüsse siud in den ziemlich undurchsichtigen vorderen Theil der Schale zurückgezogen.

Fig. js. Puppe der Sacculina purpurea, 180 mal vergr. J)ie Fäden an den Haftfüssen mögen die Anfänge der späteren Wrurzeln sein. 
Wie die Rankenfüsser und Wurzelkrebse im Allgemeinen jetzt einander weit ähnlicher sind, als in ihrem Naupliuszustande, so gilt dasselbe ebenso für die einzelnen Mitglieder jeder der beiden Ordnungen.

Die Puppen beider Ordnungen setzen sich mittelst der Haftfüsse fest; die der Rankenfüsser an Felsen, Muscheln, Schildkröten, Treibholz, Schiffe u. s. w., die der Wurzelkrebse an den Hinterleib ron Krabben, Porcellanen, Einsiedlerkrebsen. Der Panzer der Rankenfüsser verwandelt sich bekanntlich in ein eigenthümliches Gehäuse, um dessentwillen man sie früher zu den Mollusken stellte und die Schwimmfüsse wachsen zu langen Ranken aus, die dem nun geöffneten Munde Nahrung zustrudeln. Die Wurzelkrebse bleiben mundlos; sie verlieren spurlos alle Gliedmassen und erscheinen als wurst-, sack-, oder scheibenförmige mit Eiern gefüllte Auswüchse ihres Wohnthieres (Fig.59, 60); von der Anheftungsstelle senken sich wurzelartig verästelte geschlossene Röhren in das Innere des Wirthes, dessen Darm umspinnend, oder zwischen denLeberschläuchen sich ausbreitend. Die einzigen Lebensäusserungen, die diesen Non plus ultra's in der Reihe

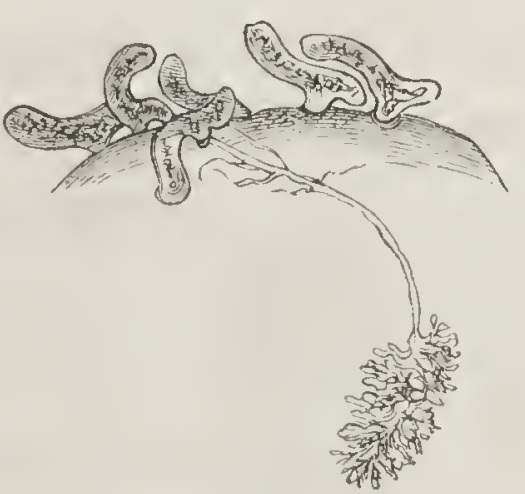

Fig. 59.

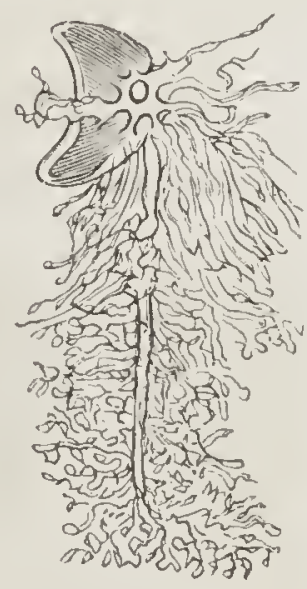

Fig. 60 . der rückschreitend sich verwandelnden Kruster geblieben, sind einmal kräftige Zusammenziehungen der Wurzeln und dann ein abwechselndes Ausdehnen und Zusammenziehen des Körpers, in Folge dessen

auf kurzen hornartigen Fortsätzen gelegen sind. Ich trage kaum Bedenken, die ()effnungen für die der "Schalendrüse, " die hornartigen Fortsätze für Ueberbleibsel der Stirnhörner zu halten.

Fig. 59. Junge Peltogaster socialis, am Hinterleibe eines kleinen Einsiedlerkrebses; bei einem derselben sind die in der Leber des Krebses büschelförmig verzweigten Wurzeln gezeichnet. Thier lund Wurzeln dottergelb.

Fig. (it). Junge Sacculina purpurea mit ihren Wurzeln; das 'Thier purpurroth, die Wurzeln dunkelgrasgrün, 5 mal vergr. 
Wasser durch eine weite Oeffnung der Bruthöhle einströmt und wieder ausgetrieben wird. ${ }^{1}$

Von mehreren in Bau und Entwicklung abweichenden Rankenfüssern verdient hier Cryptophialus minutus Erwähnung, der von DARwin massenweise in der Schale der Concholepas peruriana bei den Chonos-Inseln gefunden wurde. Das anfangs elliptische Ei wird nach DAßwis bald am vorderen Ende breiter und erhält drei keulenförmige Hörner, eins hinten, eins an jeder Vorderecke; innre Theile sind jetzt noch nicht zu entdecken. Später schwindet das hintere Horn und im Innern der vorderen lassen sich die Haftfüsse erkennen. Aus dieser „ei-ähnlichen Larve (egg-like larva; - I hardly know, what to call it, sagt Darwin) geht unmittelbar die Puppe hervor. Ihr Panzer ist wenig seitlich zusammengedrückt und behaart, wie bei Sacculina purpurea, die Haftfüsse sind von ansehnlicher Grösse, Schwimmfüsse fehlen, wie beim erwachsenen Thiere die entsprechenden Rankenfüsse.

Zum Schlusse dieses Ueberblicks einige Worte über die fruhesten Entwicklungsrorgänge im Eie der Kruster. Vor Kurzem noch galt als

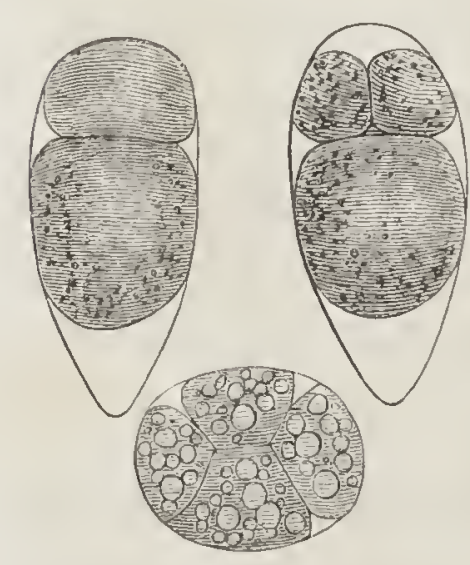

Fig. 61. 64 .

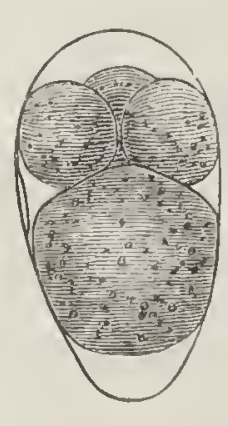

62. allgemeine Regel, dass sich durch theilweise Furchung des Dotters eine Keimscheibe und in dieser, der Bauchseite des Embryo entsprechend, ein Primitivstreifen bilde. Man weiss jetzt, dass bei den Copepoden (Cl.Aus), bei den Wurzelkrebsen (Fig. 64), und, wie ich 63. hinzusetzen kann, bei den Ranken-

1) Die Wurzeln der an einem kleinen Finsiedlerkrebse schmarotzenden Sacculina purpurea (Fig. 60) machen sich zwei schmarotzende Asseln zu Nutze, ein Bopyrus und der schon erwähnte Cryptoniscus planarioïdes (Fig. 12); sie siedeln sich unter der Sacculina an und bringen sie zum Absterben, indem sie die'von den Wurzeln zugeführte Nahrung vorwegnehmen; die Wurzeln aber wuchern auch ohne Sacculina weiter, und erlangen selbst, namentlich wo ein Bopyrus sich aus ihnen nährt, oft eine ungewöhnliche Ausdehnung.

Fig. 61. 62. 63. Eier von Tetraclita porosa in ker Furchung, 90 mal vergr. Die wrössere der beiden zuerst gebildeten Furchungskugeln ist stets dem spitzen Ende los Fies zugewandt.

Fig. 61. Ei ron Ternaeodiscus Porcellanae, in der Furchung, 90 mal vergr. 
füssern (Fig. 61-63) die Furchung eine totale ist, und die Embryonen ohne vorausgehenden Primitivstreifen in ihrer ganzen Gestalt angelegt werden. Wahrscheinlich wird Letzteres überall der Fall sein, wo die Jungen als wirkliche Nauplius, (und nicht blos mit Naupliushaut, wie bei Achtheres) ausschlüpfen. Beiderlei Entwicklungsweisen können bei nächstverwandten Thieren vorkommen, wie Achtheres unter den Copepoden beweist. '

\section{$\mathrm{X}$.}

Vielleicht vermag ein Anderer, glücklicher als ich, auch ohne DARWIN den leitenden Faden zu finden durch den Wirrwarr der bald bei nächsten Terwandten so himmelweit verschiedenen, bald bei Gliedern der entferntesten Kreise so überraschend ähnlichen Entwicklungsformen, die so eben flüchtig an uns vorüberzogen. Vielleicht vermag ein schärferes Auge mit Aciassiz den » seit Urbeginn feststehenden Plan des Schöpfers " ${ }^{2}$ herauszulesen, der auch hier wie ein portugiesisches Sprichwort sagt, ${ }^{3}$ " in krummen Linien gerade " geschrieben haben mag. Nir will es scheinen, dass von einem allgemeinen Plane, ron einer typischen, nach den einzelnen Abtheilungen, Ordnungen, Familien gegliederten Entwicklungsweise der Kruster kaum die Rede sein kann, wenn z. B. unter den langschwänzigen Krebsen der Flusskrebs in bleibender Gestalt, der Hummer mit Schizopodenfüssen, Palaemon wie die Krabben als Zoëia, Penēus wie die Rankenfüsser als Nauplius das Ei verlässt, und wenn immer noch in derselben Unterordnung der Langschwänze Palinurus und Mysis und Euphausia wieder andere und an-

1) Es ist nicht die Rede gewesen von den Pycnogoniden, weil ich sie nicht für Kruster halte; nicht von den Xiphosuren und Trilobiten, die ich nie selbst untersuchte, weil ich sie zu wenig kenne und namentlich mit den von BarRandE gegebenen Aufschlüssen über die Entwickelung der letzteren nicht im Einzelnen bekannt geworden bin.

2) "a plan fully matured in the beginning and undeviatingly pursued, "oder: "In the beginning His plan was formed and from it He has never swerred in any particular" Agassiz and Gould, Principles of Zoology.

3) "Deos escreve directo em linhas tortas. " Zum Lesen dieser sonderbaren Schrift bedarf man bekanntlich der Brille des Glaubens, die an's Mikroskop gewöhnten Augen selten passt. 
dere Jugendformen zeigen ; - wenn nene Gliedmassen bald als freie Stummel an der Bauchseite hervorspriessen, bald unter der glatt über sie hinweggehenden Haut sich bilden und beiderlei Entwicklungsweisen an verschiedenen Gliedern bei demselben Thiere, und an demselben Gliederpaare bei verschiedenen Thieren gefunden werden; - wenn bei den Podophthalmen die Gliedmassen des Mittel- und Hinterleibes bald alle gleichzeitig, bald jene und bald diese früher, und wenn wieder in jeder der beiden Gruppen bald alle Paare gleichzeitig auftreten, bald eines nach dem andern, - wenn unter den Hyperinen bei Phronima ein einfacher Fuss zur Scheere, hei Brachyscelus eine Scheere zum einfachen Fusse wird, u. s. w. --

Und doch sollte je nach der Lehre der Schule gerade in der Jugend, gerade im Laufe der Entwicklung der "Typus " am unverhülltesten hervortreten. Aber höron wir, was uns überhaupt die Schule über die Bedeutung der Entwicklungsgeschichte und ihre Beziehung zur vergleichenden Anatomie und Systematik sagt.

Lassen wir zwei ihrer bewährtesten Meister reden.

"Indem die vergleichende Anatomie, " sagte Johaxpes Müller 1844 in seinen Vorträgen über diese Wissenschaft, und die Ansichten meines unvergesslichen Lehrers sind lange Jahre die meinigen geblieben, - mindem die vergleichende Anatomie uns die unendlich mannichfache Gestaltung desselben Organes in der Thierwelt zeigt, gibt sie uns hierin das Mittel, durch Vergleichung dieser verschiedenen Formen das eigentlich Wesentliche, den Typus dieser Organe zu erkennen und davon alles Unwesentliche abzuscheiden. - Hierin dient ihr zur Controle oder Probe die Entwicklungsgeschichte. Da nämlich der Begriff der Entwicklung nicht der des Grösserwerdens ist, sondern der des Fortschritts von einem noch nicht Unterschiedenen, welches aber potentia die Unterschiede in sich enthält, zu einem actu Unterschiedenen, so leuchtet ein, dass je weniger ein Organ entwickelt ist, es sich um so mehr dem Typus nähert, und dass es bei seiner Entwicklung immer mehr Besonderheiten in sich aufuimmt. Die durch die rergleichende Anatomie und die durch die Entwicklungsgeschichte gefundenen Typen müssen nun übereinstimmen. " 
Nachdem Johaxies Müluer dann die Idee einer Stufenleiter der Thiere, und eines Durchlaufens mehrerer Thierstufen während der Entwicklung bekämpft, fährt er fort: "Das Wahre an dieser Idee ist, dass jeder Embryo anfangs nur den Typus seiner Abtheilung an sich trägt, woraus sich erst später der 'Typus der Klasse, Ordnung u. s. w. entwickelt."

Agassiz spricht sich 1856 in einem elementaren Werke, ' in das man doch nur aufzunehmen pflegt, was man als wohlgesichertes Besitzthum der Wissenschaft betrachtet, in folgender Weise aus:

"Die Eierstockseier aller Thiere sind vollkommen gleich, (identical), kleineZellen mit Dotter, Keimbläschen und Keimfleck ( ( 275). "Die Organe des Körpers werden gebildet in der Reihenfolge ihrer organischen Wichtigkeit; die wesentlichsten erscheinen immer zuerst. So die Organe des regetativen Lebens, Darm u. s. w. später als die des animalen Lebens, Nerrensystem, Skelet u. s. w., und diesen wieder gehen die allgemeineren Erscheinungen voraus, die dem Thiere als solchem zukommen " ${ }^{2}$ (\$. 31\$). "So bestehen beim Fische die ersten Veränderungen in der Dotterfurchung und der Bildung eines Keimes, - Vorgängen, die allen Thierklassen gemeinsam sind. Dann erscheint die Rückenfurche, die das Wirbelthier kennzeichnet, - das Hirn, die Simneswerkzeuge; später bilden sich Darm, Gliedmassen und die bleibende Form der Athmungswerkzenge, woraus mit Sicherheit die Klasse erkannt wird. Erst nach dem Ausschlüpfen bezeichnen die Eigenthünlichkeiten der Zahn - und Flossenbildung Gattung und Art. (\$. 319). "Daher gleichen Embryonen verschiedener Thiere einander um so mehr, je jünger sie sind." (\$. 320). "Somit ist die hohe Bedeutung der Entwicklungsgeschichte unzweifelhaft. Denn, wenn die Bildung der Organe stattfindet in der ihrer Wichtigkeit entsprechenden Ordnunga, so muss selbstverständlich

1) Principles of Zoology. Part I. Comparative Physiology. By Louis Agassiz and A. A. Gould. Revised Edition. Boston, 1556.

2) "and these, in turn, are preceded by the more general phenomena, belonging to the animal as such." 
of itselfi diese Reihenfolge ein Kriterium ihres verhältn is smässigen Werthes für die Systematik (classification) sein. Die Eigenthümlichkeiten welche früher erscheinen, soll man höher werthen should be considered of higher value), als die welche später erscheinen. " $\$$. 321). "Ein System um wahr und natürlichzu sein, muss übereinstimmen mitder Aufeinanderfolgeder Organe in der Entwicklung deș Embryo." (\$. 322).

Ich weiss nicht, ob noch heute Jemand geneigt sein wird, diese Sätze in ihrem ganzen Umfange zu unterschreiben. ' Sicher ist, dass im Wesentlichen gleiche Ansichten noch überall bei systematischen Erörterungen durchklingen, und dass sich bis in die letzten Jahre hinein die wenig glücklichen Versuche wiederholt haben, die Entwicklungsgeschichte als Grundlage der Systematik zu benutzen.

Wie stimmen nun mit diesen Sätzen unsere Erfahrungen aus der Entwicklungsgeschichte der Kruster? Dass diese Erfahrungen sich grösstentheils auf die " freie Terwandlung " nach dem Verlassen des Eies beziehen, kann der Anwendbarkeit der zunächst für die nembryonale Entwicklung " im Eie ausgesprochenen Sätze keinen Eịntrag thun; Agassiz selbst hebt herror (\$. 391), dass beiderlei Veränderungen von gleicher Natur und gleicher Wichtigkeit sind und dass kein wesentlicher Unterschied (any radical distinction) dadurch bedingt wird, dass die einen vor, die andern nach der Geburt stattfinden.

"Die Eierstockseier aller Thieresind identisch, kleine Zellen mit Dotter, Keimbläschen, Keimfleck. "Ja, etwa wie alle Insecten identisch sind, - kleine Thiere mit Kopf, Brust und Hinterleib, wenn man nämlich, nur das Gemeinsame berücksichtigend, absieht von der Terschiedenheit ihrer Entwicklung, von der Ab-oder Anwesenheit und dem mannichfaltigen Bau der Dotterhaut, von der wechselnden

1) Agassiz' eigene Ansichten sind neuerdings, soviel aus Rudolf Wagner's Anzeige seines "Essay on Classification "zu ersehen ist, wesentlich andre geworden. Eine Kritik der obigen älteren, aber noch heute weitrerbreiteten Ansichten trifft AGAssiz selbst nicht mehr. Seine neuere Auffassungsweise kenne ich leider eben nur aus R. IT.'s etwas confusem. Berichte und habe daher geglaubt, mir irgendwelche kritische Bemerkung über dieselbe nicht erlauben zu dürfen. 
Zusammensetzung des Dotters, der verschiedenen Zahl und Bildung der Keimflecken u. s. w. Zahlreiche, leicht zu vermehrende Beispiele solcher tiefgreifenden Verschiedenheiten gibt LEydic's Lehrbuch der Histologie. - Bei den Krustern liefern die Eierstockseier sogar bisweilen treffliche Merlimale zur Unterscheidung von Arten derselben Gattung, wie sie z. B. bei einer hiesigen Porcellana schwärzlichgrün, bei einer zweiten dunkelblutroth, bei einer dritten dottergelb sind; und innerhalb derselben Ordnung zeigen sie erhebliche Unterschiede in der Grösse, die, wie schon vax Benedex und Claus hervorgehoben, in innigem Zusammenhang steht mit der späteren Fntwicklungsweise.

"Die Organe des Körpers werden gebildet in der Reihenfolge ihrerorganischen Wichtigkeit; diewesentlichsten erscheinen immer zuerst. "Man könnte den Satz ron rornherein als unbeweisbar bezeichnen, da es unmöglich ist, sei es in Allgemeinen, sei es für ein besonderes Thier eine Reihenfolge der Wichtigkeit unter gleich unentbehrlichen Theilen festzustellen. - Was ist wichtiger, Lunge oder Herz? - Leber oder Niere? - Arterie oder Tene? - Man könnte statt wie Agassiz die Organe des animalen Lebens, mit gleichem Rechte die des regetativen Lebens rorausstellen, da wohl diese ohne jene, nicht aber jene ohne diese denkbar sind. Man könnte einwenden, dass je nach diesem Satze provisorische Organe als die früher entstandenen an Wichtigkeit die bleibenden später gebildeten übertreffen müssten. - Aber halten wir uns an die Kruster. Bei Polyphemus findet LExDig schon während der Furchung die erste Anlage des Darmrohrs. Bei Mysis bildet sich zuerst ein provisorischer Schwanz, bei Ligia eine madenförmige Larrenhaut. Das einfache unpaare Ange entsteht früher und wäre also wichtiger, als die zusammengesetzten paarigen; die Schuppe des Garneelenfühlers wichtiger, als die Geissel; die Kieferfüsse der Krabben und Krebse wichtiger als Scheeren und Gangfüsse, bei den Asseln die sechs vorderen Fusspaare wichtiger, als das ganz gleich gebildete siebente; bei den Amphipoden das wichtigste aller Organe der bald nach dem Ausschlüpfen spurlos verschwindende "Mikropylapparat «; bei den Cyclopen wichtiger als alle Schwimmfüsse die Borsten des Schwanzes, bei den Cirripedien die hinteren Fühler, 
von deneñ man nicht weiss, wo sie bleiben, wichtiger als die Rankenfüsse u.s. w. Die unwesentlichsten aller Organe wären die Geschlechtstheile, die wesentlichste Eigenthümlichkeit aber läge in der bis aut"s Eierstocksei zurückführbaren Farbe.

"Embryonen, Jugendzustände verschiedener Thiere gleichen einander um so mehr je jünger sie sind, "oder wie Johannes MüLler es ausdrückt, "nähern sich um so mehr dem gemeinsamen Typus. " So vers̈chieden die Begriffe sein mögen, die man mit dem Worte Typus verbindet, so wird doch Niemand bestreiten, dass die typische Form des vorletzten Fusspaares der Amphipoden die eines einfachen Gangfusses, und nicht die einer Scheere ist; denn letztere findet sich bei keinem einzigen erwachsenen Amphipoden; man kennt sie nur von den Jungen der Gattung Brachyscelus, die sich also hierin unzweifelhaft weiter vom Typus ihrer Ordnung entfermen, als die Alten. Dasselbe gilt von den jungen Männchen der Strandhüpfer (Orchestia) in Bezug auf das zweite Paar der Vorderfüsse (Gnathopoda). Ebenso wird kaum Jemand anstehen, den Besitz von sieben Fusspaaren als »typische " Eigenthümlichkeit der Edriophthalmen anzu. erkennen, die Agassiz gerade danach Tetradecapoden nennt, die jungen Asseln, die Dodecapoden sind, stehen auch hier dem "Typus “ ferner als die Alten.

Regel ist allerdings, und so lässt es DARwin's Lehre erwarten, dass im Fortschritte der Entwicklung die anfangs ähnlicheren Formen immer weiter auseinandergehen; aber hier, wie in anderen Klassen, sind die Ausnahmen, für die die Schule keine Erklärung hat, zahlreich. Nicht selten kömnte man den Satz geradezu umkehren und behaupten, dass die Terschiedenheit um so grösser wird, je weiter man in der Entwicklung zurückgeht, und das nicht nur in Fällen, wo ron zwei nahestehenden Arten die eine sich direct entwickelt, die andere mehrfache Larrenzustände durchläuft, - wie etwa der Flusskrebs und die aus Naupliusbrut hervorgehenden Garneelen. Man kann dasselbe sagen z. B. von Asseln und Amphipoden; bei den erwachsenen Thieren ist die Gliedmassenzahl dieselbe; man kann beim ersten Anblick eines Cyrtophium, einer Dulichia, man kann selbst nach sorgfältiger Untersuchung einer 
Scheerenassel in Zweifel bleiben, ob man eine Assel oder einen Amphipoden vor sich habe, bei den ausschlüpfenden Jungen ist die Zahl der Gliedmassen verschieden und geht man zurück ins Eileben, so genügt der flüchtigste Blick, um an der Krümmung nach oben oder unten selbst die jüngsten Embryonen der beiden Ordnungen zu unterscheiden.

In anderen Fällen gehen die Wege, die ron gleichem Ausgangspuncte zu gleichem Ziele führen, in der Mitte der Entwicklung weit auseinander, wie bei den oben geschilderten Garneelen mit Naupliusbrut.

Endlich, damit auch die letzte Möglichkeit erschöpft werde, kommt es ror, dass die grösste Aehnlichkeit in die Mitte der Entwicklung fällt. Das schlagendste Beispiel liefern Rankenfüsser und Wurzelkrebse, mag man nun die beiden Ordnungen mit einander, oder die Glieder einer jeden unter sich rergleichen; aus ganz verschieden ablaufender Furchung (s. Fig. 61-64) gehen mannichfaltige Nauplius herror, diese rerwandeln sich in äusserst ähnliche Puppen und aus den Puppen werden wieder himmelweit rerschiedene geschlechtsreife Thiere.

"Wenndie Bildung der Organe stattfindet in derihrer Wichtigkeit entsprechenden Ordnung, so muss selbstverständlich diese Reihenfolge ein Kriterium ihres verhältnissmässigen Wrerthes fürdie Systematiksein. "- Voransgesetzt nümlich, dass physiologischer und systematischer Werth eines 0rganes zusammenfallen! - Wie es in christlichen Landen eine Katechismusmoral gibt, die Jeder im Munde führt, Niemand zu befolgen sich rerpflichtet hält oder von Anderen befolgt zu sehen erwartet, so hat auch die Zoologie ihre Dogmen, die man ebenso allgemein bekennt, als in der Praxis verläugnet. Ein solches Dogma ist die ron Agassiz stillschweigend gemachte Voraussetzung. Unter Hundert, die sich gedrungen fühlen, als Einleitung eines Handbuchs oder einer monographischen Arbeit ihr systematisches Glaubensbekenntniss abzulegen, werden Neun und neunzig damit beginnen, dass ein natürliches System sich nicht auf ein einziges Merkmal stützen dürfe, sondern alle Merkmale, den gesammten Bau des Thieres zu berücksichtigen habe, dass man aber diese Merkmale nicht wie gleichnamige Grössen einfach summiren dürfe, dass man sie nicht zählen sonder'n wägen und das jedem einzel- 
nen beizulegende Gewicht nach seiner physiologischen Bedeutung be messen müsse. - Vielleicht folgt dann noch einiges allgemein gehaltene Wortgeklingel über die rergleichungsweise Wichtigkeit ron animalen und regetativen Organen, von Kreislauf, Athmung u. dgl. -- Geht es aber an die eigentliche Arbeit, an das Sichten und Anordnen der Arten, Gattungen, Familien u. s. w., so wird wahrscheinlich nicht Einer der Neun und neunzig sich dieser schönen Regeln erinnern und den hoffnungslosen Versuch ihrer Durchführung im Einzelnen unternehmen. -Agassiz z. B. betrachtet wie Curier und im Gegensatz zur Mehrzahl der deutschen und englischen Zoologen die Strahlthiere als eine der grossen Hauptabtheilungen des Thierreichs, trotzdem dass Niemand etwas weiss über die Bedeutung der strahligen Anordnung für das Leben dieser Thiere, und trotzdem dass die strahligen Echinodermen aus bilateralen Larven hervorgehen. Die " eigentlichen Fische " theilt derselbe in Ctenoïden und Cycloïden, je nachdem der Hinterrand der Schuppen gezähnelt oder glatt ist, --- ein Umstand, dessen Wichtigkeit für das Thier verschwindend klein sein muss gegen die Eigenthümlichkeiten der Bezahnung, der Flossenbildung, der Wirbelzahl u. s. w.

Um zu unserer Klasse der Kruster zurückzukehren, hat man bei deren Eintheilung etwa auf die Unterschiede in den "wesentlichsten Organen "vorwaltende Rücksicht genommen? - Etwa auf das Nervensystem? - Bei den Corycaeiden fand Crats alle Bauchganglien in eine einzige breite Masse verschmolzen, bei den Calaniden eine lange Bauchganglienkette, jene also hierin den Spinnenkrabben, diese dem Hummer ähnlich, aber Niemandem fällt es im Traume ein, deshalb an eine Verwandtschaft der Corycaeiden mit den Krabben, der Calaniden mit den Krebsen zu denken. -- Oder auf die Organe des Kreislaufs? - Aber da stehen unter den Copepoden die Cyclopiden und Corycaeiden ohne Herz neben den Calaniden und Pontelliden mit einem Herzen. Und ebenso stellen sich unter den Ostracoden neben die herzlosen Cypris und Cythere die, wie ich finde, ein Herz besitzenden Cypridinen. Oder auf die Athmungswerkzeuge? - Milje Edwards hatte es gethan als er die Mysis und Leucifer von den Decapoden trennte, aber er selbst hat dies später als Fehlgriff erkannt. Bei einer Cypridina sehe ich an- 
sehnliche Kiemen, die ich bei einer zweiten Art vollständig vermisse, aber dies scheint mir kein Grund diese Arten selbst nur generisch zu trennen. -

Auf der anderen Seite, was wissen wir von der physiologischen Bedeutung der Segmentenzahl und all der Dinge, die wir als typische Eigenthümlichkeiten der verschiedenen Ordnungen zu betrachten, denen wir den höchsten systematischen $W$ erth beizulegen pflegen?

"Die Eigenthümlichkeiten, welche früher erscheinen, soll man höher werthen, als die welche später erscheinen. Ein System um wahr und natürlich zu sein, muss übereinstimmen mit der Aufeinanderfolge der Organe in der Entwicklung des Embryo. "Sind früher erscheinende Eigenthümlichkeiten höher zu werthen, als später auftretende, so wird in Fällen wo der Bau des erwachsenen Thieres die eine, der Bau der Larve eine andre Stellung im System fordert, nicht jenes, sondern diese den entscheidenden Ausschlag zu geben haben. Wie man Lernaeen und Rankenfüsser um ihrer Naupliusbrut willen aus ihrem früheren Verbande löste und den Krustern zuwies, so wird man aus gleichem Grunde Peneus von den Garneelen trennen und mit Copepoden und Rankenfüssern vereinigen müssen. Aber davor dürfte wohl auch der eifrigste Embryomane zurückschrecken.

Ein » wahres und natürliches System " der Kruster würde der Reihenfolge der Erscheinungen nach in erster Linie die verschiedene Weise der Furchung, dann die Lagerung des Embryo, weiterhin die Zahl der im Ei angelegten Gliedmassen u. s. f. zu berücksichtigen haben und dürfte sich etwa in folgender W eise darstellen:

\section{Classis Crustacea.}

Suluclass. I. Holoschista. Totale Furchung. Kein Primitivstreifen. Naupliusbrut.

Ord. 1. Ceratometopa. Nauplius mit Stimhörnern. (Rankenfüsser, Wurzelkrebse). 
Ord. 2. Leiome topa. Nauplius ohne Stimhörner. Copepoden, ohne Achtheres u.s. w., Phyllopoden, Penēus).

Subclass. II. Hem is chista. Keine totale Furchung.

$A$. Nototropa. Embryo aufwärts gekrümmit.

Ord. 3. Protura. Der Schwanz bildet sich zuerst (Mysis).

Ord. 4. Sa c comor pha. Eine madenförmige Larrenhaut bildet sich zuerst. (Asseln).

B. Gasterotropa. Embryo bauchwärts gekrümmit.

Ord. 5. Zoëogona. Gliedmassen nicht vollzählig im Ei angelegt. Zoëabrut. (Mehrzahl der Podophthalmen).

Ord. 6. Ametabola. Gliedmassen rollzählig im Ei angelegt. (Astacus. Gecarcinus. Amphipoden, ohne Hyperia?

Die Probe nnag genügen. Je weiter man auf diesem Wege ins Einzelne einginge, um so glänzender würde sich, wie man sich denken kann, die Natürlichkeit einer solchen Anordnung herausstellen.

Alles in Allem genommen, so darf man wohl das Urtheil, das Agassiz über DARwin's Lehre aussprach, mit weit grösserem Rechte auf die eben beleuchteten Sätze anwenden: "Keine Theorie, so plausibel sie auch erscheinen mag, kann in der Wissenschaft zugelassen werden, wenn sie nicht durch Thatsachen unterstützt wird."

\section{XI.}

Von dem nicht wohl zu umgehenden unerquicklichen Seitenblicke auf die Schule, die so rornehm herabzublicken weiss auf den "geistreichen Traum "DARwix"s und auf die "schwindelhafte Begeisterung " seiner Freunde, wende ich mich zu der angenehmen Aufgabe, die Entwicklungsgeschichte der Kruster aus dem Gesichtspuncte der DARwIx' schen Lehre zu betrachten.

DARWix selbst hat bereits die aus seinen Voraussetzungen für das Gebiet der Entwicklungsgeschichte sich ergebenden Folgerungen im dreizehnten Kapitel seines Buches erörtert. Für eine mehr ins Einzelne 
gehende Anwendung wird es indess nöthig, zunächst im Allgemeinen diesen Folgerungen etwas weiter nachzugehen, als es dort geschehen ist.

Die Veränderungen, durch welche sich Junge von ihren Erzeugern entfermen und deren allmähliche Häutung die Entstehung neuer Arten, Gattungen, Fanilien reranlasst, können in früherem oder späterem Lebensalter auftreten, in der Jugend oder zur Zeit der Geschlechtsreife. Denn letztere ist bei weitem nicht immer eine Zeit des Stillstandes, wie bei den Insecten; die meisten anderen Thiere fahren auch damn noch fort, zu wachsen und sich zu verändern. (Man rergl. das oben über die Männchen der Amphipoden Bemerkte. Gewisse Abweichungen können sngar ihrer Natur nach erst eintreten, wemn das Junge die Entwicklungsstufe der Eltern erreicht hat. So besitzen die Seeraupen (Polynoë) anfangs nur wenige Leibesringe, die während der Entwicklung allmählich zu einer für verschiedene Arten verschiedenen, für jede derselben beständigen Zahl anwachsen; ehe nun ein Junges die Ringzahl seiner Eltern überschreiten könnte, musste es sie natürlich erreicht haben. Man wird einen ähnlichen nachträglichen Fortschritt überall vermuthen dürfen, wo die Abweichung der Nachkommen in einem Zuwachse neuer Ringe und Gliedmassen besteht.

Die Nachkommengelangen also zu einem neuen Ziele entweder indem sie schon auf dem Wege zur elterlichen Form früher oder später abiren, oder indem sie diesen Weg zwar unbeirt durchlaufen, aber dann statt stille zu stehen noch weiter schreiten.

Die erstere Weise wird rorwiegend gewirkt haben, wo die Nachkommenschaft gemeinsamer Ahnen einen in den wesentlichsten Zügen auf gleicher Stufe stehenden Formenkreis bildet, wie etwa sämmtliche Amphipoden, oder Krabben, oder Vögel. Dagegen wird man zur Annahme der zweiten Weise des Fortschreitens geführt, sobald man ron gemeinsamer Stammform Thiere abzuleiten sucht, ron denell die einen übereinstimmen mit Jugendzuständen der anderen.

Im ersteren Falle wird die Entwicklungsgeschichte der Nachkommen mit der ihrer Torfahren nur bis zu dem Puncte zusammenfalleu 
können, an dem ihre Wege sich schieden, über deren Bau im erwachsenen Zustande wird sie nichts lehren. Im zweiten Falle wird die ganze Entwicklungder Vorfahren auchvonden Nachkommen durchlaufen und soweit daher die Entstehung einer Art a uf dieser zweiten Weise des Fortschreitens beruht, wird diegeschichtliche Entwicklung der Art sichabspiegeln in deren Entwicklungsgeschichte. - In der kurzen Frist weniger Wochen oder Monden führen die wechselnden Formen der Embryonen und Larven ein mehr oder minder vollständiges, mehr oder minder treues Bild der Wandlungen an uns vorüber, durch welche die Art im Laufe ungezählter Jahrtausende zu ihrem gegenwärtigen Stande sich emporgerungen hat.

Eines der einfachsten Beispiele bietet

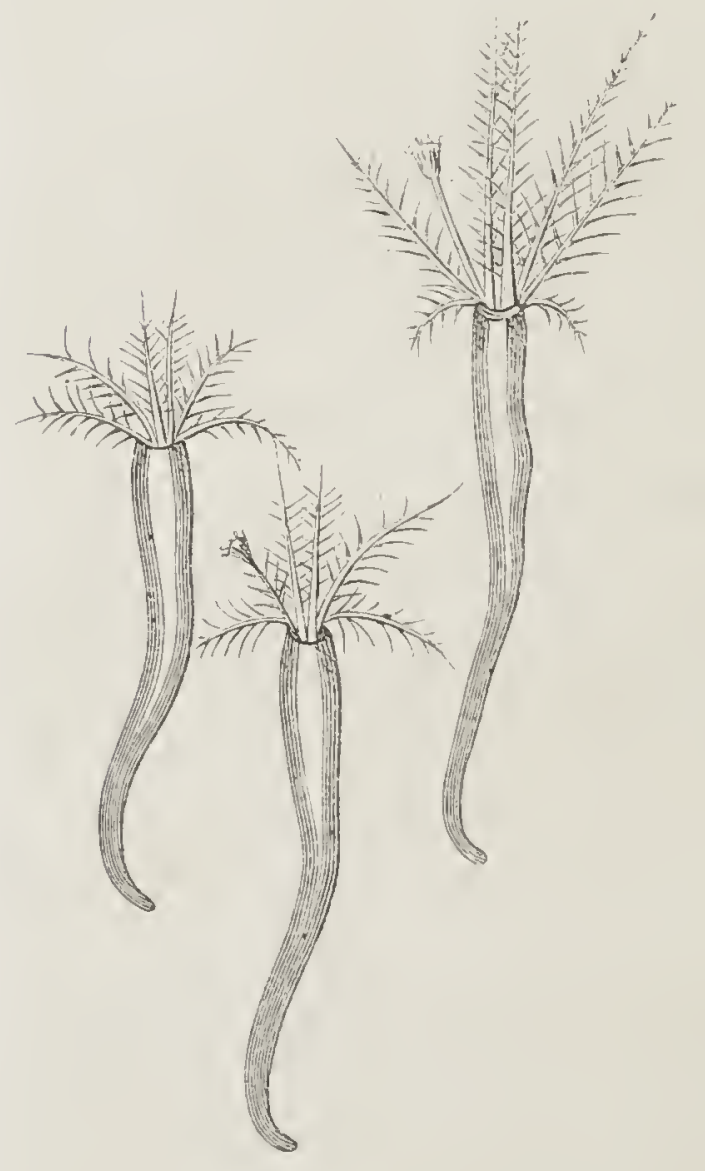
die Entwicklung der Wurmröhren. Gerade durch seine Einfachheit aber scheint es geeignet, auch Manchem, der nicht seher möchte, die Augen zu öffnen, und mag deshalb hier Platz finden. Vor drei Jahren fand ich an der Wand eines meiner Gläser einige kleine Wurmröhren (Fig. 65), deren Bewohner drei Paar bärtige Kiemenfäden trugen und eines Deckels entbehrten. Man hätte sie danach zur Gattung Protula stellen müssen. Wenige Tage später hatte sich einer der Kiemenfäden am Ende zu einem keulenförmigen Deckel verdickt (Fig. 66.). Fig. 65. 66. $6 \overline{6}$. Jetzt erinnerten die Thiere durch den

Fig. 65-67. Junge Wurmröhre, mit der einfachen Linse, etwa 6 mal rergr. Fig. 65. ${ }^{1}$ ohne Deckel, Protulastufe.

Fig. 66. mit bärtigem Deckelstiel, Filogranastufe.

Fig. 67. mit nacktem Deckelstiel, Serpulastufe.

1) Fig. 65 ist aus der Erinnerung gezeichnet, da mir die Thierchen, die ich anfangs für junge Portula nahm, erst merkwürdig wurden und ich sie zeichnete, als ich das Auftreten des Deckels bemerkte. 
bärtigen Deckelstiel an die Gattung Filograna, nur dass diese zwei Deckel besitzt. Nach weiteren drei Tagen, während deren ein neues Paar Kiemenfäden hervorgesprosst war, hatte der Deckelstiel seine seitlichen Fäden verloren (Fig. 67) und die Würmer waren zu Serpula geworden. Hier bietet sich von selbst die Annahme, dass die Urwurmröhre eine Protula war, - dass einige Nachkommen derselben, die sich bereits zu rollständigen Protula entwickelt hatten, nachträglich sich durch die Bildung eines Deckels vervollkommneten, der ihre Röhre vor feindlichen Eindringlingen schützte, - dass spätere Nachkommen dieser letzteren endlich die seitlichen Fäden des Deckelstiels wieder verloren, die sie wie ihre Torfahren entwickelt hatten.

Was sagt die Schule zu diesem Falle? Woher und wozu, wenn die Serpula als fertige Arten entstanden oder erschaffen wurden, diese seitlichen Fäden des Deckelstiels? Sie blos um eines einmal entworfenen unabänderlichen Bauplanes willen herrorspriessen zu lassen, selbst wenn sie sofort wieder als überflüssig eingezogen werden mussten, wäre doch sicher eher Beweis kindischer Tändelei oder schulmeisterlichen Pedantismus, als unendlicher Weisheit. Aber nein, ich irre mich, von Urbeginn her wusste ja auch der Schöpfer, dass einst neugierige Menschenkinder über Analogien und Homologien grübeln, dass christliche Naturforscher sich abmühen würden, seine Schöpfungsgedanken nachzudenken; - jedenfalls, um diesen die Einsicht zu erleichtern, dass der Deckelstiel der Serpula einem Kiemenfaden homolog sei, liess er denselben bei seiner Entwicklung einen Tmweg machen und durch die Form eines bärtigen Kiemenfadens hindurchgehen.

Die in der Entwicklungsgeschichte erhaltene ge schichtliche Urkunde wird all mählich verwischt, indem die Entwicklung einen immer geraderen Wegrom Ei zum fertigen Thiere einschlägt, und sie wird häufig gefälscht durch den Kampf ums Dasein, den die freilebenden Lar. ven zu bestehen haben.

Wie nämlich das Gesetz der Erblichkeit kein strenges ist, wie es individuellen Schwankungen Raum gibt in Betreff der Form der Eltern, so gilt ein Gleiches auch für die Zeitfolge der Entwicklungsvorgänge. 
Jeder Familienvater, der darauf Acht hatte, weiss ja, dass selbst bei Kindern derselben Eltern z. B. die Zähne weder in genau demselben Alter, noch in derselben Folge hervorbrechen oder gewechselt werden. - Nun wird es im Allgemeinen einem Thiere ron Nutzen sein, der Vorzüge, durch die es im Kampfe ums Dasein sich behauptet, so früh als möglich theilhaftig zu werden. Ein verfrühtes Auftreten später erworbener Eigenthümlichkeiten wird meist Vortheil, ein verspätetes Nachtheil bringen; ersteres, wo es einmal zufällig sich zeigt, wird durch die natürliche Auslese erhalten werden. Ebenso jede Abänderung, die den Kreuz- und Querzügen durch mannichfache Larvenzustände eine mehr geradlinige Richtung gibt, den Entwicklungsgang vereinfacht, abkürzt, in frühere Lebenszeit und endlich ins Eileben zurückdrängt.

Da dieser Uebergang einer durch verschiedenartige Jugendzustände hindurchgehenden in eine mehr unmittelbare Entwicklung nicht Folge eines inwohnenden mystischen Triebes, sondern abhängig ist von zufällig sich bietenden Fortschritten, so wird derselbe bei nächstverwandten Thieren auf die verschiedenste $W$ eise vor sich gehen und sehr verschiedene Zeit zu seinem Ablaufe erfordern können. Eines ist jedoch hierbei nicht zu übersehen. Die geschichtliche Entwicklung der Art dürfte schwerlich je im fortwährend gleichmässigen Flusse vor sich gegangen sein; Zeiten der Ruhe werden mit Zeiten rascheren Fortschreitens gewechselt haben. Formen nun, die in Zeiten rascheren Fortschrittes nach kurzem Bestande von anderen abgelöst wurden, dürften auch der Entwicklungsgeschichte der Nachkommen sich weniger tief' eingeprägt haben, als solche, die in Zeiten der Ruhe bei einer langen Reihe aufeinanderfolgender Geschlechter sich unverändert wiederholten. Diese besser befestigten Formen, weniger zu Abänderungen geneigt, werden bei dem Uebergange zu directer Entwicklung zäheren Widerstand leisten und auch bei sonst noch so verschiedenem Verlaufe dieses Vorganges in gleichmässiger Weise und bis zuletzt sich erhalten.

Im Allgemeinen wird es wie gesagt den Jungen rortheilhaft sein, in Gestalt der Eltern, mit all deren Vorzügen ausgerüstet den Kampf ums Dasein zu beginnen, im Allgemeinen, - doch nicht ohne Ausnahmen. Dass festsitzenden Thieren eine der Ortsbewegung fähige Brut 
fast unentbehrlich ist, dass die.munter durchs Meer schwärmenden Larven träger Schnecken, im Boden wühlenden Gewürmes u. s. w. durch Ausstreuen der Art über weitere Strecken wesentliche Dienste leisten, liegt auf der Hand. In andern Fällen ist eine Verwandlung dadurch unentbehrlich geworden, dass sich eine Theilung der Arbeit zwischen den verschiedenen Lebensaltern herausgebildet hat, dass z. B. die Larven ausschliesslich das Geschäft der Ernährung übernomınen haben. - Ein fernerer in Betracht zu ziehender Umstand liegt in der Grösse der Eier, ein einfacher Bau ist mit weniger Stoff herzustellen, als ein mehr zusammengesetzter; je unvollkommner die Larre, um so kleiner kann das Ei sein, eine um so grössere Menge derselben kann die Mutter bei gleichem Aufwand an Stoff liefern. In der Regel, glaube ich, wird zwar dieser Vortheil einer zahlreicheren den einer vollkommneren Brut bei weitem nicht aufwiegen; wohl aber in Fällen, wo die Hauptschwierigkeit für die Jungen darin besteht, einen passenden Ort für ihre Entwicklung zu finden und wo es daher gilt, die grösstmögliche Menge ron Keimen auszustreuen. So bei vielen Schmarotzern.

Es mag hier, wo vom Uebergang der ursprünglichen Entwicklung mit Verwandlung in directe Entwicklung die Rede ist, an der Stelle sein, cin Wort zu sagen über den oben berührten Mangel der Verwandlung bei Süsswasser - und Landthieren, deren meerbewohnende Verwandte noch eine solche durchlaufen. Dieses Verhalten scheint in zwiefacher Weise erklärbar. Entweder wanderten besonders Arten ohne Verwandlung ins süsse Wasser ein, oder die Verwandlung wurde bei den Uebergesiedelten rascher beseitigt, als bei den im Meere zurückgebliebenen Genossen.

Thiere ohne Verwandlung konnten natürlich leichter übersiedeln, da sie nur sich selbst und nicht zugleich mannichfache Jugendformen den neuen Verhältnissen anzuschmiegen hatten. Bei Thieren mit Verwandlung aber musste im Allgemeinen die immer bedeutende Sterblichkeit der Larven eine noch grössere sein in neuen, als in altgewohnten Verhältnissen; jeder Schritt zur Vereinfachung des Entwicklungsganges musste also hier ein noch grösseres Uebergewicht über die Artgenossen geben und das Verwischen der Verwandlung daher rascher vor sich 
gehen. Was in jedem Einzelfalle stattgefunden hat, ob die Art einwanderte, nachdem sie die Verwandlung verloren, - oder die Verwandlung verlor, nachdem sie einwanderte, wird nicht immer leicht zu entscheiden sein. Wo meerbewohnende Verwandte ohne oder mit geringer Verwandlung sich finden, wie der Hummer als Vetter des Flusslirebses, wird man nach der ersteren, - wo auf dem Lande oder im süssen Wasser noch Verwandte mit Verwandlung leben, wie bei Gecarcinus, zu letzterer Annahme greifen dürfen.

Wie neben diesem allmählichen Verklingen der Urgeschichte zugleich eine Fälschung der in der Entwicklungsgeschichte niedergelegten Urkunde stattfinde durch den Kampf ums Dasein, den die freilebenden Jugendzustände zu bestehen haben, bedarf keiner weiteren Ausführung. Denn selbstverändlich muss auf Larven, die für sich selbst zu sorgen haben, der Kampf ums Dasein und die damit verbundene natürliche Auslese in gleicher Weise verändernd und fortbildend wirken, wie auf erwachsene Thiere. Die von den Fortschritten des erwachsenen Thieres unabhängigen Veränderungen der Larve werden um so bedeutender sein, je länger die Lebensdauer der Larve im Vergleich zu der des erwachsenen 'Thieres, je abweichender ihre Lebensweise und je schärfer ausgesprochen die Theilung der Arbeit zwischen den verschiedenen Entwicklungsstufen. Diese Vorgänge haben in gewisser W eise eine dem allmählichen Verklingen der Urgeschichte entgegengesetzte Wirkung; sie vergrössern die Unterschiede zwischen den einzelnen Entwicklungsstufen und man begreift, wie selbst ein geradliniger Entwicklungsgang durch sie wieder in eine Entwicklung mit Verwandlungen umgebildet werden kann. So lassen sich manche und wie mir scheint triftige Gründe für die Ansicht geltend machen, dass die ältesten Insecten den heutigen Geradflüglern, vielleicht den flügellosen Schaben, näher standen als irgend einer anderen Ordnung und dass die »vollkommene Terwandlung " der Käfer, Schmetterlinge u. s. w. späteren Ursprungs ist. Es hat, glaube ich, früher vollkommnere Insecten, als Raupen oder Puppen, dagegen weit früher Nauplius und Zoëa als vollkommene Garneelen gegeben. Man könnte im Gegensatz zu der ererbten Verwand- 
lung der Garneclen, die der Käfer, Schmetterlinge u. s. w. eine er worbene nennen.

Welche der verschiedenen zur Zeit in einer Thierklasse bestehenden Entwicklungsweisen beanspruchen dürte, als die der ursprünglichen zunächst stehende zu golten, ist nach dem Obigen leicht zu ermessen.

DieUrgeschichteder Artwirdin ihrer Entwicklungsgeschichte um so vollständiger erhalten sein, je länger die Reihe der Jugendzustände ist, die sie gleichmässigen schrittes durchläuft, und um sotreuer, je weniger sich die Lebensweise der Jungen von der der Alten entfernt, und je weniger die Eigenthümlichkeiten der einzelnen Jugendzustände als a us späteren in fä̈here Lebensabschnitte zurückverlegt oder als selbstständig erworben sich auffassen lassen.

Machen wir die Anwendung auf die Kruster.

\section{XII.}

Nach allen im letzten Satze aufgestellten Kemzeichen erschcint bis jetzt die Garneele, die wir (Fig. 2S-31) von Nauplius durch Zoëa und Mysis ähnliche Zustände bis zur Gestalt eines langschwänzigen Krebses begleiteten, als dasjenige Thier, welches in Bereiche der höheren Kruster Malacostraca) die vollständigste und treueste Kunde gibt ron seiner Urgeschichte. Die vollständigste, das licgt auf der Hand. Die treueste, das ist anzunehmen, einmal weil die Lebensweise de. einzelnen Altersstufen eine minder verschicdene ist, als bei der Mehrzahl der übrigen Podophthalmen; - denn vom Nauplius bis zur jungen Garneele wurden sie frei schwimmend in Mcere getroffen, während Krabben, Porcellanen, die Tatuira, Squilla und viele Langschwänze erwachsen unter Steinen, in Felsspalten, Erdlöchern, unterirdischen Gängen, im Sande u.s.w. sich anfzuhalten pflegen, noch abweichenderer Sitten nicht zu gedenken, wic sie Einsiedlerkrebse, Muschchwächter u. s. w. zeigen, - und zweitens vorzüglich weil die Eigenthümlichkeiten, die namentlich die Zoëa dieser Art ror anderen Zoëa auszeichnen, 
die Benutzung der vordersten Gliedmassen zum Schwimmen, der gablige Schwanz, das einfachere Herz, der anfängliche Mangel der parigen Augen und des Hinterleibes u. s. w.), weder aus einem Zurückverlegen später erworbener Vorzüge in dieses frühere Lebensalter abzuleiten sind, noch überhaupt als Vorzüge vor anderen Zoëa erscheinen, welche die Larve im Kampfe um's Dasein erworben haben könnte.

Eine ähnliche Entwicklung musste einst der Urahn aller Malacostraca durchlaufen, verschieden von der unserer Garneele wohl besonders dadurch, dass sie noch gleichmässigeren Schrittes durchmessen wurde ohne die plötzlichen Wechsel der Form und der Bewegungsweise, die bei letzterer besonders daraus entstehn, dass bei dem Nauplius gleichzeitig vier, bei der Zoëa gleichzeitig fünf Gliedmassenpaare herrorspriessen und mit einem Male in Thätigkeit treten. Es ist anzunehmen, dass sich nicht nur ursprünglich, sondern auch noch bei den Larven der ersten Malacostraca die neuen Leibesringe und Gliedmassenpare einzeln, zuerst die Ringe des Vorderleibes, dann des Hinterleibes, und zuletzt des Mittelleibes, und zwar in jedem Leibesabschnitte die vorderen früher als die hinteren bildeten, zuletzt also von allen der hinterste Ring des Mittelleibes. - Von dieser ursprünglicheren Weise sind heute noch mehr oder minder deutliche Spuren selbst bei Arten geblieben, bei denen sonst der Entwicklungsgang der Vorfahren schon ziemlich verwischt ist. So bilden sich einzeln, ron vorn nach hinten, die Hinterleibsfüsse der Fig. 33 gezeichneten Garneelenlarve und später als sie die letzten Füsse des Mittelleibes; so bei Palinurus die beiden letzten Fusspaare des Mittelleibes später als die übrigen; so entbehren bei jungen Maulfüsserlarven noch die drei letzten Hinterleibsringe, bei älteren noch der letzte dersclben der Gliedmassen; so entsteht bei den Asseln noch heute das geschichtlich jüngste Fusspaar später als alle übrigen. Vollständiger erhalten, als bei irgend einem der höheren Kruster ist diese schrittweise von vorn nach hinten vorrückende Bildung neuer Leibesringe und Gliedmassen bei den Copepoden ${ }^{1}$.

1) Man weiss, dass in mehreren Fällen selbst bei erwachsenen 'Thieren der letzte Ring des Mittelleibes oder einige der letzten entweder ihrer Gliedmassen entbehren oder selbst röllig fehlen. (Entoniscus Porcellanae $\sigma^{\top}$, Leucifer u. s. w.). 


\section{3}

Die ursprüngliche von der niedersten Stufe, die wir überhaupt freilebend in der Klasse der Kruster kennen, von Nauplius ausgehende Entwicklung der Malacostraca ist heute bei der Mehrzahl derselben ziemlich rerwischt. Dass dieses Verwischen wirklich in der Weise ror sich gegangen, die oben aus DARwin's Lehre als deren unmittelbare Folge abgeleitet wurde, wird um so leichter nachzuweisen sein, je mehr dieser Vorgang noch im lebendigen Flusse begriffen, je weniger vollständig er bereits abgelaufen ist. Die schlagendsten Beispiele darf man in der noch unbekannten Entwicklungsgeschichte der verschiedenen Schizopoden, Perieiden überhaupt der langschwänzigen Krebse zu erhalten hoffen. Für jetzt erscheinen als besonders lehrreich die mannichfachen Zoëaformen. Fast alle Eigenthümlichkeiten, durch die sie sich von der Urform der Penëus-Zoëa (Fig. 29, 30, 32) entfernen, lassen sich in der That auffassen als aus späterer Zeit in diesen früheren Lebensabschnitt zurückverlegt. So die grossen zusammengesetzten Augen; so die Bildung des Herzens; so die Raubfüsse bei Squilla; so der kräftige, musculöse, gerade ausgestreckte Hinterleib bei Palaemon, Alpheus, Hippolyte und den Einsiedlerkrebsen; - - bei letzteren ist gegenwärtig der Hinterleib des erwachsenen Thieres freilich ein ungeschlachter mit Leber und Geschlechtstheilen gefüllter Sack, aber ziemlich kräftig noch auf der Glaucothoëstufe, und noch kräftiger war er jedenfalls, als die Stufe noch die bleibende Form des Thieres war). - So auch der meist unter die Brust geschlagene, dabei aber kräftige Hinterleib der Zoëa ron Krabben, Porcellanen und der Tatuira; letztere beide schwimmen noch jetzt leidlich mittelst des Hinterleibes, selbst erwachsen; die Krabben wenigstens in der Jugend, als sogenannte Megalops. - So endlich die Verwendung

Das könnte davon herrühren, dass die Thiere sich von dem gemeinsamen Stamme trennten, ehe noch diese Gliedmassen aberhaupt gebildet wurden. Doch ist es mir in den Fällen, die ich näher kenne, wahrscheinlicher, dass dieselben später wieder verloren gegangen sind. Dass gerade diese Gliedmassen und Ringe sich leichtel verloren, als andere ("N. DANA believes, that in ordinary Crustaceous, the abortion of the segments with their appendages takes almost always place at the posterior end of the cephalothorax ". DARwin, Balanidae, S.111), findet seine Erklürung darin, dass sie als die jüngsten weniger als die anderen durch langdauernde Vererbung befestigt waren. 
der beiden rorderen Gliedmassenpaare als Fühler. Merkwürdig ist besonders das zweite Fühlerpaar, das bei den rerschiedenen Zoëa sich immer einen Schritt hinter dem des erwachsenen Thieres hält. Bei den Krabben fehlt eine "Schuppe " rollständig; ihre Zoëa haben sie angedeutet in Form eines oft sehr winzigen beweglichen Anhanges. Bei den Einsiedlerkrebsen findet sich ein solcher meist beweglicher dornförmiger Fortsatz als Rest der Schuppe: ihre Zoëa haben eine wohlentwickelte aber ungegliederte Schuppe. Eine eben solche Schuppe besitzen die crwachsenen Garneelen, bei deren Zoëa erscheint sie noch gegliedert, wie der äussere Ast am zweiten Fusspaare der Nauplius oder der PeneusZoëa. -

Die langen stachelförmigen Fort:ätze am Panzer der Krabbenund Porcellanen-Zoëa sind auf diesem Wege nicht zu erklären, doch ist ihr Nutzen für die Larren augenscheinlich. Wenn z. B. der Leib der Zoëa von Porcellana stellicola (Fig. 24) ohne die Fortsätze des Panzers und ohne den nicht steif ausstreckbaren Hinterleib kaum eine halbe Linie, mit den Fortsätzen vier Linien lang ist, so bedarf es eines achtmal weiteren Maules, um das so ausgerüstete Thierchen zu rerschlingen ${ }^{1}$. Somit können diese Fortsätze des Panzers als ron der Zoëa selbst im Kampfe ums Dasein erworben angesehen werden.

Auf ein früheres Eintreten ursprünglich später erfolgender Vorgänge ist auch die Bildung neuer Gliedmassen unter der Haut der Larren zurückzuführen. Der ursprüngliche Hergang war jedenfalls, dass sie erst nach der Häutung frei am Bauche des im nächsten Larvenstadium hervor:prossten während sie jetzt schon ror der Häutung sich entwickeln und so nur ein Stadium früher in Thätigkeit treten. Bei Larren, die aus anderen Gründen als der Urform näher stehend gelten müssen, pflegt auch hierin die ursprüngliche $W$ eise rorzuherrschen. So bilden sich die Sehwanzfüsse (die sseitlichen Schwanzblätter (i) frei an Bauche bei Euphausia und den Garneelen mit Naupliusbrut, innerhalb des

1) In ähnlicher Weise dienen der Persephone, einer seitenen Krabbe aus der Familie der Jeucosiden, ihre langen Scheerenfüsse. Frgreift man das Thier, so streckt es dieselben stocksteif gerade nach unten und man würde sie wahrscheinlich eher brechen, als biegen können. 
Schwanzblattes bei den Garneelen mit Zoëabrut, bei Pagurus, bei Porcellana.

Ein Zusammendrängen mehrerer Stadien in eines und dadurch eine Abkürzung, Tereinfachung des Entwicklungsganges spricht sich aus in dem gleichzeitigen Auftreten mehrerer neuen Gliedmassenpaare.

Wie frühere Jugendzustände nach und nach vollständig verloren gehen können, zeigen Mysis und die Asseln. Bei Mysis findet sich noch ein Rest des Naupliusstadiums; zurückgedrängt in eine Zeit, wo er noch nicht selbst für sich zu sorgen hatte, ist der Nauplius zu einer blossen Haut herabgesunken; bei Ligia (Fig. 36, 37) hat diese Larvenhaut die letzten Spuren von Gliedmassen verloren, bei Philoscia (Fig. 38) ist sie kaum mehr nachzuweisen.

Wie die Stachelfortsätze der Zoëa, so sind die Scheeren am vorletzten Fusspaare des jungen Brachyscelus als ron der Larve selbst erworben anzusehen. Die erwachsenen Thiere schwimmen vortrefflich und sind nicht an ihr Wohnthier gebunden; sobald die Chrysaora Blossevillei Less. oder das Rhizostoma cruciatum Less., an dem sie sitzen, in der Nähe des Strandes ein Spiel der Wellen wird, fliehen sie dieselben, sie sind nur von lebensfrischen Quallen zu erhalten. Die Jungen sind unbchülfliche Geschöpfe, schlechte Schwimmer; für sie musste ein besonderes Werkzeug zum Festhalten von grossem Nutzen sein.

Die Entwicklungsgeschichte der verschiedenen Malacostraca im Einzelnen durchzusprechen, dürfte keine dem Zeitaufwande entsprechende Ausbeute liefern; bei volllständigerer Kenntniss würde es lohnender sein. Ich verzichte hier darauf, will jedoch nicht unerwähnt lassen, dass sich dabei manche bis jetzt nicht befriedigend zu lösende Schwierigkeiten herausstellen würden. Auf diese vereinzelten Schwierigkeiten lege ich indess um so weniger Gewicht, als ja noch ror Kurzem, vor Entdeckung der Garneelennauplius, dieses ganze Gebiet der Entwicklung der Malacostraca für DARwix's Lehre fast unzugänglich war.

Auch bei den Widersprüchen, die sich aus der Anwendung der DARwix'schen Lehren auf diesem Gebiete zu ergeben scheinen, verweile ich nicht. Ich überlasse es den Gegnern, sie aufzusuchen. Die meisten sind leicht als nur scheinbar nachzuweisen. Nur zweien dieser Einwen- 
dungen, die zu nahe liegen, um nicht gemacht zu werden, glaube ich rorbeugen zu müssen.

"Die Eigenthümlichkeiten, in welchen die Zoëa der Krabben, der Porcellanen, der Tatuira, der Einsiedlerkrebse, der Garneelen mit Zoëabrut übereinstimmen und durch welche sie sich gemeinsam von den aus Nauplius hervorgehenden Larren der Peneus unterscheiden, drängen (wird man sagen können) zu der Annahme, dass schon der gemeinsame Stammvater dieser verschiedenen Decapoden in ähnlicher Zoëaform das Ei verliess. Auf diesen Stammvater würden dann aber weder die Peneus mit ihrer Naupliusbrut, noch selbst wie es scheint die Panzerkrebse sich zurückführen lassen. - Die Entwicklungsweise der Peneus, der Palinurus, sowie mehrere eigenthümliche Larren von unbekannter Herkunft, die aber mit aller Wahrscheinlichkeit langschwänzigen Krebsen zuzuschreiben sind, verlangen dagegen die entgegengesetzte Annahme, dass die verschiedenen Gruppen der Langschwänze unabhängig von einander und unabhängig von den Krabben von der ursprünglichen zu ihrer gegenwärtigen Entwicklungsweise gelangten. " - Darauf ist zu antworten, dass das Vorkommen der Zoëaform bei all den genannten Decapoden, dass ihr Bestehen bei Peneus während des ganzen an Fortschritten reichsten Lebensabschnitles, in dem die weite Kluft von Nauplius bis zum Decapoden sich ausfüllt, dass ihre Wiederkehr selbst in dem so abweichenden Entwicklungsgang der Maulfüsser, dass das Auftreten einer den jüngsten Peneus-Zoëa sich eng anschliessenden Larvenform bei der Schizopodengattung Euphausia, dass die Anklänge an den Bau der Zoëa, die selbst die erwachsenen Scheerenasseln in ihrer Athmungsweise bewahrt haben, - dass Alles dieses die Zoëa als eine jener Entwicklungsstufen bezeichnet, die während einer langen Zeit der Ruhe, vielleicht durch cine ganze Reihe geologischer Formationen als bleibende Form bestanden und dadurch auch der Entwicklung der Nachkommen sich tiefer einprägten und hier einen festeren Kern bildeten inmitten anderer leichter zu verwischender Jugendzustände So kann es denn nicht befremden, dass auch bei unabhängig erfolgendem Uebergange der ursprünglichen Verwandlungsweise in directe Entwicklung dennoch in verschiedenen Familien, bei denen die früheren Entwicklungsstufen 
rerwischt sind, das Larvenleben in gleicher Weise mit dieser Zoëaform anhebt. Ausser dem aber, was allen Zoëa gemeinsam ist, und dem was sich leicht als aus einem späteren Stadium in dieses zurück verlegt erKlären lässt, stimmen z. B. die Zoëa der Krabben mit denen von Pagurus und Palaemon in keinerlei Einzelheiten des Baues überein, die eine gemeinsame Ererbung anzunehmen geböten. Somit erscheint die Annahme unbedenklich, dass als Krabben und Krebse sich schieden, die Stammeltern jeder dieser Gruppen noch eine vollständigere Verwandlung durchliefen, dass der Uebergang in die heutige Entwicklungsweise einer späteren Zeit angehört. Man kann für die Krabben hinzusetzen, dass bei ihnen dieser Uebergang nur wenig später stattfand und zwar beror die heutigen Familien sich trennten. Die Anordnung der Panzerfortsätze und mehr noch die gleiche Zahl der Schwanzborsten bei den verschiedensten Krabbenzoëa (Fig. 19--23) beweisen es. Eine ähnliche Uebereinstimmung in der Zahl so unwichtig scheinender Gebilde ist nur aus gemeinsamer Ererbung erklärbar. Man kann mit Bestimmtheit voraussagen, dass unter den Krabben keine Art sich finden wird, die ähnlich wie Peneus noch heute Naupliusbrut hervorbrächte ${ }^{1}$.

Von allen übrigen Krustern entfernen sich, wie wir sahen, Mysis und die Asseln in höchst auffallender Weise dadurch, dass ihre Embryonen nach oben statt wie sonst nach unten gekrümmt sind. Weist, könnte man fragen, diese so vereinzelt stehende Eigenthümlichkeit nicht, im Sinne der Darwin'schen Lehre, auf gemeinsame Ererbung hin? Verlangt sie nicht, dass man einerseits als Kinder gleicher Stammeltern Mysis mit den Asseln, andererseits die übrigen Podophthalmen mit den Amphipoden vereinige? - Ich denke nein. - Nur für denjenigen, der eine Eigenthümlichkeit um desswillen höher werthet, weil sie in früherer Zeit des Eilebens auftritt, besteht eine solche Nöthigung. Wer die

1) Ich darf nicht unterlassen zu bemerken, dass das über die Entwicklung der Krabben Gesagte, eigentlich nur für die von ALpIr. MILnE EDwards als Eustomés zusammengefassten Gruppen der Cyclometopa, Catometopa und Oxyrhyncha gilt. Aus der Gruppe der Oxystomata, so wie der den Krabben nahe stehenden Anomura apterura EDw. sind mir von keiner Art die frühesten Jugendzustände bekannt geworden. 
Arten nicht als unabhängig und unreränderlich erschaffen, sondern als allmählich geworden ansieht, wird sich sagen, dass als die Torfahren unserer Mysis, wahrscheinlich viel später als die der Amphipoden und Asseln, dazu kamen, schon als Embryonen zahlreiche Leibesringe und Gliedmassen zu entwickeln, als sie nun gerade ausgestreckt im Eie nicht mehr Platz fanden und sich daher krümmen mussten, diess eben nur entweder abwärts oder aufwärts geschehen konnte, und dass welche Umstände auch für die eingeschlagene Richtung entscheidend sein mochten, dabei schwerlich eine nähere verwandtschaftliche Beziehung zu einer der beiden Edriophthalmenordnungen im Spiele war.

Die verschiedene Krümmung des Embryo bei Amphipoden und Asseln ist, das sei hier noch bemerkt, insofern belehrend, als sie beweist, dass die heutige Entwicklungsweise erst nach der Scheidung dieser Ordnungen sich bildete, dass bei dem Urstamme der Edriophthalmen die Embryonen, wenn nicht Nauplius, so doch noch kurzleibig genug waren, um wie die von der Naupliushaut umschlossenen Achthereslarven, gerade ausgestreckt im Eie Platz zu finden. Andererseits zeugt die innerhalb jeder der beiden Ordnungen herrschende Gleichförmigkeit der Entwicklung, die sich bei den Amphipoden z. B. in der Bildung des "Mikropylapparates ", bei den Asseln im Mangel des letzten Paares der Gangfüsse ausspricht, dafür dass die heutige Entwicklungsweise aus sehr früher Zeit herrührt und bis vor die Trennung der jetzigen Familien zurückreicht. Auch in diesen beiden Ordnungen darf man wie bei den Krabben kaum Spuren früherer Jügendzustände zu finden hoffen, es sei denn in der Familie der Scheerenasseln 1. Man führe mir einen Amphipoden, eine Assel mit Naupliusbrut vor, deren Bestehen doch bei unabhängig entstandenen Arten nicht auffallender sein würde, als das einer Garneele mit Naupliusbrut, und ich gebe die ganze Darwix'sche Lehre verloren.

1) Ob der Mangel der Hinterleibsfüsse bei den jungen Tanais ein Erbstück aus der Zeit der Urassel, oder eine später erworbene Eigenthümlichkeit ist, was mir für jetzt annehmbarer scheint, wirl sich vielleicht mit einiger Sicherheit entscheiden lassen, wenn man Entwicklung und Lebensweise der Familiengenossen, Apseudes und Rhoea, kennen gelernt hat. Letztere ist bekanntlich die einzige Assel, die noch eine Nebengeissel an den vorderen Fühlern besitzt. 
Wenn wir bei den Krabben und ebenso bei Asseln und Amphipoden zu der Annahme geführt wurden, dass um die Zeit, wo diese Gruppen von dem gemeinsamen Stamme sich lösten, zugleich eine Vereinfachung ihres Entwicklungsganges stattfand, so erscheint auch dies von Dakwix's Lehre aus begreiflich. Wenn irgendwelche einer Thiergruppe günstige Umstände eine weitere Ausbreitung derselben, ein Auseinandergehen in neue verschiedenen Lebensrerhältnissen sich anpassende Formen veranlassten, so wird einmal schon diese grössere Veränderlichkeit, die eben in der Bildung neuer Formen sich kundgibt, auch die fast immer rortheilhafte Vereinfachung der Entwicklung begünstigen und es wird ausserdem gerade jetzt, bei dem Einleben in neue Verhältnisse, wie oben in Betreff der Süsswasserthiere angedeutet wurde, diese Vereinfachung doppelt rortheilhaft sein und daher in dieser Beziehung eine doppelt strenge Auslese stattfinden.

Soviel über die Entwicklung der höheren Kruster.

Eines näheren Eingehens in die Entwicklungsgeschichte der niederen Kruster bedarf es nicht nach dem, was im Allgemeinen über die geschichtliche Bedeutung der Jugendzustände gesagt, lind nach der Anwendung, die daron eben auf die Malacostraca gemacht wurde. Man sieht ohne Weiteres, wie die ron CLAus gegebene Schilderung der Copepodenentwicklung fast Wort für Wort als Urgeschichte dieser Thiere gelten kann, man findet in der Naupliushaut der Achthereslarven, in der eiähnlichen Larre ron Cryptophialus ganz ähnliche Spuren eines Uebergangs zu directer Entwicklung, wie sie schon die Naupliushülle der Mysisembryonen und die madenförmige Larve der Ligia zeigten, u. s. w.

Es genüge, auf einen wesentlichen Unterschied im Entwicklungsgange der höheren und niederen Kruster hinzuweisen. Bei letzteren werden alle neuen Leibesringe und Gliedmassen, die sich zwischen die Endabschnitte des Naupliusleibes einschieben, in ununterbrochener Folge von vorn nach hinten gebildet; bei ersteren tritt noch einmal eine Neubildung in der Mitte des Leibes auf, der Mittelleib, der sich auf ähnliche Weise zwischen Torderleib und Hinterleib drängt, wie diese ihrerseits zwischen Kopf und Schwanz des Nauplius. - Was schon die 
Vergleichung der Gliedmassen der erwachsenen Thiere wahrscheinlich macht, findet also in der Entwicklungsgeschichte eine neue Stütze, dass nämlich den niederen Krustern, ebenso wie den Insecten, ein dem Mittelleibe der Malacostraca entsprechender Leibesabschnitt völlig abgeht. Dass die Schwimmfüsse der Copepoden, sowie der Puppen ron Rankenfüssern und Wurzelkrebsen den Finterleibsfüssen der Malacostraca entsprechen, d. h. mit ihnen aus gleicher Quelle durch Ererbung sich ableiten, ist wahrscheinlich.

Es wäre leicht, die einzelnen Fäden, welche die Jugendformen der verschiedenen Kruster liefern, zu einem Gesammtbilde der Urgeschichte dieser Kllasse zu verweben. Ein solches Gemälde, mit einigem Geschick angelegt und in frischen Farben ausgeführt, würde sicher mehr Anziehendes haben, als die trockenen Erörterungen, die sich an die Entwicklungsgeschichte dieser Thiere knüpfte. Noch aber wäre die Verschürzung der losen Fäden vielfach eine willkürliche, mit gleichem Rechte so oder so auszuführen; noch wäre manche Lücke nur durch mehr oder minder gewagte Voraussetzungen auszufüllen. Minder auf diesem Gebiete Bewanderte würden dann leicht auch da auf sicherem Boden zu wandeln glauben, wo nur die Phantasie eine luftige Brücke geschlagen; Kenner dagegen würden bald diese schwachen Stellen des Baues herausfinden, aber dann leicht auch das als in der Luft schwebend ansehen, was auf wohlerwogene Thatsachen gebaut wurde. Diesen Missdeutungen seines wirklichen Gehaltes nach einer und der anderen Seite vorzubeugen, wäre es nöthig, ein solches Bild fortlaufend mit langen dürren Erläuterungen zu begleiten. Das hat mich abgehalten, die Unrisse, die ich schon entworfen hatte, weiter auszumalen.

Bei dem äussersten, am weitesten in die nebelgraue Urzeit zurückweichenden Vorposten der Klasse, dem Nauplius, angelangt, blickt man sich natürlich um, ob von da aus nicht Wege zu erspähen sind nach anderen naheliegenden Gebieten. Man könnte mit Oscar Scmunt bei der Hinterleibsbildung der Nauplius an die bewegliche Schwanzgabel der Räderthiere erinnern, in denen ja Manche überhaupt nahe Verwandte der Kruster, oder doch der Arthropoden erkennen wollen; man könnte bei den sechs den Mund umstehenden Füssen an einen ur- 


\section{1}

sprünglich strahligen Bau denken, u. s. w. Sicheres vermag ich nicht zu sehen. - Selbst nach den näher liegenden Gebieten der Tausendfüsse und der Spinnen finde ich keine Brücke. Nur für die Insecten bietet vielleicht die Entwicklung der Malacostraca einen Anknüpfungspunct. Wie manche Zoëa besitzen die Insecten drei Paar der Nahrungsaufnahme, drei Paar der Bewegung dienende Gliedmassen; wie die Zoëa, haben sic einen anhanglosen Hinterleib; wie bei allen Zoëa, entbehren bei allen Insecten die Kinnbacken des Tasters. Allerdings des Gemeinsamen wenig, bei dem Vielen was diese beiden Thierformen unterscheidet. Immerhin mag die Vermuthung, dass die Insecten ihren gemeinsamen Stammvater in einer Zoëa hatten, die sich zum Leben auf dem Lande erhob, weiterer Prüfung empfohlen sein.

Manches in den obigen Aufstellungen mag verfehlt sein, manche Deutung misslungen, manche Thatsache nicht ins rechte Licht gestellt. Eines aber, hoffe ich, soll mir gelungen sein, - u n befangene Leser zu überzeugen, dass wirklich Dakwix's Lehre, wie für so viele andere ohne sie unerklärbare Thatsachen, so auch für die Entwicklungsgeschichte der Kruster den Schlüssel des Terständnisses bietet. Die Mängel also dieses Versuches wolle man nicht dem von der sicheren Hand des Meisters vorgezeichneten Plane, man wolle sie einzig dem Ungeschick des Handlangers zur Last legen, der nicht für jedes Werkstück die rechte Stelle zu finden verstand. 




